Pablo César Serrano Arámbulo

Estudo da camada dielétrica para o desenvolvimento de transistores de efeito de campo orgânicos (OFET) baseados em polímeros conjugados

Dissertação de Mestrado

Dissertação apresentada como requisito parcial para obtenção do grau de Mestre pelo Programa de Pós-Graduação em Física da PUC-Rio.

Orientador: Prof. Marco Cremona Co-orientadora: Profa. Cecília Vilani

Rio de Janeiro

Maio de 2016 


\title{
Estudo da camada dielétrica para o desenvolvimento de transistores de efeito de campo orgânicos (OFET) baseados em polímeros conjugados
}

\begin{abstract}
Dissertação apresentada como requisito parcial para obtenção do grau de Mestre pelo Programa de Pós-Graduação em Física do Departamento de Física do Centro Técnico Científico da PUC-Rio. Aprovada pela Comissão Examinadora abaixo assinada.
\end{abstract}

\author{
Prof. Marco Cremona \\ Orientador \\ Departamento de Física - PUC-Rio \\ Profa. Cecília Vilani \\ Co-orientadora \\ Departamento de Química - PUC-Rio \\ Prof. Tommaso Del Rosso \\ Departamento de Física - PUC-Rio \\ Prof. Rogerio Valaski \\ INMETRO \\ Prof. Márcio da Silveira Carvalho \\ Coordenador Setorial do Centro \\ Técnico Científico - PUC-Rio
}

Rio de Janeiro, 13 de maio de 2016. 
Todos os direitos reservados. É proibida a reprodução total ou parcial do trabalho sem autorização da universidade, do autor e do orientador.

\section{Pablo César Serrano Arámbulo}

Bacharel em física pela Universidade Nacional de San Agustin de Arequipa (UNSA). Tem experiência na área de matéria condensada com ênfase em eletrônica orgânica.

Ficha Catalográfica

Serrano Arámbulo, Pablo César
Estudo da camada dielétrica para o
desenvolvimento de transistores de efeito de campo
orgânicos (OFET) baseados em polímeros conjugados /
Pablo César Serrano Arámbulo ; orientador: Marco
Cremona. - 2016.
109 f. : il. color. ; $30 \mathrm{~cm}$
Dissertação (Mestrado)-Pontifícia Universidade
Católica do Rio de Janeiro, Departamento de Física, 2016.
Inclui bibliografia
1. Física - Teses. 2. OFET. 3. Dielétricos. 4.
Polímeros conjugados. 5. Mobilidade. 6. Razão ON/OFF.
I. Cremona, Marco. II. Pontifícia Universidade Católica do
Rio de Janeiro. Departamento de Física. III. Título.

CDD: 530 


\section{Agradecimentos}

Primeiramente agradecer a este País, o Brasil, por ter me recebido com os braços abertos.

Aos meus Pais e irmãos, por ter ajudado moral e economicamente.

Ao Prof. Marco Cremona, pela orientação, compreensão e ajuda nos momentos difíceis. Também por que ele soube delegar às pessoas adequadas para ajudar na pesquisa.

À Profa. Cecilia Vilani, por ter co-orientado na pesquisa e por dar ânimo nos momentos difíceis.

Aos colegas e amigos do LOEM: especialmente ao Harold, que soube transmitirme tudo o que sabe; também ao Rian, Arthur, Leonardo e Rafael; pelo apoio, paciência e por ensinar todo que precisava saber para a pesquisa.

À PUC-Rio pela utilização das instalações, laboratórios e por brindar as condições idôneas para a pesquisa.

Ao departamento de física e seus Professores pelo ensinado.

À Marta, que foi companheira fiel durante boa parte de minha estadia no Rio, não tivesse conseguido isto sem sua ajuda e a de sua família.

Aos amigos que me apoiaram em tudo momento: Loren, Neileth, Luchito, Neuza, Martinha, Marcelo, Melissa, Javier, Nilton, Stéfani e Camilo.

Ao CNPq, CAPES e à PUC-Rio, pelos auxílios concedidos, sem os quais este trabalho não poderia ter sido realizado; e por não ter limite na idade dos pesquisadores para a concessão das bolsas. 


\section{Resumo}

Arámbulo, Pablo Serrano; Cremona, Marco (Orientador); Vilani, Cecília (Co-orientadora). Estudo da camada dielétrica para o desenvolvimento de transistores de efeito de campo orgânicos (OFET) baseados em polímeros conjugados. Rio de Janeiro, 2016. 109p. Dissertação de Mestrado - Departamento de Física, Pontifícia Universidade Católica do Rio de Janeiro.

Nos últimos anos, polímeros conjugados ganharam muita atenção na eletrônica orgânica por seu uso na fabricação de dispositivos flexíveis e de baixo custo. Como resultado, diferentes tipos de dispositivos têm sido desenvolvidos como: diodos emissores de luz orgânicos (OLEDs), células fotovoltaicas orgânicas (OPVs) e transistores de efeito de campo orgânicos (OFETs). Em particular, para os OFETs seu desempenho depende da interface isolante/semicondutor, principalmente, devido ao acúmulo de portadores de carga. Além disso, as propriedades da interface afetam fortemente o transporte de carga através do canal de dispositivo. Por estas razões, a pesquisa de novos polímeros semicondutores e novos materiais dielétricos é um fator chave para aprimorar o desempenho dos dispositivos. Neste trabalho, os polímeros PMMA, PVA, FORMVAR e PU foram investigados como materiais dielétricos. Inicialmente foram fabricados capacitores de placas planas paralelas do tipo ITO/dielétrico/Al para determinar a constante dielétrica dos isolantes, as curvas $J x V$ e a capacidade por unidade de área. Desenvolveu-se OFETs tipo Top-Gate/Bottom-Contacts (TGBC) com a estrutura Au/P3HT/PMMA/Ag e Au/P3HT/PU/Ag. No trabalho, a espessura dos dielétricos foi variada para aprimorar o desempenho dos dispositivos. Para os OFETs de PMMA obteve-se resultados concordantes com os da literatura. Os novos OFETs de PU apresentaram tensões de operação menores que $5 \mathrm{~V}$, que é um requisito para a integração destes OFETs em aplicações da eletrônica orgânica. A mobilidade obtida nestes OFETs de PU foi de 1.25 cm2/V.s, com uma tensão limiar de 0.02 e uma razão On/Off de 100.

\section{Palavras-chave}

OFET; Dielétricos; polímeros conjugados; mobilidade; razão ON/OFF. 


\section{Abstract}

Arámbulo, Pablo Serrano; Cremona, Marco (Advisor); Vilani, Cecília (Coadvisor). Investigation of dielectric layer for the development of Organic Field Effect Transistors (OFET) based on conjugated polymers. Rio de Janeiro, 2016. 109p. MSc. Dissertation - Departamento de Física, Pontifícia Universidade Católica do Rio de Janeiro.

In the last years, conjugated polymers have received much attention in organic electronics for their use in the fabrication of low cost and flexible devices. As a result, different types of devices have been developed e.g. organic light emitting diodes (OLEDs), photovoltaic devices (OPVs) and field effect transistors (OFETs). For the OFETs in particular, their performance depends primarily on insulator/semiconductor interface, mainly due to charge carrier accumulation. Moreover, the interface properties strongly affect the charge transport through the device channel. For these reasons, the research for new semiconductor polymers and new dielectric materials is key to advancing the performance improvement of devices. In this work, the polymers PMMA, PVA, FORMVAR and PU were used as dielectric materials. Initially, parallel plate capacitors of the structure ITO/dielectric/A1 were made, in order to determine the dielectric constant of the insulators, get the curves $J x V$ and the capacity per unit area. It was used to develop Top-Gate/Bottom-Contacts (TGBC) OFETs with structures of $\mathrm{Au} / \mathrm{P} 3 \mathrm{HT} / \mathrm{PMMA} / \mathrm{Ag}$ and Au/P3HT/PU/Ag. The thicknesses of the dielectric materials were varied to improve the performance of the devices. For the PMMA OFETs, the results obtained were concordant with those of the existing literature. The new PU OFETs presented with operating voltages of less than $5 \mathrm{~V}$, appropriate for applications of these OFETs in organic electronics. The mobility of the PU OFETs was $1.25 \mathrm{~cm}^{2} / \mathrm{V} \cdot \mathrm{s}$, the threshold voltage $0.02 \mathrm{~V}$ and the On/Off ratio 100 .

\section{Keywords}

OFET; Dielectric; conjugated polymers; mobility; ON/Off ratio. 


\section{Sumário}

$\begin{array}{ll}\text { 1. Introdução } & 17\end{array}$

$\begin{array}{ll}\text { 1.1. Objetivos } & 20\end{array}$

1.1.1. Objetivo Principal 20

1.1.2. Objetivos Específicos 20

1.2. Apresentação 21

2. Fundamentação teórica 22

2.1. Propriedades elétricas nos semicondutores orgânicos 22

2.2. Transporte de carga em materiais orgânicos 26

$\begin{array}{ll}\text { 2.3. Materiais Semicondutores } & 31\end{array}$

2.3.1. O poli(3-hexiltiofeno)-P3HT 31

2.4. Materiais Isolantes 33

$\begin{array}{ll}\text { 2.4.1. PMMA } & 34\end{array}$

$\begin{array}{ll}\text { 2.4.2. PVA } & 35\end{array}$

$\begin{array}{ll}\text { 2.4.3. FORMVAR } & 35\end{array}$

2.4.4. Poliuretano (PU) 35

2.5. Dispositivos 37

2.5.1. Capacitor de placas paralelas $\quad 37$

2.5.1.1. Curvas $J x V$

2.5.1.1.a. Corrente de fuga no dielétrico 38

2.5.1.1.b. Deslocamento da Curva $J x V$ do Zero e efeitos de carga 39

2.5.2. Transistor de efeito campo orgânico (OFET) 40

2.5.2.1. Arquiteturas dos OFETs 41

2.5.2.2. Funcionamento de um OFET 42

3. Materiais e Métodos $\quad 48$

3.1. Semicondutor Orgânico (SO)-P3HT 48 
$\begin{array}{ll}\text { 3.2. Dielétricos } & 48\end{array}$

$\begin{array}{ll}\text { 3.2.1. PMMA } & 48\end{array}$

$\begin{array}{ll}\text { 3.2.2. PVA } & 48\end{array}$

$\begin{array}{ll}\text { 3.2.3. FORMVAR } & 48\end{array}$

$\begin{array}{ll}\text { 3.2.4. PU } & 49\end{array}$

3.3. Limpeza dos substratos $\quad 49$

3.4. Técnicas de Deposição 51

3.4.1. Spin coating $\quad 51$

3.4.2. Evaporação Térmica Resistiva 52

3.4.2.1. Descrição do sistema de deposição utilizado 53

3.4.3. Técnica de Deposição por Feixe de Elétrons 54

3.5. Técnicas de caracterização $\quad 57$

$\begin{array}{ll}\text { 3.5.1. Perfilômetria } & 57\end{array}$

3.5.2. Caracterização Elétrica dos Dispositivos 58

3.5.2.1. Capacitores Orgânicos 58

3.3.2.1.a. Obtenção das curvas densidade de corrente versus $\begin{array}{ll}\text { tensão } & 59\end{array}$

3.3.2.1.b. Medida da Capacitância 60

$\begin{array}{ll}\text { 3.5.2.2. OFETS } & 61\end{array}$

3.5.2.2.a. OFETs utilizando PMMA e PU como isolantes 61

3.5.2.2.b. Caracterização elétrica dos OFETs 63

4. Resultados e Discussão 64

4.1. Capacitores Orgânicos 64

$\begin{array}{ll}\text { 4.1.1. Curvas JxV } & 64\end{array}$

$\begin{array}{ll}\text { 4.1.1.1. PMMA } & 64\end{array}$

4.1.1.2. PVA com diferentes tratamentos térmicos 66

$\begin{array}{ll}\text { 4.1.1.3. PVA para diferentes espessuras } & 67\end{array}$

4.1.1.4. FORMVAR dissolvido em clorofórmio 68 
4.1.1.5. FORMVAR dissolvido em dimetilformamida(DMF) 69

4.1.1.6. PU dissolvido em tetraidrofurano(THF) 70

$\begin{array}{ll}\text { 4.1.1.7. PU dissolvido em MEK } & 71\end{array}$

4.1.2. Capacitância por unidade de área e constante dielétrica 73

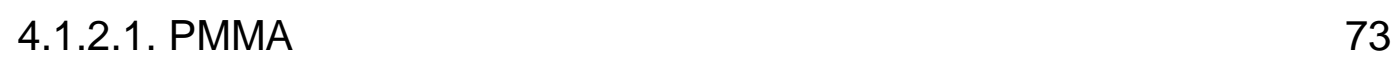

$\begin{array}{ll}\text { 4.1.2.2. PVA } & 75\end{array}$



4.1.2.4. PU dissolvido em THF: PU(THF) 77

4.1.2.5. PU dissolvido em MEK: PU(MEK) 78

$\begin{array}{ll}\text { 4.2. OFETS } & 79\end{array}$

$\begin{array}{ll}\text { 4.2.1. OFETS com PMMA } & 81\end{array}$

$\begin{array}{ll}\text { 4.2.3. OFETs com PU(MEK) } & 91\end{array}$

$\begin{array}{ll}\text { 5. Conclusões } & 100\end{array}$

$\begin{array}{ll}\text { 6. Referências Bibliográficas } & 103\end{array}$ 


\section{Lista de figuras}

Figura 1.1 Digrama do dispositivo de ponto de contato.

Figura 1.2 a) Estrutura química do poliacetileno. b) Estrutura

química do poliacetileno dopado com diodo, onde a condutividade

se incrementa marcadamente.

Figura 1.3 Mobilidade de portadores de carga para transistores

de filmes finos produzidos com SOs até o ano 2010.

Figura. 1.4 Dispositivos eletrônicos orgânicos.

Figura 2.1 Estruturas químicas dos SOs.

Figura 2.2 Formação de uma ligação dupla entre dois átomos

de carbono.

Figura 2.3 Estrutura energética formada por orbitais ligante e antiligante.

Figura 2.4 A excitação eletrônica menor acontece entre os orbitais $\pi$ e $\pi^{*}$.

Figura 2.5 Distribuições dos níveis HOMO e LUMO em SOs.

Figura 2.6 Distribuição Gaussiana dos estados eletrônicos HOMO

e LUMO com os níveis de armadilhas num material orgânico

Figura 2.7 Representação esquemática do transporte de cargas por "hopping" em polímeros conjugados.

Figura 2.8 a) Densidade de estados LUMO (linha sólida) 
b) Concentração no centro da distribuição Gaussiana dos

estados localizados, onde existe processo de "hopping"

Figura 2.9 Esquema da curva característica de SCLC para um

isolante com um nível de armadilha.

29

Figura 2.10 Esquema dos processos de injeção termiônica e tunelamento numa estrutura metal/SO/metal.

Figura 2.11 Estrutura química do rr-P3HT.

32

Figura 2.12 Estrutura química do rra-P3HT.

Figura 2.13 Representação esquemática de uma estrutura molecular interdigitada do rr-P3HT.

Figura 2.14 Alguns polímeros orgânicos utilizados como dielétricos na fabricação de OFETs.

Figura 2.15 Estrutura química do Polivinil formal (FORMVAR).

Figura 2.16 Estrutura química do poliuretano (PU).

Figura 2.17 Capacitor de placas paralelas com um dielétrico.

Figura 2.18 Curvas JxV de um capacitor ITO/ PVAIA-BaTiO3/Au, o PVAIA é dopado com nanopartículas de BaTiO3

Figura 2.19 As quatro arquiteturas fundamentais para OFETs.

Figura 2.20 Esquema de um OFET com arquitetura Bottom-Gate/ Bottom-Contacts (BGTC), onde se mostra o campo elétrico formado no isolante e o canal (tipo p) criado na interface.

Figura 2.21 Circuito de funcionamento de um OFET com arquitetura Bottom-Gate/Bottom-Contacts (BGBC), onde pode-se apreciar a 
Tensão na porta $\mathrm{Vg}$ e a tensão entre o dreno e a fonte $\mathrm{Vds}$.

Figura 2.22 Esquema de um OFET com arquitetura Bottom-Gate/ Bottom-Contacts (BGBC), onde se mostra o comprimento (L) e a largura $(\mathrm{W})$ do canal.

Figura 2.23 Familia de curvas de saída $I_{D} \times V_{D}$ para diferentes valores de $V_{G}$, na figura pode-se apreciar os dois regimes caractericticos do transistor: linear e saturação.

Figura 2.24 (a) Familia de curvas de transferência $I_{D} \times V_{G}$ para diferentes valores de $V_{D}$. (b) Gráfico $\log I_{D} \times V_{G}$, nesta curva é indicada a definição dos parâmetros ON/OFF e S.

Figura 3.1 ITO litografado sobre vidro.

Figura 3.2 Sistema de deposição térmica do LOEM da PUC-Rio.

Figura 3.3 Cadinho de tungstênio utilizado para depositar alumínio.

Figura 3.4 Equipamento utilizado no LOEM para a deposição por

Electron beam.

Figura 3.5 Unidade de evaporação por feixe de elétrons com cadinho rotante com quatro compartimentos

Figura 3.6 Perfilômetro Veeco Dektak 150, utilizado no LOEM da PUC-Rio para as medidas da espessura e rugosidade.

Figura 3.7 Medida do desnível efetuada pelo perfilômetro para medir a espessura e rugosidade.

Figura 3.8 Esquema do circuito utilizado para a obtenção das curvas JxV. 
Figura 3.9 Fonte Keithley 2400 dual programável destacando o programa em linguagem LabVIEW utilizado para medir as curvas JxV 59 Figura 3.10 Esquema do circuito utilizado para a obtenção da capacitância.

Figura 3.11 Multímetro digital 21105 1/2 marca Keithley, utilizado para medir a capacitância.

Figura 3.12 Mascara do LOEM utilizada para depositar os contatos de $\mathrm{Cr} / \mathrm{Au}$.

Figura 3.13 Mascara do LOEM utilizada para depositar a porta dos OFETs.

Figura 3.14 Etapas da deposição das camadas dos OFETs e sua arquitetura Top-Gate/Bottom-Contacts (TGBC) já pronta.

Figura 3.15 Esquema de um circuito montado para extrair as curvas de transferência e de saída num OFET.

Figura 3.16 Montagem do circuito no LOEM para obter as curvas de transferência e saída nos OFETs.

Figura 4.1 Curvas semi-logarítmicas JxV dos dispositivos ITO/PMMA/AI para diferentes espessuras de PMMA.

Figura 4.2 Curvas semi-logarítmicas JxV dos dispositivos ITO/PVA/AI para diferentes tratamentos térmicos.

Figura 4.3 Curvas semi-logarítmicas JxV dos dispositivos ITO/PVA/Al com o mesmo tratamento térmico.

Figura 4.4 Curvas semi-logarítmicas JxV dos dispositivos 
ITO/FORMVAR(Cloroformio)/AI para diferentes espessuras.

Figura 4.5 Curvas semi-logarítmicas JxV dos dispositivos

ITO/FORMVAR(DMF)/AI.

Figura 4.6 Curvas semi-logarítmicas JxV dos dispositivos ITO/PU(THF)/Al para diferentes espessuras.

Figura 4.7 Curvas semi-logarítmicas JxV dos dispositivos

ITO/PU(MEK)/AI para diferentes espessuras.

72

Figura 4.8 Gráfico das capacitâncias por unidades de área Ci versus as inversas das espessuras 1/d para o PMMA.

Figura 4.9 Gráfico das capacitâncias por unidade de área $\mathrm{Ci}$

versus as inversas das espessuras $1 /$ d para o PVA.

Figura 4.10 Gráfico das capacitâncias por unidade de área Ci versus as inversas das espessuras $1 / \mathrm{d}$ para o FORMVAR.

Figura 4.11 Gráfico das capacitâncias por unidade de área Ci versus as inversas das espessuras $1 /$ d para o $\mathrm{PU}(\mathrm{THF})$

Figura 4.12 Gráfico das capacitâncias por unidade de área Ci versus as inversas das espessuras $1 /$ d para o PU (MEK)

Figura 4.13 Gráfico que ilustra a extração de parâmetros para o calculo da mobilidade $\left(\mu_{s}\right)$ no regime de saturação, razão On/Off e a voltagem limiar $\left(V_{T}\right)$.

Figura 4.14 Curvas de transferência do OFET com PMMA para o substrato 1.

Figura 4.15 Curvas de saída do OFET com PMMA para o substrato1. 82 
Figura 4.16 Curvas utilizadas para calcular as grandezas características do OFET de PMMA com 980nm de espessura para $V_{d s}=-50 \mathrm{~V}$.

Figura 4.17 Curvas utilizadas para calcular as grandezas características do OFET de PMMA com 980nm de espessura para $V_{d s}=-40 \mathrm{~V}$. 84

Figura 4.18 Curvas de transferência de um OFET com PMMA para o substrato 2.

Figura 4.19 Curvas de saída do OFET com PMMA para o substrato2. 85

Figura 4.20 Curvas utilizadas para calcular as grandezas

características do OFET de PMMA com 700nm de espessura

para $V_{d s}=-50 \mathrm{~V}$.

Figura 4.21 Curvas de transferência de um OFET com PMMA para o substrato 3 .

Figura 4.22 Curvas de saída do OFET com PMMA para o substrato3. 87 Figura 4.23 Curvas utilizadas para calcular as grandezas características do OFET de PMMA com 570nm de espessura para $V_{d s}=-50 \mathrm{~V}$. 88

Figura 4.24 Curvas de transferência de um OFET com PMMA para o substrato. 89

Figura 4.25 Curvas de saída do OFET com PMMA para o substrato4. 89 Figura 4.26 Curvas utilizadas para calcular as grandezas características do OFET de PMMA com 500nm de espessura 
para $V_{d s}=-30 \mathrm{~V}$.

Figura 4.27 Curvas de transferência de um OFET com

PU para o substrato 2.

92

Figura 4.28 Curvas de saída do OFET com PU para o substrato $2 . \quad 92$

Figura 4.29 Curvas utilizadas para calcular as grandezas

características do OFET de PU com 600nm de espessura

para $V_{d s}=-1 V$.

Figura 4.30 Curvas de transferência de um OFET com

PU para o substrato 3.

94

Figura 4.31 Curvas de saída do OFET com PU para o substrato $3 . \quad 94$

Figura 4.32 Curvas utilizadas para calcular as grandezas características do OFET de PU com 700nm de espessura

para $V_{d s}=-1 V$.

95

Figura 4.33 Curvas utilizadas para calcular as grandezas

características do OFET de PU com 700nm de espessura

para $V_{d s}=-5 \mathrm{~V}$.

Figura 4.34 Curvas de transferência de um OFET com

PU para o substrato 4.

Figura 4.35 Curvas de saída do OFET com PU para o substrato 4.

Figura 4.36 Curvas utilizadas para calcular as grandezas características do OFET de PU com 750nm de espessura para $V_{d s}=-1 V$. 


\section{Introdução}

O continuo desenvolvimento da eletrônica digital representa uma necessidade na nossa sociedade atual, porque de fato, muitos dos equipamentos eletrônicos utilizados no nosso dia a dia funcionam com esta tecnologia. Um dispositivo fundamental para este desenvolvimento é, sem duvida, o transistor. Os transistores de efeito de campo baseados em silício estão presentes em quase todos os equipamentos eletrônicos.

A descoberta dos semicondutores orgânicos deu início a uma busca pela fabricação de novos dispositivos, entre eles os transistores que permitissem novas aplicações e possibilitou a criação de uma nova área: a Eletrônica Orgânica. Transistores de efeito de campo orgânicos (OFETs-do inglês Organic Field Effect Transistor) tem sido objeto de muitas pesquisas (Dimitrakopoulos \& Mascaro, 2001). Isto se deve ao fato de que os materiais orgânicos possuem excelentes propriedades, tais como sua facilidade de processamento, simplicidade de deposição em forma de filmes finos, flexibilidade mecânica (circuitos eletrônicos flexíveis), entre outras. Todo este conjunto faz dos dispositivos baseados em semicondutores orgânicos (SOs) apresentarem uma boa relação custo-benefício.

O panorama histórico da evolução dos transistores inicia-se com o primeiro tríodo baseado nos diodos em tubos a vácuo foi patenteado em 1907 por Lee De Forest (US Patent 879,532). Este dispositivo foi por muito tempo um elemento imprescindível na amplificação de sinais para que os equipamentos eletrônicos da época pudessem trabalhar. Porém, entre outros problemas, estes dispositivos eram frágeis e seu consumo de energia elétrica era alto. Devido a estes motivos, muitos esforços foram dedicados para criar um substituto dos dispositivos termiônicos para dispositivos no estado sólido. Em 1930, Julius Edgar Lilienfeld fez a primeira tentativa com um dispositivo baseado no efeito de campo, mas não deu certo (US Patent 1,745,175). Posteriormente em 1947, três cientistas, da Bell Telephone Laboratories: William Shockley, John Bardeen e Walter Brattain obtiveram a primeira versão do transistor de contato utilizando sobre o germânio dois pontos de contato de ouro (Riordan, 2007), separados por menos de um 
milímetro e abaixo dele outro contato, conforme apresentado na Figura 1.1. Um dispositivo similar foi feito independente e separadamente em 1948 por Herbert Mataré e Heinrich Welker (Maciel, 2012).



Figura 1.1 Diagrama do dispositivo de ponto de contato. Figura retirada da referência (Maciel, 2012).

Já em 1951, Shockley produziu um transistor de junção e, pouco depois, em 1954, Gordon Teal desenvolveu o primeiro transistor de junção baseado em silício, em quanto trabalhava para a Texas Instruments (Riordan, 2007). Em 1956 os cientistas da Bell Telephone Laboratories Shockley, Bardeen e Brattain obtiveram o prêmio Nobel de Física por suas investigações relacionadas aos semicondutores e pela criação do transistor. Posteriormente, em 1959, Dawon Kahng e Martin Atalla, trabalhando também na Bell Telephone Laboratories, fabricaram o transistor de efeito de campo metal-óxido-semicondutor (MOSFET-Metal Oxide Semiconductor) (Riordan, 2007). Este dispositivo deu origem à criação de circuitos de chaveamento que consistem em dois MOSFETs, um deles do tipo-p e outro do tipo-n, ligados de forma complementar CMOS (do inglês Complementary Metal-Oxide-Semiconductor), tal circuito permitiu a criação da lógica CMOS que consta das portas lógicas até hoje presentes nos circuitos de processamento de dados que são a base da eletrônica digital atual (Maciel, 2012).

Foi em 1977 que acidentalmente foi descoberta a condutividade elétrica no polímero poliacetileno dopado com iodo, sua estrutura é representada na Figura 1.2 b. A partir daí se despertou o interesse da aplicação de polímeros conjugados para a fabricação de dispositivos eletrônicos (Shirakawa, 1977). Contudo, foram só dez anos depois que Koezuka e colaboradores apresentaram o primeiro OFET funcional (Horowitz, 1998). Um dos principais problemas dos SOs é a baixa mobilidade dos portadores de carga em comparação com os inorgânicos; tal 
característica se deve ao desordem estrutural que estes materiais possuem (Seidel, 2008). Grandes esforços estão sendo realizados para aumentar a mobilidade dos portadores de carga nos SOs, através do aprimoramento da síntese de novos polímeros. A Figura 1.3 mostra a evolução dos valores de mobilidade de portadores de carga de transistores produzidos a partir de filmes finos de SOs.<smiles>C/C=C\C=C/C=C\C</smiles>

a)<smiles>C/C=C/C=C/C=C/C</smiles>

b)

Figura 1.2 a) Estrutura química do poliacetileno. b) Estrutura química do poliacetileno dopado com diodo, onde a condutividade se incrementa marcadamente. Figura retirada da referência (Shirakawa, 1977).



Figura 1.3 Mobilidade de portadores de carga para transistores de filmes finos produzidos com SOs até o ano 2010. Figura retirada da referência (AIST, 2016). 
Dado que os valores de mobilidade de portadores de carga em semicondutores inorgânicos cristalinos são, em geral, maiores que em SOs, os OFETs não são dispositivos ótimos para aplicações que necessitam de uma alta velocidade de chaveamento. Contudo, devido ao desenvolvimento da chamada eletrônica orgânica, estes materiais estão sendo utilizados eficientemente em aplicações como: diodos emissores de luz orgânicos (OLEDs) (Hung, 2002), células fotovoltaicas orgânicas (OPVs) (Bundgaard, 2007) e os já mencionados OFETs (Horowitz, 2004). A Figura 1.4 ilustra as principais aplicações dos dispositivos eletrônicos desenvolvidos a partir de materiais orgânicos.
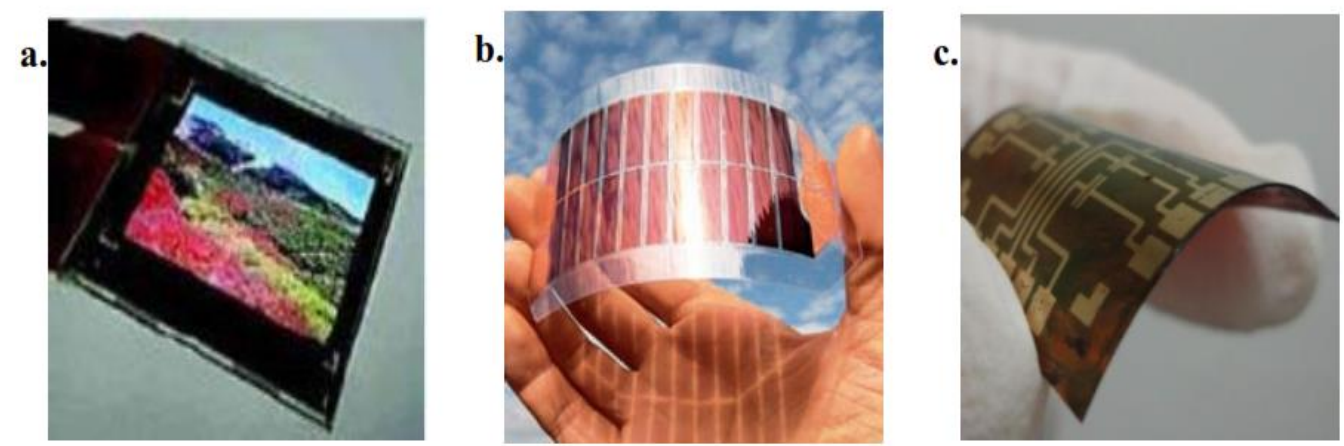

Figura 1.4 Dispositivos eletrônicos orgânicos: a. Tela de OLED (Shimoda, 2003) b. Células fotovoltaicas orgânicas (OEA, 2009) c. OFETs (Stefanelo, 2014).

\subsection{Objetivos}

\subsubsection{Objetivo Principal}

Produzir e caracterizar eletricamente dispositivos OFETs, utilizando um único SO como camada ativa e diversos polímeros dielétricos como camada isolante.

\subsubsection{Objetivos Específicos}

Depositar filmes de polímeros isolantes distintos, PMMA (polimetacrilato de metila), PVA (álcool polivinílico), PVF (polivinilformal - FORMVAR) e PU (poliuretano); para saber a espessura e rugosidade dos filmes produzidos, e avaliar sua potencial aplicação na construção de capacitores orgânicos e OFETs.

Fabricar capacitores orgânicos planos com diferentes polímeros isolantes e caracterizar os filmes poliméricos quanto a suas propriedades dielétricas em 
função da espessura do filme e, de acordo com os resultados obtidos, avaliar se podem ser utilizados na fabricação dos OFETs.

Construir dispositivos OFETs com as arquiteturas adequadas a partir dos melhores polímeros isolantes testados, utilizando as espessuras já caracterizadas para aprimorar e estudar as suas grandezas elétricas, conservando o mesmo semicondutor orgânico, o poli(3-hexiltiofeno)-P3HT como camada ativa constante.

\subsection{Apresentação}

O presente trabalho foi dividido em seis capítulos:

A introdução foi colocada no capítulo 1, com uma breve história da origem do transistor, o descobrimento dos SOs, os tipos de dispositivos fabricados com eles e suas aplicações na eletrônica orgânica.

No capítulo 2 foram abordados os fundamentos teóricos da estrutura química dos SOs, suas propriedades elétricas e o transporte de portadores de carga neles. Apresentou-se também uma informação teórica sobre os materiais utilizados, tanto sobre o $\mathrm{SO}$ e os polímeros isolantes, tratando-se o comportamento dielétrico, capacitância e constante dielétrica dos últimos. Na última parte deste capítulo, tratou-se o modelo teórico dos OFETs utilizado para a caracterização elétrica e obtenção dos resultados experimentais.

No capítulo 3 foram descritas as características específicas, técnicas de deposição e caracterização dos materiais utilizados; assim como os equipamentos utilizados na construção e caracterização elétrica dos dispositivos feitos com estes materiais. Os dispositivos dividiram-se em capacitores e OFETs.

A discussão dos resultados no capítulo 4, dividiu-se em duas partes: os resultados provenientes dos condensadores e dos OFETs.

Por fim, no capítulo 5 expôs-se os aspectos relevantes alcançados nesta dissertação e as conclusões; e no capítulo 6, foram apresentadas as referências bibliográficas utilizadas. 


\section{Fundamentação teórica}

\subsection{Propriedades Elétricas nos Semicondutores orgânicos}

Os Semicondutores Orgânicos (SOs) podem ser de três tipos: monômeros, oligômeros conjugados e polímeros conjugados. O termo conjugado se deve a disposição alternada entre ligações simples e duplas. Tal divisão esta baseada no número de repetições de um grupo molecular em especial, denominado mero, definidas como moléculas conjugadas de baixo peso molecular. Sendo assim, podemos dividir, i) monômeros, se tiverem só uma molécula conjugada, ii) oligômeros conjugados, diz-se de aqueles que têm somente uma pequena repetição, ou um número finito de repetições, de um grupo em particular e iii) polímeros conjugados, quando tiverem uma grande repetição de moléculas conjugadas, exemplificadas na Figura 2.1, formando as chamadas macromoléculas (Doi, 1997; Rezende, 1996; Seidel, 2008; Tonezer, 2007).

(a)

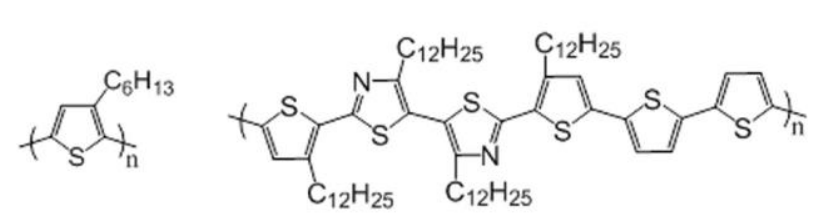

P3HT

PQTBTz-C12

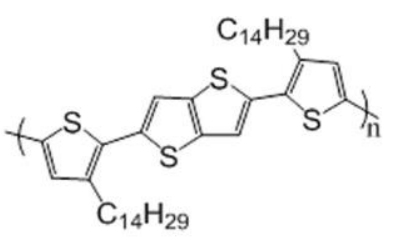

РВTTT

(b)

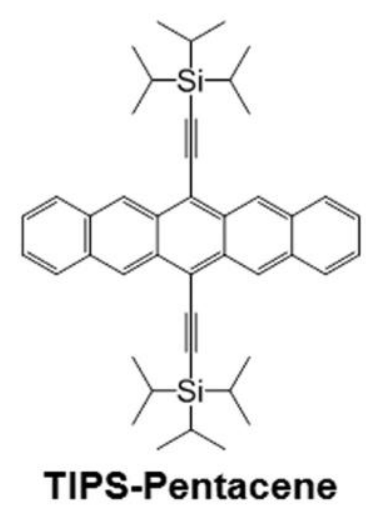



$C_{n}$-BTBT

Figura 2.1 Estruturas químicas dos SOs: (a) Poliméricos (b) Pequenas moléculas. Figura retirada da referência (Boseok, 2013).

A estrutura eletrônica dos SOs pode ser melhor explicada observando as ligações entre dois átomos de carbono que são do tipo covalente, ilustradas na Figura 2.2. 
Existem dois tipos de sobreposições: aquela dos orbitais que têm hibridização do tipo $p_{z}$, dando origem às ligações $\pi$; e a dos orbitais que possuem hibridização do tipo $s p^{2}$, que formam ligações $\sigma$ (Tonezer, 2007; Koehler, 2000). A aparição das ligações duplas entre os átomos de carbono deve-se justamente a estas ligações $\pi e \sigma$, e é por causa da alternância entre ligações duplas e simples que aparece a característica semicondutora dos materiais orgânicos (Meier, 1974) (observada na Figura 2.1), o que será explicado a seguir.

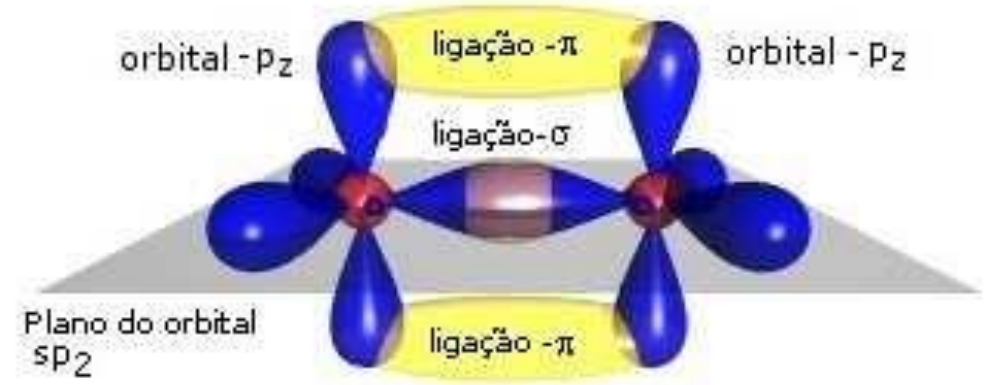

Figura 2.2 Formação de uma ligação dupla entre dois átomos de carbono. Figura modificada da referência (OSW, 2016).

As funções de onda dos orbitais que fazem parte das ligações químicas geram um orbital molecular ligante quando a sobreposição delas for construtiva, e antiligante (*) quando a sobreposição das ondas for destrutiva. No estado base, o orbital antiligante se mantém vazio, enquanto o orbital ligante é ocupado por dois elétrons (OSW, 2016; Seidel, 2008). Uma estrutura energética desta configuração pode ser observada na Figura 2.3.

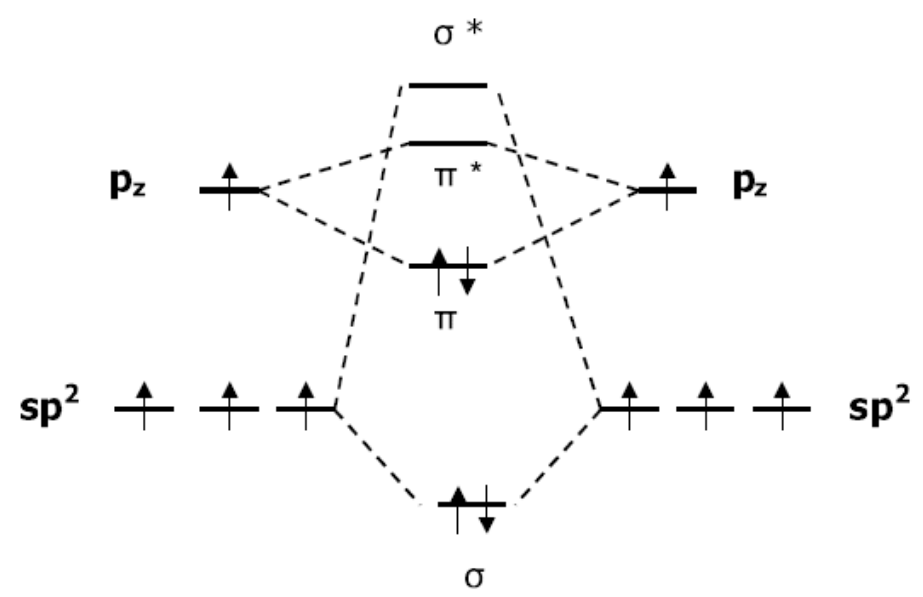

Figura 2.3 Estrutura energética formada por orbitais ligante e antiligante. Figura modificada da referência (OSW, 2016). 
Os átomos de carbono nos SOs possuem ligações que geram uma separação nos níveis de energia, criando-se quatro novos orbitais na molécula: $\pi$ ligante e $\pi^{*}$ antiligante, assim como, $\sigma$ ligante e $\sigma^{*}$ antiligante (OSW, 2016). Tendo como configuração mais estável no conjunto, a proporcionada pela descrição da Figura 2.3, é nessa situação que cada um dos orbitais ligantes $\pi e \sigma$ que são os que têm menos energia contêm dois elétrons com spins opostos. Pode-se apreciar nesta configuração que na molécula $\pi$-conjugada, a diferença de energia entre os orbitais $\pi e \pi^{*} e ́$ menor que a diferença de energia entre os orbitais $\sigma e \sigma^{*}$. Consequentemente as ligações $\sigma e \sigma^{*}$ são mais estáveis que as $\pi e \pi^{*}$, por conseguinte as ligações $\pi$ são as responsáveis pelo caráter semicondutor dos materiais orgânicos, que pode ser visto na Figura 2.4, já que estão mais propensas à excitação eletrônica (Brütting, 2005; Tonezer, 2007; Seidel, 2008).

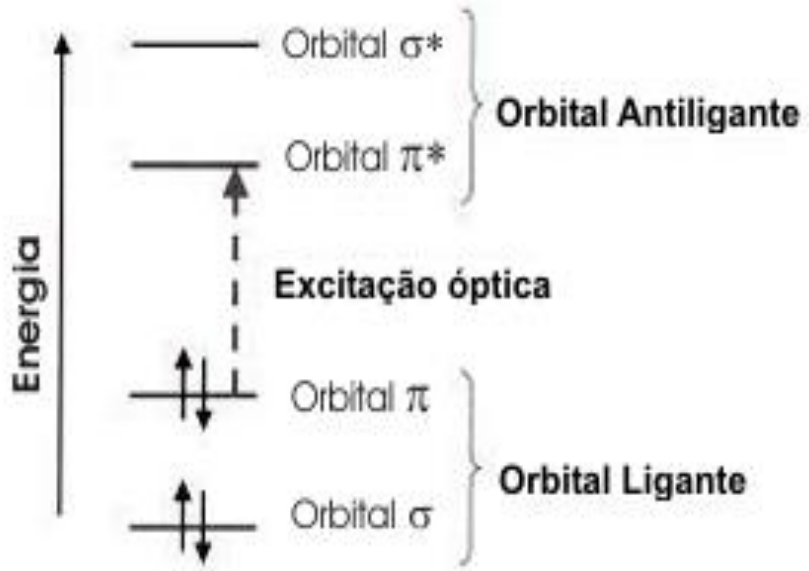

Figura 2.4 A excitação eletrônica menor acontece entre os orbitais $\boldsymbol{\pi} \boldsymbol{e} \boldsymbol{\pi}^{*}$. Figura adaptadada da referência (Brütting, 2005).

Uma vez que se conhece a estrutura molecular de dois átomos de carbono e suas ligações, é mais simples explicar a estrutura eletrônica dos polímeros conjugados. Na molécula $\pi$-conjugada, os orbitais $\pi e \pi^{*}$ dão origem aos orbitais de fronteira, nomeados, respectivamente, como HOMO (Highest Occupied Molecular Orbital) que é o orbital molecular ocupado mais alto ou de maior energia e LUMO (Lowest Unoccupied Molecular Orbital), sendo o orbital molecular desocupado mais baixo ou de menor energia. Numa cadeia polimérica não é apropriado se referir a HOMO e LUMO como bandas de energia, já que estes níveis de energia podem mudar de molécula para molécula, mesmo sendo do mesmo material. No 
entanto, nestes materiais amorfos, pode-se dizer que se gera um conjunto discreto de níveis de energia, formando uma distribuição de orbitais HOMO e LUMO, como mostrado na Figura 2.5. Assim, pode-se estabelecer um paralelo com a banda de valência e condução, respectivamente, em semicondutores inorgânicos. Tais distribuições HOMO e LUMO têm uma diferença de energia que poderia ser chamada de banda proibida ou "gap" (Brütting, 2005; Tonezer, 2007; Seidel, 2008).

Os SOs devem ter certo número de repetições não interrompidas de ligações simples e duplas alternadas ao longo deles, esta estrutura é conhecida como comprimento de conjugação. Devido à desordem estrutural molecular inerente aos materiais orgânicos, o comprimento de conjugação sofre flutuações e, portanto os níveis HOMO e LUMO também; produzindo um conjunto discreto de níveis de energia, podendo tratá-los como uma densidade de estados, descrita por uma distribuição Gaussiana de orbitais moleculares localizados em moléculas individuais, apresentadas nas Figuras 2.5 e 2.6 (Brütting, 2005; Seidel, 2008).

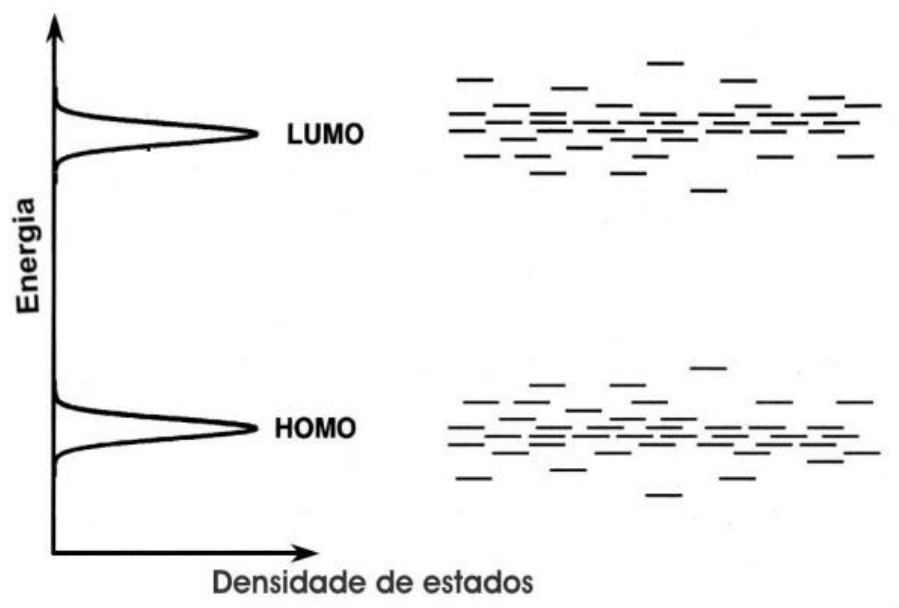

Figura 2.5 Distribuições dos níveis HOMO e LUMO em SOs. Figura adaptadada da referência (Brütting, 2005).

Por outro lado, tem-se que levar em consideração também, a aparição de defeitos, que se deve, por exemplo, à inserção de impurezas durante a sintetização do material, também podem aparecer na deposição dos filmes e na quebra de ligações químicas na cadeia polimérica (defeitos estruturais) (Campbell, 1997; Benvenho, 2005; Serbena, 2005). Todos estes defeitos criam níveis intermediários 
localizados no "gap", podendo ser eletricamente ativos e atuando como armadilhas de carga, como se ilustra na Figura 2.6.

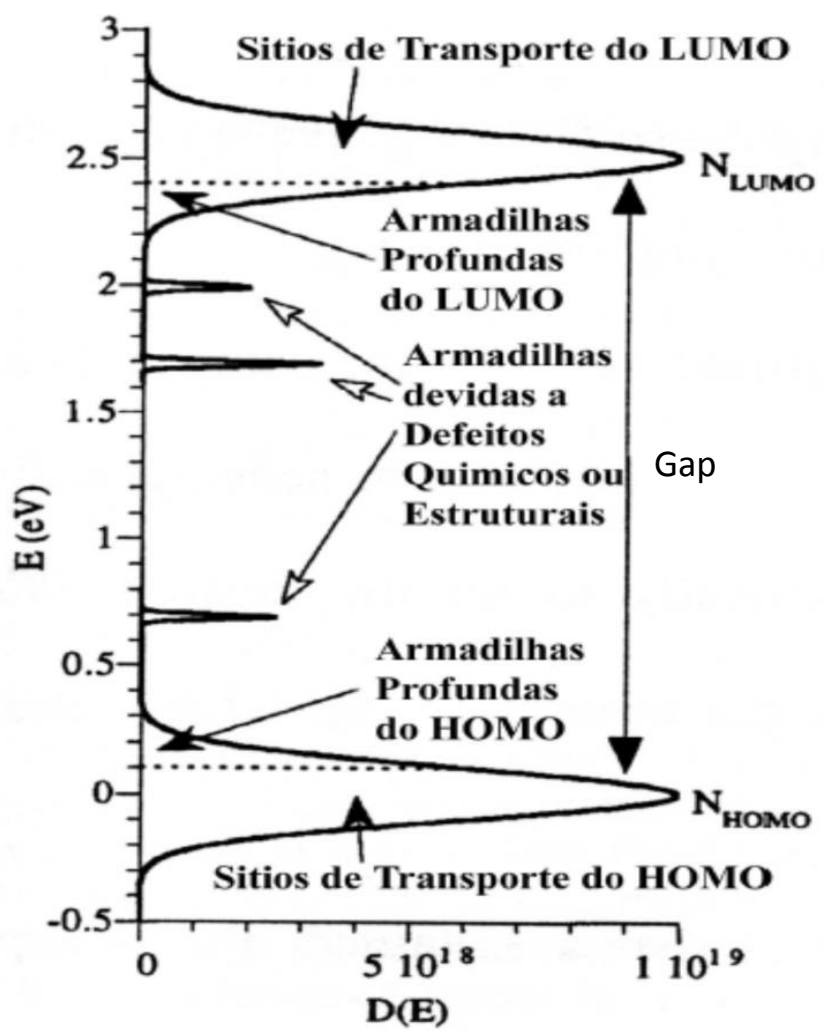

Figura 2.6 Distribuição Gaussiana dos estados eletrônicos HOMO e LUMO com os níveis de armadilhas num material orgânico conjugado. Figura modificada da referência (Campbell, 1997).

\subsection{Transporte de carga em materiais orgânicos}

Em polímeros conjugados o transporte de carga tem um caráter randômico dado pela posição dos níveis de energia das moléculas e pela localização dos estados eletrônicos de cada uma destas. Consequentemente, o transporte de carga acontece por ativação térmica entre os orbitais moleculares localizados, cuja mobilidade aumenta com a temperatura e o campo elétrico (Baldo \& Forrest, 2001). A razão entre velocidade $(v)$ e intensidade do campo elétrico $(E)$ é definida como mobilidade $(\mu)$ :

$$
\mu=\frac{v}{E}
$$

O modelo já mencionado de transporte de carga termicamente ativado é denominado de "hopping", onde os portadores de carga se movimentam de 
molécula em molécula tunelando ou saltando a barreira de potencial entre os estados energéticos localizados dentro do polímero (Kao \& Hwang, 1981). Com respeito aos saltos, sua probabilidade depende da distância espacial e diferença de energia entre dois estados, conforme representado na Figura 2.7. Um elétron num estado eletrônico determinado pode emitir ou absorver um fônon (vibração da rede) e saltar para outro estado eletrônico qualquer com uma diferente energia da que possuía. Especificamente, se o salto acontecer de um estado de energia maior para um de energia menor o portador emite um fônon, e se acontecer de um estado de energia menor para um de energia maior o portador precisa absorver um fônon. O fator limitante da corrente num dispositivo e, por conseguinte da mobilidade a nível macroscópico, é o tempo que os portadores de carga permanecem em cada estado (Botteger, 1985; Serbena, 2005).

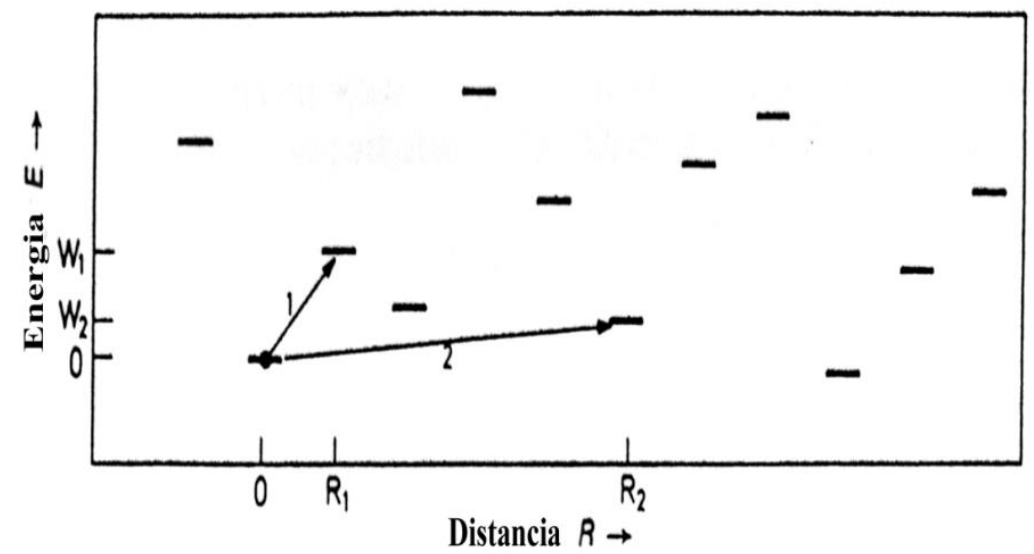

Figura 2.7 Representação esquemática do transporte de cargas por "hopping" em polímeros cojugados. Figura modificada da referência (Madelung, 1996).

Numa distribuição de estados localizados HOMO ou LUMO pode-se verificar (Figura 2.8) a grande concentração no centro da distribuição Gaussiana (por isso o modelo) dos estados localizados que estão distribuídos em estados de energias próximas, onde o processo de "hopping" é mais simples. Contudo, nos extremos da distribuição Gaussiana, existem poucos estados com energias próximas, complicando o transporte de carga entre estes sítios, tornando-os estados de armadilha, como apresentados nas Figuras 2.6 e 2.8.

A limitação da corrente num dispositivo pode ser devido não só ao material, senão também ao contato eletrodo-material orgânico. No caso do contato ôhmico, o 
eletrodo pode fornecer mais corrente do que o SO pode transportar, criando um acúmulo de cargas ao interior do polímero e alterando o campo elétrico interno que controla a injeção dos portadores. Este processo é conhecido como corrente limitada por carga espacial (SCLC do inglês Theory of Space Charge Limited Current). Desta forma, a mobilidade possui uma limitação: quanto maior o acúmulo de cargas menor a corrente e, portanto, menor a mobilidade. Um menor acúmulo de cargas leva a um aumento na corrente e, consequentemente a uma mobilidade maior, sendo este um dos principais propósitos da eletrônica orgânica.

A teoria da SCLC tem sua origem no modelo teórico que desenvolveram Mott e Gurney em 1948 para a injeção de portadores de carga em isolantes. Foram Rose e Lampert que anos mais tarde em 1959, propuseram uma descrição simplificada com o nome atual, a qual começou a ser utilizada nos SOs em 1962 por Helfrich e Mark (Pope \& Swenberg, 1999).



a)

b)

Figura 2.8 a) Densidade de estados LUMO (linha sólida). b) concentração no centro da distribuição Gaussiana dos estados localizados, onde o processo de hopping é mais simples que nos extremos. Figura modificada da referência (O’neill \& Kelly, 2011).

Sabe-se também que a densidade de corrente $(J)$ sob a premissa da inexistência de armadilhas, pode-se escrever para baixas tensões como

$$
J=q n_{0} \mu \frac{V}{d}
$$

Onde $q$ é a carga do portador, $n_{0}$ é a densidade de portadores livres no equilíbrio térmico, $\mu$ a mobilidade, $d$ a espessura da camada do material e $V$ a tensão no 
dispositivo. É importante fazer notar que a equação (2.2) descreve a dependência de $J$ versus $V$ para o regime ôhmico, conforme região (1) da Figura 2.9.

E para tensões altas (quando o SO deixa o regime linear inicial) a equação é (Blom et al., 1997):

$$
J=\frac{9}{8} \varepsilon \mu \frac{V^{2}}{d^{3}}
$$

Sendo $\varepsilon$ é a constante dielétrica do material e $\mu$ a mobilidade.

A igualdade (2.3) é a equação característica da SCLC que descreve a dependência quadrática da corrente com a tensão, verificado nas regiões (2) e (4) da Figura 2.9. Esta equação é conhecida também como a lei quadrática livre de armadilhas ou lei quadrática de Mott-Gurney, que na Física do estado sólido é citada como a lei de Child para SCLC no vácuo (Pope \& Swenberg, 1999).

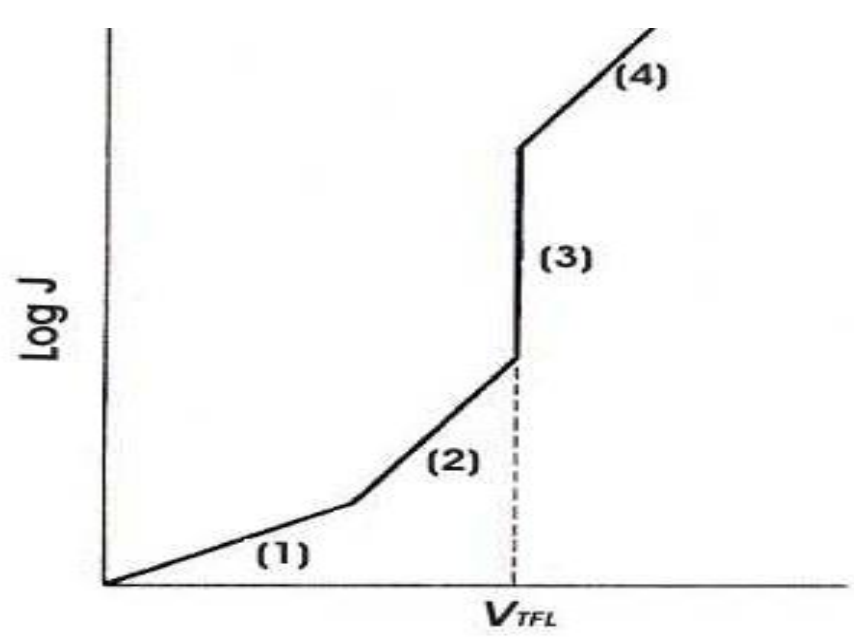

Figura 2.9 Esquema da curva característica de SCLC para um isolante com um nível de armadilha: (1) região ôhmica, (2) lei quadrática de Mott-Gurney na presença de armadilhas rasas, (3) tensão limite de preenchimento de armadilhas $V_{T F L}$, (4) lei quadrática de Mott-Gurney na ausencia de armadilhas, sendo esta a corrente máxima que pode atingir no modelo SCLC. Figura retirada da referência (Pope \& Swenberg, 1999).

Quando se aumenta a tensão num dispositivo capacitivo, considerando ôhmicos seus contatos, o fluxo da corrente deve aumentar também. Este fato torna uma armadilha qualquer numa armadilha profunda, quer dizer, com uma alta probabilidade de ser preenchida. Quando esta situação acontece, os portadores injetados não são mais aprisionados, indicando que já não tem armadilhas para 
preencher; provocando um aumento na corrente considerável. A voltagem na qual esta situação sobrevém é chamada tensão limite de preenchimento de armadilhas (do inglês, Trap-filled limit Voltage $V_{T F L}$ ) onde a corrente é proporcional a $V^{n}$ com $n>2$, representado na região (3) da Figura 2.9 (Pope \& Swenberg, 1999; Seidel, 2008).

No segundo caso, se o contato eletrodo-polímero conjugado não for ôhmico, a corrente será limitada pela injeção de cargas. Este fato deve-se a que na interface existem barreiras de potencial que não permitem ao eletrodo injetar adequadamente portadores de carga dentro do polímero. $\mathrm{Na}$ literatura, os processos mais reportados que limitam a corrente nos SOs pela injeção de cargas são dois: o de injeção termiônica, e o de tunelamento.

A injeção termiônica acontece quando a energia térmica dos portadores de carga é da ordem da altura de barreira na interface, logo os portadores "saltam" sobre ela, como mostra a Figura 2.10. A densidade de corrente $(J)$, neste caso, define-se como (Valaski et al., 2002):

$$
J=q N_{v} \mu F \exp \left(\frac{-\varphi+\beta F^{1 / 2}}{K_{B} T}\right)
$$

Onde $q$ é carga elementar, $N_{v}$ a densidade de estados energéticos, $\mu$ a mobilidade, $F$ campo elétrico, $\varphi$ altura de barreira de potencial, $K_{B}$ constante de Boltzman, $T$ a temperatura, e $\beta$ é dada pela equação:

$$
\beta=\left(\frac{q^{3}}{4 \pi \epsilon}\right)^{1 / 2}
$$

Sendo $\epsilon$ a permissividade elétrica do material. Tem-se que salientar que a mobilidade $\mu$, nos casos específicos das equações (2.2-2.4) é considerada constante. No processo de tunelamento, a altura da barreira na interface é muito maior que a energia dos portadores. Por isso é preciso ter um alto campo elétrico para "tunelar" através da barreira triangular entre o eletrodo e o nível energético do material, mostrado na Figura 2.10. Segundo o modelo de tunelamento a densidade de corrente $(J)$ neste caso é (Hümmelgen et al.,1996): 


$$
J \propto F^{2} \exp \left(-\frac{K}{F}\right)
$$

Onde $F$ é o campo elétrico no material e $K$ é uma constante.

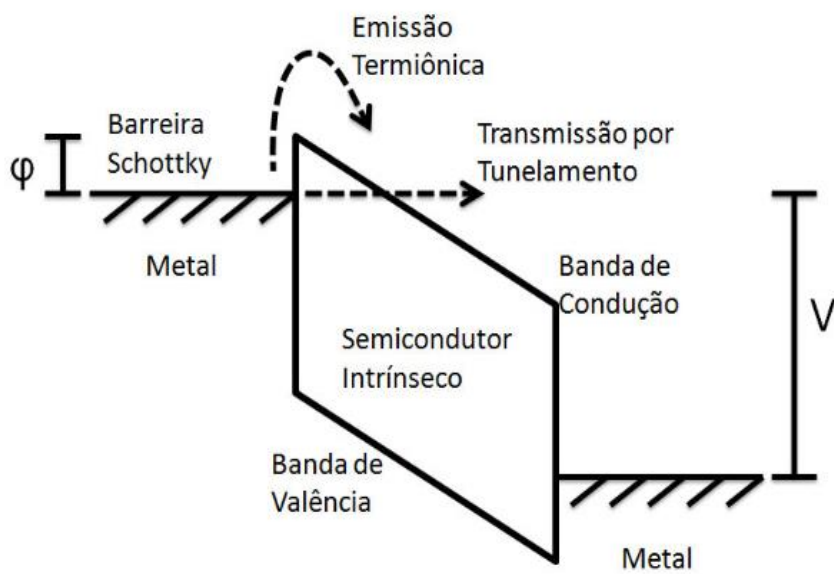

Figura 2.10 Esquema dos processos de injeção termiônica e tunelamento numa estrutura metal/SO/metal. Figura retirada da referência (Aderne, 2013).

\subsection{Materiais Semicondutores}

\subsubsection{O poli(3-hexiltiofeno)-P3HT}

Comumente conhecido como P3HT, o poli(3-hexiltiofeno) é um dos polímeros semicondutores mais investigados na eletrônica orgânica. Este fato deve-se as propriedades do material de apresentar boa solubilidade e alta estabilidade (Ukai et al., 2005). Conhece-se também que foram feitos OFETs com P3HT cujas mobilidades chegaram até $0,2 \mathrm{~cm}^{2} / V . s$ (Wang et al., 2003). Esta alta mobilidade no P3HT é como consequência da formação de estruturas lamelares auto organizadas, devido às suas cadeias laterais (Sirringhaus et al., 1999). Tais estruturas lamelares formam domínios semicristalinos "encravados" na matriz amorfa do polímero (Malik, 2002; Maciel, 2012).

O P3HT tem a capacidade de ser sintetizado na forma regiorregular (rr-P3HT) observada na Figura 2.11 (Maciel, 2012). O rr-P3HT tem suas cadeias laterais de hexil todas alinhadas para o mesmo lado de forma alternada entre os anéis tiofenos (Chen et al., 1995). Esta configuração, conhecida como "head-to-tail", é de extrema importância desde que a mobilidade do rr-P3HT possa ser até duas 
ordem de grandezas maior do que seu isômero P3HT regioaleatório (rra-P3HT), apresentado na Figura 2.12 (Bao et al., 1996). Observa-se que no caso do rraP3HT, apenas metade das cadeias laterais estão alinhadas como no modo "headto-tail” (Maciel, 2012).

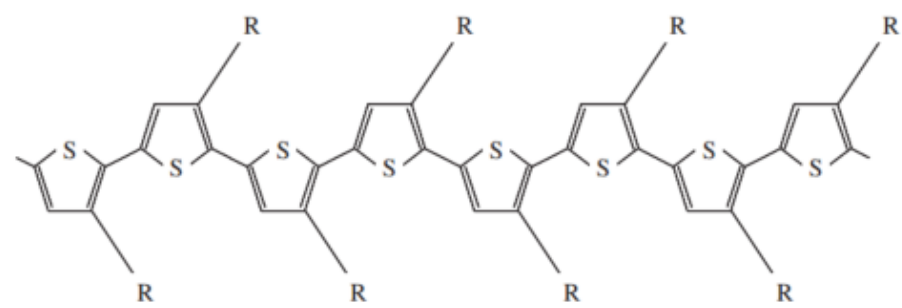

Figura 2.11 Estrutura química do rr-P3HT, note-se que o radical R é a cadeia lateral hexil. Figura retirada da referência (Maciel, 2012).

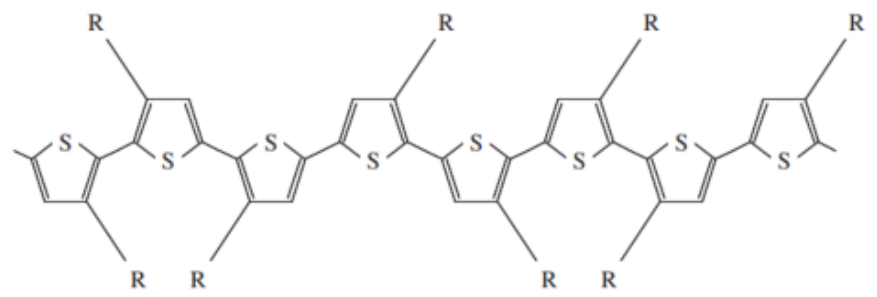

Figura 2.12 Estrutura química do rra-P3HT, note-se que o radical R é a cadeia lateral hexil. Figura retirada da referência (Maciel, 2012).

No rr-P3HT, as intensas interações entre as cadeias laterais, orientadas regularmente, conduzem à formação de uma estrutura molecular "interdigitada", que pode ser representada como na Figura 2.13; que permite um incremento da conjugação- $\pi$ entre as moléculas. Como resultado, uma estrutura cristalina pode ser obtida com mobilidades maiores que no rra-P3HT (Machado, 2011).

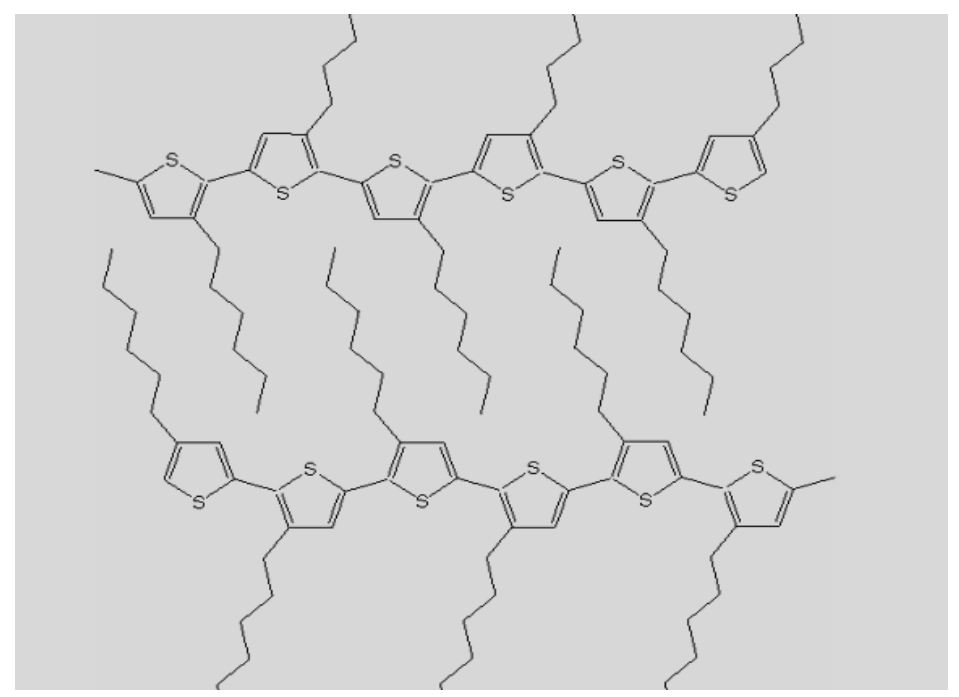

Figura. 2.13 Representação esquemática de uma estrutura molecular interdigitada do rr-P3HT. Figura retirada da referência (Machado, 2011). 
Tem sido demonstrado que a orientação dos domínios do rr-P3HT com respeito ao substrato depende do grau de regiorregularidade e da rapidez de formação do filme. Sirringhaus et al. (1999) concluíram que a utilização do P3HT com alto grau de regiorregularidade e a utilização de condições de deposição que favoreçam uma cristalização lenta do filme polimérico induziram a formação de filmes com domínios orientados, melhorando o transporte de cargas e aumentando a mobilidade dos portadores de cargas. Sendo assim, a utilização de solventes de alta temperatura de evaporação é preferida, o que permite uma lenta evaporação do solvente durante a deposição do polímero, dando tempo suficiente para as moléculas se arranjarem de forma mais cristalina (Chang et al., 2004; Machado, 2011)

\subsection{Materiais Isolantes}

Além dos materiais SOs que compõem os OFETs, a escolha da camada isolante apropriada é fundamental para garantir uma boa performance do dispositivo. O dióxido de silício é um dos dielétricos mais utilizados nos FETs (Field Effect Transistor) inorgânicos e com o objetivo de testar SOs, foi também incorporado na fabricação dos OFETs. No entanto, se a finalidade é a construção de dispositivos orgânicos, a substituição da maior quantidade possível de elementos inorgânicos pelos respectivos orgânicos vem sendo priorizada nos trabalhos desenvolvidos sobre OFETs (Stefanelo, 2014). No caso dos dielétricos, o mundo orgânico oferece uma ampla gama de substitutos com propriedades dielétricas equivalentes, como exemplos de materiais utilizados tem-se vários polímeros, como mostra a Figura 2.14 (Veres et al., 2004). Além disso, os isolantes orgânicos trazem consigo a vantagem do processamento em solução, favorecendo sua utilização em substratos flexíveis, formam filmes reprodutíveis e pouco rugosos (Stefanelo, 2014).

Como os OFETs objetivam aplicações potencialmente de baixo valor agregado, dielétricos cujo processo de fabricação seja simples e de baixo custo são de grande interesse; tal característica inclui os dielétricos poliméricos. O método mais comum de produção de um filme dielétrico é a deposição da solução do polímero e subsequente tratamento térmico para a evaporação do solvente. As propriedades dos filmes poliméricos obtidos (espessura, rugosidade, estabilidade, etc.) são 
determinadas pela formulação das soluções, pelos processos de deposição utilizados, e pelas características do polímero (Machado, 2011).

Ao lado das propriedades isolantes, outras características são fundamentais para o uso destes materiais nos OFETs, tais como a estabilidade química e térmica, e uma excelente propriedade de formação de filmes finos. Isto limita a utilização de alguns polímeros por não satisfazerem algumas destas condições (Machado, 2011).
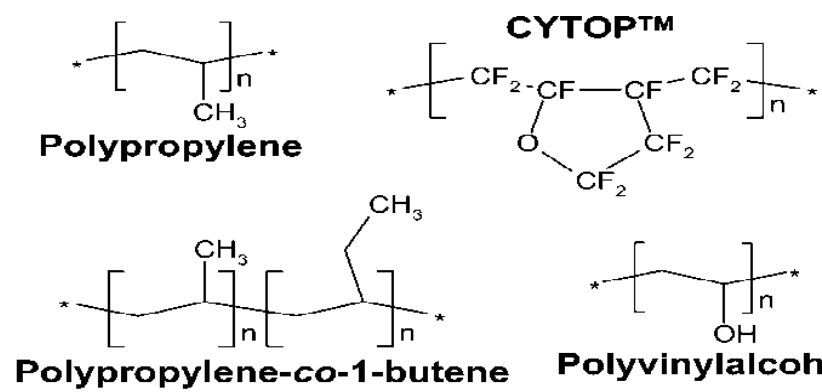

Polyvinylalcohol
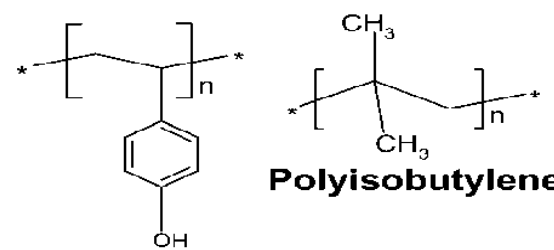

Polyisobutylene

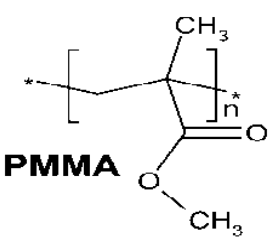

Polyvinylphenol
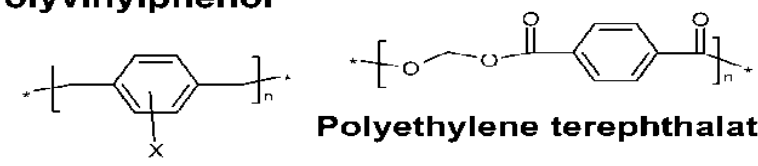

Polyethylene terephthalate (PET)
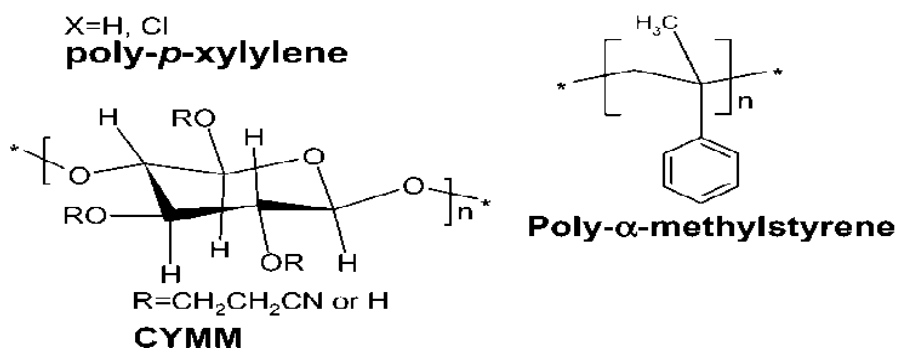

CYMM

Figura 2.14 Alguns polímeros orgânicos utilizados como dielétricos na fabricação de OFETs. Figura retirada da referência (Veres et al., 2004).

\subsubsection{PMMA}

Dentre dos polímeros isolantes mais utilizados na construção de OFETs, está o poli(metacrilato de metila) (PMMA), de estrutura molecular representada na Figura 2.14 (Veres et al., 2004). O PMMA é um termoplástico transparente, solúvel numa variedade de solventes orgânicos, tal como o Metil-Etil-Cetona 
(Methyl Ethyl Ketone-MEK), cuja formula química é $\mathrm{C}_{4} \mathrm{H}_{8} \mathrm{O}$ e com um ponto de ebulição de $80^{\circ} \mathrm{C}$.

\subsubsection{PVA}

Outro isolante polimérico muito utilizado é o álcool polivinílico (PVA) (Veres et al., 2004), cuja estrutura química está apresentada na Figura 2.14. O PVA destacase por ser um material solúvel em água, um solvente não poluente. Ainda, o processo de preparação das soluções de PVA é relativamente simples, resultando em filmes homogêneos e uniformes.

Outros materiais isolantes conhecidos, porém não utilizados na construção de OFETs são o polivinil formal (FORMVAR) e o poliuretano (PU), que serão apresentados a seguir.

\subsubsection{FORMVAR}

O polivinil formal (FORMVAR), cuja estrutura química é mostrada na Figura 2.15 é uma resina isolante que tem diferentes aplicações na indústria, que vão desde filmes de suporte TEM (Transversal eletromagnético), revestimentos de fios e cabos, e adesivos. O FORMVAR é solúvel numa variedade de solventes orgânicos, tais como o dicloreto de etileno, o dioxane, e o mais utilizado o clorofórmio (Spi Supplies, 2016).

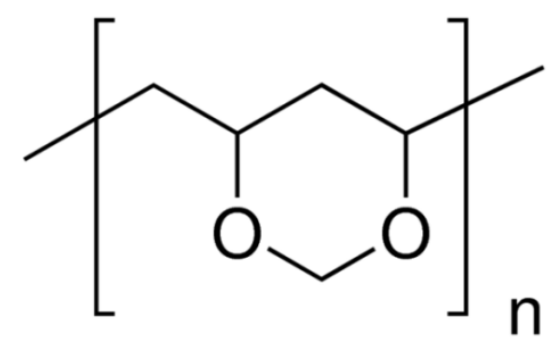

Figura 2.15 Estrutura química do Polivinil formal (FORMVAR). Figura retirada da referência (Sigma-Aldrich, 2016).

\subsubsection{Poliuretano (PU)}

Os poliuretanos apresentam estruturas moleculares indicadas na Figura 2.16 e são polímeros que possuem excelentes características para a indústria, como flexibilidade, leveza, resistência à abrasão (riscos) e possibilidade de design 
diferenciado. Contudo, a sua aplicação contém sérias restrições quando o tema é reciclagem (ACC, 2016).

O poliuretano é resultante da reação química de dois componentes básicos, um poliol e um isocianato, em associação com aditivos que controlam e homogenizam o resultado. O PU é, sem sombra de dúvidas, um dos polímeros de maior uso e maior importância em praticamente todos os mercados de bens de consumo e uso industrial. Versátil, o PU apresenta-se sob diversas formas (espuma, moldado, filme, aplicado por bico, etc.) que depende da aplicação e dos requisitos de uso (ACC, 2016).

O PU é um polímero isolante, solúvel em tetraidrofurano (THF) e parcialmente solúvel em Metil-Etil-Cetona (Methyl Ethyl Ketone-MEK).



Figura 2.16 Estrutura química do poliuretano (PU). Figura retirada da referência (ACC, 2016).

A constante dielétrica $\left(\varepsilon_{i}\right)$ e a rigidez dielétrica destes polímeros isolantes apresentados, e de interesse no presente trabalho, são mostradas na Tabela 2.1.

\begin{tabular}{|l|c|c|c|}
\hline Dielétricos & $\begin{array}{c}\text { Constante } \\
\text { dielétrica }^{*}(\mathrm{a} \\
60 \mathrm{~Hz})\end{array}$ & $\begin{array}{c}\text { Rigidez dielétrica } \\
(\mathrm{mV} / \mathrm{nm})\end{array}$ & Referências \\
\hline PMMA & 3.5 & $30-110$ & $\begin{array}{c}\text { (Veres et al., 2004) }^{*} \\
\text { (Park et al., 2007) }^{\dagger}\end{array}$ \\
\hline PVA & $5-10$ & $>1000$ & $\begin{array}{c}\text { (Etten et al., 2014) }^{*} \\
\text { (Gokçen \& Tunç, 2013) }^{\dagger}\end{array}$ \\
\hline FORMVAR & $3-4$ & $26-39$ & (Spi Supplies, 2016) $^{* \dagger}$ \\
\hline PU & $4-11$ & $13-25$ & $\begin{array}{c}\text { (Lorenzini et al., 2013) }^{*} \\
\text { (Global Polymer }^{\dagger}\end{array}$ \\
\hline
\end{tabular}

Tabela 2.1 Constante e rigidez dielétrica dos isolantes utilizados no presente trabalho. 


\subsection{Dispositivos}

\subsubsection{Capacitor de Placas Paralelas}

O capacitor é um dispositivo elétrico usado para armazenar energia elétrica, consiste de dois condutores com um isolante entre eles. Quando se estabelece uma diferença de potencial $\mathrm{V}$ entre os condutores, após um processo de carga e descarga eles ficam carregados com uma carga $\pm \mathrm{Q}$. Um fato empírico é que $Q \propto V$, e a constante de proporcionalidade $C$ é a capacitância:

$$
C=\frac{Q}{V}
$$

Para um capacitor de placas paralelas, com um material dielétrico em seu interior, conforme apresentado na Figura 2.17, a capacitância é:

$$
C=\varepsilon_{i} \varepsilon_{0} \frac{A}{d}
$$

Sendo $\varepsilon_{i}$ a constante dielétrica do material isolante, $\varepsilon_{0}$ a permissividade elétrica do vácuo, $A$ a área das placas e $d$ a espessura da camada isolante.

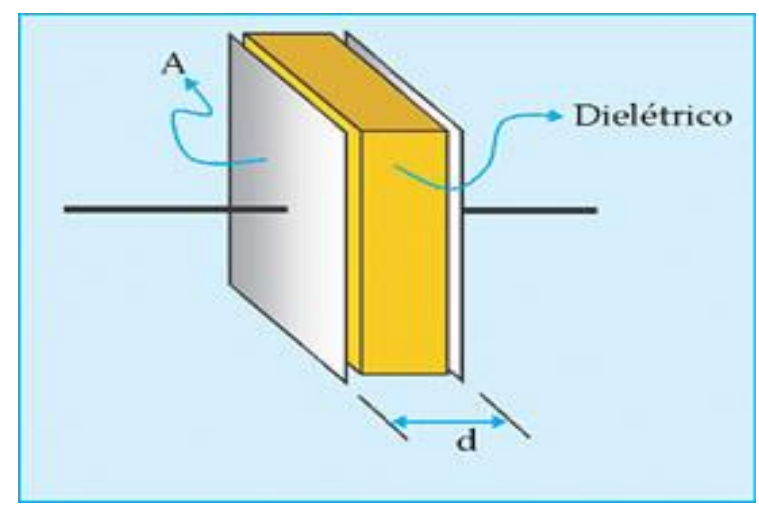

Figura 2.17 Capacitor de placas paralelas com um material dielétrico em seu interior.

Da equação (2.7), a capacitância por unidade de área $\left(C_{i}\right)$, que será a forma utilizada para os OFETs é:

$$
C_{i}=\frac{C}{A}=\varepsilon_{0} \varepsilon_{i} \frac{1}{d}
$$

A capacitância por unidade de área $\left(C_{i}\right)$ está intimamente ligada ao bom desempenho dos OFETs, como será explicado no item 2.5.2. Relacionando as equações 2.6 e 2.8 , pode-se deduzir que: 


$$
V \propto 1 / C_{i}
$$

Um dos principais problemas que limitam a aplicação dos OFETs é sua alta tensão de operação, frequentemente excedendo $20 \mathrm{~V}$. Um possível caminho para se obter transistores que operam a baixas tensões é aumentar a capacitância por unidade de área $\left(C_{i}\right)$ do dielétrico, em concordância com a equação (2.8.a). Baseando-se na equação (2.8) existem duas formas de se obter uma maior $C_{i}$ : aumentando a constante dielétrica do material isolante $\left(\varepsilon_{i}\right)$ ou diminuindo a espessura do filme dielétrico $(d)$ (Machado, 2011). O risco em fazer camadas muito finas está em ultrapassar a rigidez dielétrica dos isolantes e que estes atinjam a ruptura dielétrica, ou seja, que percam suas propriedades isolantes. Outra consequência deste fenômeno, num filme muito fino, é que aumentem as correntes de fuga no dielétrico (Stefanelo, 2014). Ao contrário, aumentando a espessura da camada isolante, de acordo à equação (2.8), obtém-se uma $C_{i}$ menor; o que se traduz, segundo a equação (2.8.a) em voltagens de operação maiores. Este fato é um limitante em aplicações da microeletrônica orgânica que precisa de voltagens de operação menores que $7 \mathrm{~V}$.

De um capacitor de placas paralelas, pode-se obter entre outros resultados: a curva densidade de corrente $(J)$ versus tensão $(V)$, a capacitância por unidade de área $\left(C_{i}\right)$ e calcular a constante dielétrica $\left(\varepsilon_{i}\right)$ do material isolante utilizando a equação (2.8).

\subsubsection{Curvas $J x V$}

É possível também, do capacitor plano, obter a curva densidade de corrente $(J)$ versus tensão $(V)$, mais conhecida como curva $J x V$. Desta curva pode-se conhecer a corrente de fuga no dielétrico. Assim como prever, mediante o deslocamento da Curva $J x V$ do zero, no eixo da voltagem, se um dielétrico pode funcionar a tensões baixas ou altas. A seguir, se tratarão em detalhe estas questões.

\subsubsection{1.a. Corrente de fuga no dielétrico}

A partir do trabalho de Schroeder e colaboradores (2005), pode-se apresentar uma análise geral do comportamento típico de uma curva $J x V$. Desta referência, tomou-se a Figura 2.18. Nela observa-se quatro curvas $J x V$ (com $V$ medida em 
unidades do campo elétrico $\mathrm{MV} / \mathrm{cm}$ ) para o isolante poli(vinil álcool)-co-poli(vinil acetato)-co-poli(acido itaconico) (PVAIA), dopado com nanopartículas de BaTiO3 em quatro diferentes proporções, com o objetivo de aumentar sua $\varepsilon_{i}$. As medidas foram feitas num capacitor de placas paralelas, composto de: óxido de índio e estanho (Indium tin oxide-ITO)/ PVAIA-BaTiO3/Au (Schroeder et al., 2005).

Na Figura 2.18, observa-se que no ponto $0.0 \mathrm{MV} / \mathrm{cm}$ do eixo do campo elétrico, as densidades de corrente das curvas $J x V$ não são zero, mas deveriam sê-lo. Pois teoricamente sabe-se que ao não ter voltagem ou campo elétrico, não deveria existir densidade de corrente. Porém todas as curvas $J x V$ apresentaram em $0.0 \mathrm{MV} / \mathrm{cm}$ densidades de corrente, com valores entre $10^{-9}$ e $10^{-8}\left(\mathrm{~A} / \mathrm{mm}^{2}\right)$. Este fato indica que existe em $0.0 \mathrm{MV} / \mathrm{cm}$, uma corrente de fuga nos dielétricos (Schmidt, 1979; Schroeder et al., 2005); que pode ser calculada com a área das placas, sendo um valor mensurável no capacitor.

Geralmente os gráficos $J x V$ são apresentados em escala semi-logarítmicas, colocando a densidade de corrente $(J)$ na escala logarítmica; pois as correntes de fuga num dielétrico são, em geral pequenas e não se consegue observá-las numa escala linear.

Esta corrente de fuga é uma grandeza que pode afetar o desempenho de um OFET. Se a corrente de fuga num dielétrico for da ordem de nano-ampere, é pouco provável que um OFET funcione adequadamente, já que as correntes geradas num OFET são geralmente da ordem de microampère.

\subsubsection{1.b. Deslocamento da Curva $J x V$ do zero e efeitos de carga}

Na Figura 2.18, observa-se um deslocamento das Curvas $J x V$ do zero, no eixo do campo elétrico. Este fenômeno deve-se em geral a efeitos de carga, por exemplo, da polarização das moléculas do polímero, elétrons livres no solvente ou nas moléculas do polímero; como neste caso particular das nanopartículas de BaTiO3 (Schmidt, 1979; Schroeder et al., 2005). Também se pode prever a partir de que campo elétrico ou voltagem, podem ter um melhor desempenho os dielétricos; e consequentemente um dispositivo OFET. No caso das curvas $J x V$ da Figura 2.18, observa-se que os isolantes têm um deslocamento das Curvas $J x V$ do zero, no eixo 
do campo elétrico de aproximadamente $1 \mathrm{MV} / \mathrm{cm}$. Este fato significa que um OFET feito com qualquer destes dielétricos funcionaria melhor a partir de $1 \mathrm{MV} / \mathrm{cm}$, pois para valores entre $0-1 \mathrm{MV} / \mathrm{cm}$ existem correntes de fuga. Em tanto que para valores a partir que $1 \mathrm{MV} / \mathrm{cm}$, estas correntes são menores.

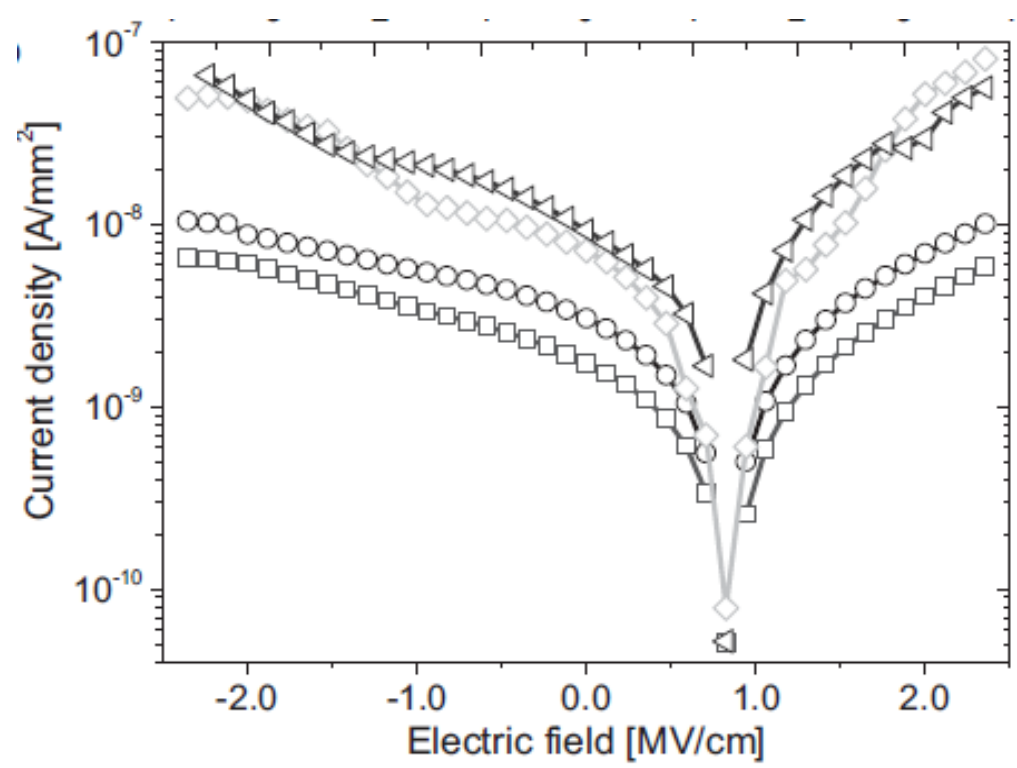

Figura 2.18 Curvas $\boldsymbol{J} \boldsymbol{x} \boldsymbol{V}$ de um capacitor ITO/ PVAIA-BaTiO3/Au, o PVAIA foi dopado com nanopartículas de $\mathrm{BaTiO} 3$ em quatro diferentes proporções. Figura retirada da referência (Schroeder, et al., 2005).

\subsubsection{Transistor de efeito campo orgânico (OFET)}

A eletrônica orgânica teve seu inicio por volta dos anos 80 com as aplicações dos diodos orgânicos emissores de luz orgânicos (OLEDs) (Tang \& Slyke, 1987), das células fotovoltaicas orgânicas (OPVs) (Tang, 1986) e dos já citados OFETs (Tsumura et al., 1986). Foi Tsumura quem fabricou neste último trabalho mencionado, um transistor com uma camada semicondutora orgânica, utilizando um politiofeno depositado por eletroquímica; iniciando a eletrônica orgânica.

O fundamento elementar dos transistores de efeito de campo (FETs-em inglês Field Effect Transistor) é modular a intensidade da corrente elétrica que decorre entre o eletrodo fonte (source) até o eletrodo dreno (drain) por causa de um campo elétrico aplicado por um terceiro eletrodo porta (Gate) (Seidel, 2008). 


\subsubsection{Arquiteturas dos OFETs}

Fundamentalmente os OFETs podem ser fabricados em quatro estruturas, como representados na Figura 2.19; e possuem três partes constituintes: um isolante, um SO e os três contatos (Fonte, Dreno e Porta). Em contato direto com o SO estão a fonte e o dreno; e o gate (porta) fica isolado do SO pelo dielétrico. A fabricação de um OFET consiste na deposição sucessiva de filmes finos de diferentes materiais. A ordem destas deposições determina o tipo de arquitetura do OFET.

Os tipos de arquiteturas dos OFETs podem ser divididos em dois grupos, dependendo da localização da porta (Gate) em relação ao substrato e subdivididos pela posição dos eletrodos fonte e dreno com respeito ao semicondutor. Uma dessas divisões é denominada de Bottom-Gate (BG), ou seja, porta inferior. Nesse caso este eletrodo é o primeiro a ser depositado, e acima dele a camada isolante, como é mostrado na Figura 2.19 a. e 2.19.b. Esse grupo pode estar subdividido, e dependendo da localização dos contatos fonte e dreno, pode-se classificar em: Bottom-Gate/Bottom-Contacts $(B G B C)$ onde os eletrodos estão na parte inferior do semicondutor (Figura 2.19 a.) e Bottom-Gate/Top-Contacts (BGTC) onde os contatos estão na parte superior do semicondutor (Figura 21.9 b.).
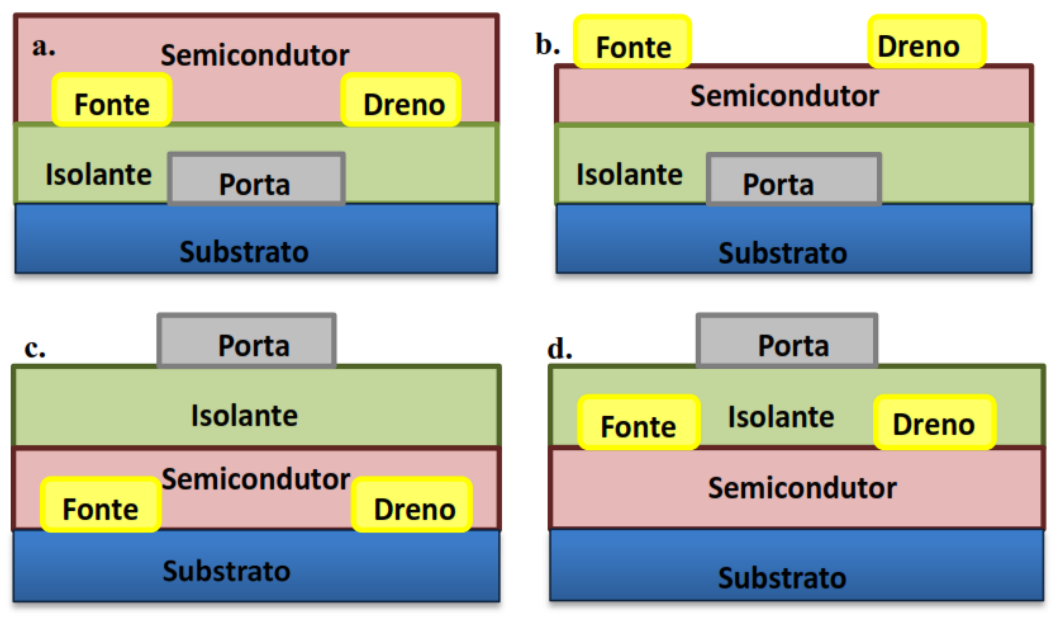

Figura 2.19 As quatro arquiteturas fundamentais para OFETs: a. Bottom-Gate/Bottom-Contacts (BGBC). b. Bottom-Gate/Top-Contacts (BGTC). c. Top-Gate/Bottom-Contacts (TGBC). d. Top-Gate/TopContacts (TGTC). Figura retirada da referência (Stefanelo, 2014).

Por outro lado, a segunda divisão é conhecida como Top-Gate (TG), ou seja, porta superior. Neste caso o eletrodo é depositado sobre todas as outras camadas e 
embaixo dele está a camada isolante, conforme apresentado na Figura 2.19 c. e 2.19.d. Esta classe pode subdividir-se em: Top-Gate/Bottom-Contacts (TGBC) se os contatos fonte e dreno estiverem por baixo do semicondutor (Figura 2.19 c.) e Top-Gate/Top-Contacts (TGTC) se os eletrodos fonte e dreno estiverem por cima do semicondutor (Figura 2.19 d.) (Smith et al., 2010; Xu et al., 2015; Stefanelo, 2014; Maciel, 2012).

\subsubsection{Funcionamento de um OFET}

Quando se aplica uma voltagem entre a porta e a fonte num OFET, produz-se um campo elétrico no isolante, cuja função é induzir portadores de carga na interface semicondutor- dielétrico, criando um canal de condução entre fonte e dreno, mostrado na Figura 2.20. Este processo é chamado: modo de acumulação de portadores de carga na interface. Então se pode dizer que o eletrodo que modula a densidade de portadores de carga no canal é o "gate" e aquele que se encarrega de drenar estes portadores do canal condutor é a voltagem aplicada entre a fonte e o dreno (Horowitz, 1998; Seidel, 2008; Rossi, 2013). Sendo assim, apresentam-se dois regimes no modo de acumulação: regime linear e regime de saturação.

No regime linear, a densidade de portadores livres induzidos no semicondutor orgânico é proporcional à tensão na porta (gate) $V_{g}$ e independente da tensão entre o dreno (Drain) e a fonte (Source) $V_{D S}$. Esse regime acontece quando $V_{D S}<V_{g}$, o circuito é apresentado na Figura 2.21 (Horowitz, 1998; Seidel, 2008; Rossi, 2013).



Figura 2.20 Esquema de um OFET com arquitetura Bottom-Gate/BottomContacts (BGTC), onde se mostra o campo elétrico formado no isolante e o canal (tipo p) criado na interface semicondutor-dielétrico. Na direita, uma maximização de uma região da interface semicondutor-isolante, onde é esquematizado uma parcela do capacitor gerado na acumulação. Figura retirada da referência (Maciel, 2012). 
No regime de saturação, a diferença de potencial $V_{D S}$ não consegue drenar mais portadores de cargas dos que estão sendo injetados pela porta, então acontece uma saturação na corrente. Este regime ocorre quando $V_{D S} \geq V_{g}$, o circuito é mostrado na Figura 2.21 (Horowitz, 1998; Seidel, 2008; Rossi, 2013).

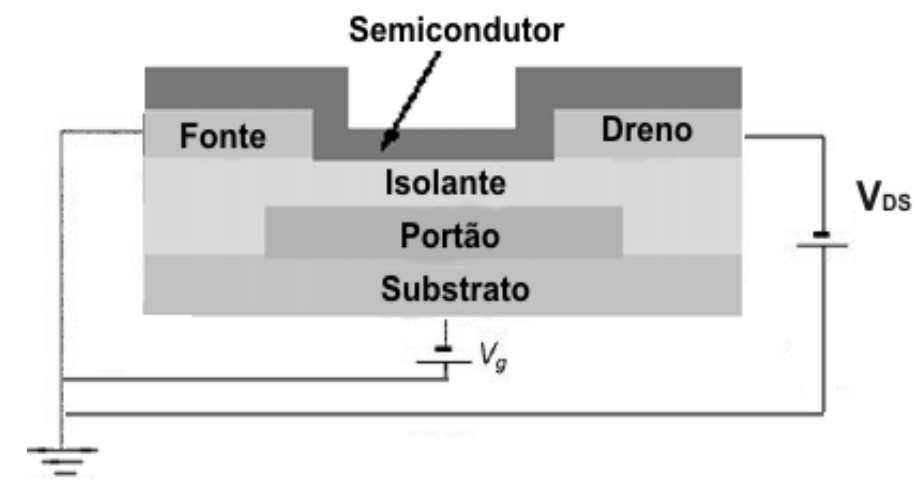

Figura 2.21 Circuito de funcionamento de um OFET com arquitetura Bottom-Gate/Bottom-Contacts (BGBC), onde pode-se apreciar a tensão na porta $V_{g}$ e a tensão entre o dreno e a fonte $V_{D S}$. Figura adaptada da referência (Dimitrakopoulos \& Mascaro, 2001).

Para o cálculo das equações num OFET, parte-se do princípio de que a equação da corrente entre o dreno e a fonte $I_{D S}$ é proporcional à carga total no canal de condução dividido pelo tempo $t$ que os portadores de carga precisam para atravessar o canal, ou seja (Seidel, 2008):

$$
I_{D S}=-\frac{Q_{g}}{t} W L
$$

Onde $Q_{g}$ é a carga total injetada no canal condutor por unidade de área, $W$ e $L$ são a largura e o comprimento do canal respectivamente, em concordância com a Figura 2.22; e $t$ o tempo de trânsito, definindo a este como:

$$
t=\frac{L}{v}
$$

Também se sabe:

$$
v=\mu E(x)=\mu \frac{V_{D S}}{L}
$$

Sendo $v$ e $\mu$ a velocidade e mobilidade efetiva dos portadores de carga, respectivamente; $E(x)$ o campo elétrico na direção $x$. 




Figura 2.22 Esquema de um OFET com arquitetura Bottom-Gate/BottomContacts (BGBC), onde se mostra o comprimento $(L)$ e a largura $(W)$ do canal, assim como a tensão na porta $V_{g}$ e a tensão entre o dreno e a fonte $V_{D S}$. Figura modificada da referência (Stallinga, 2009).

Utiliza-se nos OFETs uma aproximação de canal gradual para a obtenção das equações e são aceitas as seguintes aproximações (Maciel, 2012):

i) O campo elétrico criado $E(x)$ pela diferença de potencial entre os eletrodos dreno e fonte $\left(\Delta V_{D S}\right)$ é paralelo à interface semicondutor-isolante e independente de $x$.

ii) A mobilidade de efeito de campo $\mu$ é uma constante.

iii) Não são consideradas a influência dos eletrodos, resistências parasitas ou corrente de fuga no cálculo da corrente.

iv) $\mathrm{O}$ acúmulo de efeitos capacitivos na interface semicondutor-isolante, conforme ilustrado na Figura 2.20, produz uma densidade de carga por unidade de área $Q_{g}(x)$, que pode ser expressa como (Seidel, 2008):

$$
Q_{g}(x)=-C_{i}\left(V_{g}-V_{T}-V(x)\right)
$$

Onde $C_{i}$ é a capacitância por unidade de área, como já definido na equação (2.8).

E sabe-se também que $V_{T}$ é a voltagem limiar (do inglês, "threshold voltage") definida como a tensão mínima que deve ser aplicada na porta para que comece o acúmulo de portadores de carga no canal e $V(x)$ é a voltagem num ponto $x$ dentro do canal. Substituindo as equações (2.9), (2.10) e (2.11) em (2.12) para $V_{g}>$ $V_{T}$, tem-se (Seidel, 2008):

$$
I_{D S}=C_{i}\left(V_{g}-V_{T}-V(x)\right) \mu E(x) W
$$


Sabe-se que:

$$
E(x)=\frac{d V}{d x}
$$

Substituindo (2.14) em (2.13) e integrando (2.13):

$$
I_{D S} \int_{0}^{L} d x=\mu C_{i} W \int_{0}^{V_{D S}}\left(V_{g}-V_{T}-V(x)\right) d V_{x}
$$

Consequentemente, obtém-se a corrente $I_{D S}$ no regime de acumulação no canal entre o dreno e a fonte (Dimitrakopoulos \& Mascaro, 2001; Smith et al., 2010):

$$
I_{D S}=\mu C_{i} \frac{W}{L}\left[\left(V_{g}-V_{T}\right) V_{D S}-\frac{V_{D S}^{2}}{2}\right]
$$

Deve-se reparar que a equação (2.15) é válida só no limite $V_{D S} \leq 2\left(V_{g}-V_{T}\right)$, já que como se sabe os OFETs trabalham no regime de acumulação.

A partir da equação (2.15) pode-se obter e analisar as equações dos regimes linear e de saturação dos OFETs (Smith et al., 2010; Maciel, 2012; Seidel, 2008):

No regime linear, onde $V_{D S} \ll\left(V_{g}-V_{T}\right)$ :

$$
I_{D S}=\mu_{l} C_{i} \frac{W}{L}\left[\left(V_{g}-V_{T}\right) V_{D S}\right]
$$

No regime de saturação, onde $V_{D S} \geq\left(V_{g}-V_{T}\right)$ e especificamente a corrente satura no valor de $V_{D S}=\left(V_{g}-V_{T}\right)$, ficando:

$$
I_{D S}=\mu_{S} C_{i} \frac{W}{2 L}\left(V_{g}-V_{T}\right)^{2}
$$

Tendo esta teoria em mente, é possível caracterizar um OFET por duas medidas padrões: as curvas de saída e as de transferência. As primeiras são obtidas através da medida de $I_{D S}\left(\right.$ ou $\left.I_{D}\right) \times V_{D}$ para diferentes valores de $V_{G}$. Se várias varreduras em $V_{D}$ forem feitas para diferentes valores de $V_{G}$, obtém-se uma família de curvas de saída, como é mostrado na Figura 2.23. Esta família de curvas apresenta um comportamento linear de $I_{D} \operatorname{com} V_{D}$ para pequenos valores de $\left|V_{D}\right|$ e depois uma 
região de saturação, onde a corrente do canal torna-se independente da tensão do dreno, ou seja, quando $\left|V_{D}\right| \gtrsim\left|V_{G}\right|$ (Maciel, 2012).

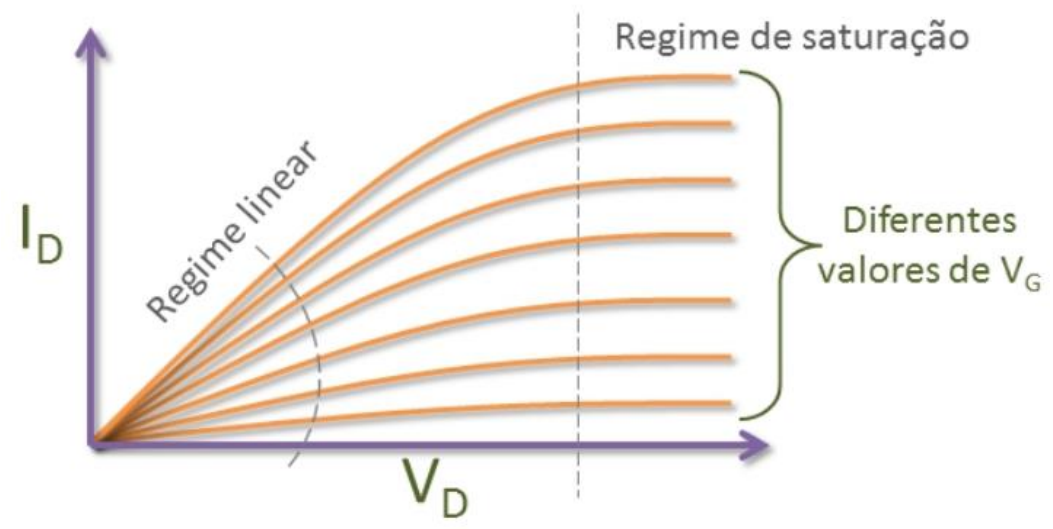

Figura 2.23 Familia de curvas de saída $I_{D} \times V_{D}$ para diferentes valores de $\mathrm{V}_{\mathrm{G}}$, na figura pode-se apreciar os dois regimes caractericticos do transistor: linear e saturação. Figura retirada da referência (Maciel, 2012).

O segundo tipo de curvas são obtidas através das medidas de $I_{D} \times V_{G}$ para diferentes valores de $V_{D}$. A Figura 2.24 mostra as curvas de transferência: (a) na escala linear e (b) na escala logarítmica para a corrente. Observe-se na Figura 2.24 (a) que a corrente $\left|I_{D}\right|$ aumenta com o incremento de $\left|V_{G}\right|$, sendo este comportamento uma manifestação da dependência da mobilidade $\mu$ com o potencial da porta $V_{G}$ (Maciel, 2012). Pode-se também verificar nesta mesma Figura 2.24 (a), uma das formas de calcular o potencial limiar $V_{T}$ por extrapolação. Por outro lado, a tensão $V_{T}$ pode ser extraída da extrapolação da enésima raiz da corrente $I_{D}$ em função de $V_{G}$, tal que a curva seja linearizada por completo no regime de saturação. Este método seria necessário para evitar que a dependência da $\mu$ atrapalhe a extração de $V_{T}$ (Stallinga, 2009).

Outros parâmetros podem ser calculados também das curvas de transferência, por exemplo, no gráfico semi-logarítmico observado na Figura 2.14 (b), a razão da corrente $I_{D}$ ON/OFF e o valor de $\mathrm{S}$, que representa quantos Volts são necessários para que a corrente varie uma década na região sub-limiar. Esta grandeza está diretamente ligada à quantidade de armadilhas para portadores de carga presente no SO (Kano et al., 2009). 




(a)

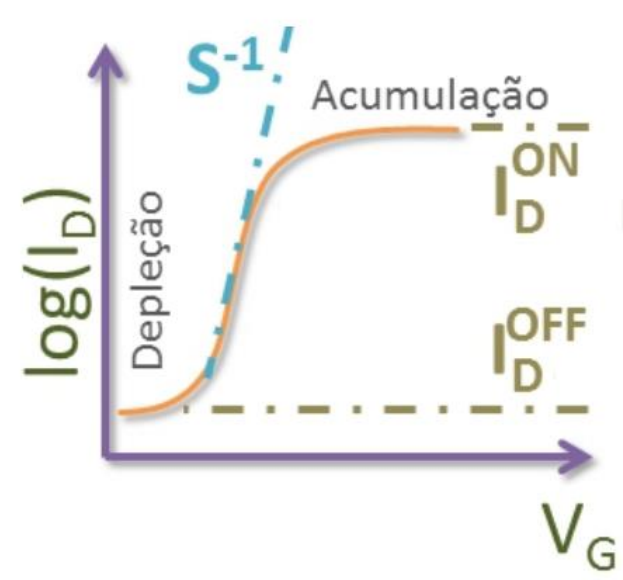

(b)

Figura 2.24 (a) Familia de curvas de transferência $I_{D} \times V_{G}$ para diferentes valores de $V_{D}$. A linha tracejada indica a extrapolação utilizada para obter $V_{T}$. (b) Gráfico $\log I_{D} \times V_{G}$, nesta curva é indicada a definição dos parâmetros ON/OFF e S. Figura retirada da referência (Maciel, 2012). 


\section{Materiais e Métodos}

\subsection{Semicondutor Orgânico (SO)-P3HT}

Utilizou-se o P3HT com regiorregularidade (rr-P3HT) maior que 90\%, comprado da Sigma-Aldrich. Para a preparação das soluções do P3HT foi utilizado como solvente o tolueno, cuja temperatura de ebulição é $110^{\circ} \mathrm{C}$. A concentração da solução $(\mathrm{m} / \mathrm{V})$ utilizada foi de $10 \mathrm{mg} / \mathrm{ml}$. Para que fosse possível dissolver o P3HT a solução foi aquecida a $90^{\circ} \mathrm{C}$ durante 10 minutos sem agitação. Antes da solução ser utilizada na preparação de filmes para OFETs, esta foi resfriada até a temperatura ambiente.

\subsection{Dielétricos}

Neste trabalho utilizaram-se primeiro dois polímeros dielétricos conhecidos, o PMMA e o PVA; e como isolantes novos, foram testados o FORMVAR e o PU.

\subsubsection{PMMA}

Para dissolver o PMMA comprado da Sigma-Aldrich, foi utilizado o Metil-EtilCetona (Methyl Ethyl Ketone-MEK), o qual tem um ponto de ebulição de $80^{\circ} \mathrm{C}$. Decidiu-se por uma concentração de $40 \mathrm{mg} / \mathrm{ml}$, e para a dissolução do PMMA, deixou-se esta solução em repouso por $24 \mathrm{~h}$, sem agitação e aquecimento.

\subsubsection{PVA}

O PVA foi comprado da Sigma-Aldrich, este polímero foi solubilizado em água. Para a deposição dos filmes, utilizou-se uma solução com uma concentração de $60 \mathrm{mg} / \mathrm{ml}$, utilizando-se água ultrapura deionizada (Milli-Q). Esta solução foi aquecida a $90^{\circ} \mathrm{C}$ durante 6 horas para dissolver o PVA.

\subsubsection{FORMVAR}

Para dissolver o FORMVAR, utilizaram-se dois solventes, um deles foi o clorofórmio, com uma concentração de solução $(\mathrm{m} / \mathrm{V})$ de $60 \mathrm{mg} / \mathrm{ml}$, agitando por duas horas. O clorofórmio é volátil, sendo o ponto de ebulição de $61^{\circ} \mathrm{C}$. 
O outro solvente foi a dimetilformamida (DMF), cujo ponto de ebulição é $153^{\circ} \mathrm{C}$. A concentração da solução $(\mathrm{m} / \mathrm{V})$ utilizada foi de $40 \mathrm{mg} / \mathrm{ml}$, que se deixou agitando por $12 \mathrm{~h}$.

\subsubsection{PU}

O PU pode ser dissolvido em tetraidrofurano (THF), solvente cuja temperatura de ebulição é de $66^{\circ} \mathrm{C}$. Fez-se uma concentração de solução $(\mathrm{m} / \mathrm{V})$ de $60 \mathrm{mg} / \mathrm{ml}$, deixando em agitação por $12 \mathrm{~h}$ para uma completa dissolução do PU.

Foi utilizado um segundo solvente para o PU, optou-se pelo MEK (utilizado já para o PMMA), um solvente menos volátil que o THF, cujo ponto de ebulição é $80^{\circ} \mathrm{C}$. Decidiu-se por uma concentração de solução $(\mathrm{m} / \mathrm{V})$ de $20 \mathrm{mg} / \mathrm{ml}$, que foi aquecida a $100^{\circ} \mathrm{C}$ por 48 horas em agitação. Sabe-se que o MEK dissolve o PU parcialmente, por esse motivo foi necessário filtrar até três vezes a solução PU/MEK: a primeira com papel filtro de $47 \mu \mathrm{m}$, depois com filtro de $0,45 \mu \mathrm{m}$ e finalmente com mais um filtro de $0,22 \mu \mathrm{m}$. Concentrações maiores que $20 \mathrm{mg} / \mathrm{ml}$ são muito densas, e o PU tende a grudar quando esfria, mesmo já filtrado; fazendo que as soluções sejam impróprias para a deposição por spin coating.

\subsection{Limpeza dos substratos}

Os substratos devem estar com a superfície suficientemente limpa para não ter perdas de adesão entre o substrato e o material depositado, bem como para que não haja contaminação prejudicial ao funcionamento dos dispositivos. Para assegurar a qualidade do substrato procedeu-se com o seguinte método de limpeza (Legnani, 2006; Aderne, 2013):

1. Utilizou-se luvas para evitar a contaminação do substrato pelas impurezas nas mãos (gordura e partículas).

2. Desengorduramento da superfície do substrato: podem ser utilizados desengraxantes como éter de petróleo e tricloro etileno. Para isto colocou-se o substrato entre dois tecidos, próprios para limpeza e embebidos em éter, esfregando-se os tecidos sobre as superfícies do substrato. 
3. Remoção do éter de petróleo: após a etapa 2, foi necessário a remoção do éter, que foi feito imergindo-se os substratos em um béquer contendo água destilada e detergente neutro Extran MA 02 fabricado pela MERCK e aquecendo-se até a temperatura de ebulição da solução. Em seguida, substituise a solução de água destilada e detergente por água destilada pura até que não houvesse mais a formação de espuma, ou seja, até que não tenha mais detergente na água. Feito isso, a água foi aquecida novamente até a ebulição e deixada esfriar.

4. Imersão dos substratos em acetona e agitação ultrassônica: visando eliminar quaisquer partículas que porventura ainda estivessem sobre o substrato, retirou-se a água destilada, colocou-se a acetona e levou-se ao agitador ultrassônico por 15 minutos.

5. Imersão dos substratos em álcool isopropílico e agitação ultrassônica: visando eliminar a acetona e quaisquer partículas que porventura ainda estivessem sobre o substrato, retirou-se a acetona, colocou-se álcool isopropílico e levouse ao agitador ultrassônico por 15 minutos.

6. Imersão em água deionizada, aquecimento e agitação ultrassônica: após a etapa 5, removeu-se o álcool isopropílico, adicionou-se água deionizada, aqueceu-se até a temperatura de ebulição e levou-se, em seguida, ao agitador ultrassônico por 10 minutos, para a retirada de impurezas iônicas da superfície do substrato.

7. Finda a etapa 6, os substratos foram mergulhados e armazenados num recipiente com álcool isopropílico. Para sua utilização, aplicou-se um jato de nitrogênio de 99,995 obliquamente de forma a secá-los.

Deve-se ter em conta que os substratos utilizados para construir os capacitores foram diferentes de aqueles utilizados para fabricar OFETs. Para a fabricação dos capacitores se utilizaram substratos de $15 \mathrm{~mm} \times 25 \mathrm{~mm}$ de Óxido de índio e estanho (Indium tin oxide-ITO) litografado sobre vidro, comprado da LumTec, 
conforme mostrado na Figura 3.1; e para os transistores substratos de vidro de $15 \mathrm{~mm} \times 20 \mathrm{~mm}$.



Figura 3.1 ITO litografado sobre vidro, comprados à empresa LumTec. Figura retirada da referência (Avila, 2012).

\subsection{Técnicas de deposição}

\subsubsection{Spin coating (Revestimento por rotação)}

No método spin-coating, uma solução do composto orgânico escolhido com um

solvente particular foi depositada sobre um substrato que, por meio de centrifugação, elimina todo o excesso de solução da sua superfície. Como resultado, filmes finos e razoavelmente homogêneos foram obtidos. As etapas mostradas na Tabela 3.1 ilustram esse método e mostram como foram preparados alguns dos filmes usados neste trabalho (Gianini, 2007).

Etapa \begin{tabular}{c}
\multicolumn{1}{c}{ Descrição } \\
Um substrato é fixado sobre a \\
plataforma giratória do spin-coating. \\
O substrato é preso a um o-ring pela \\
sucção de uma bomba mecânica \\
ligada ao eixo central. \\
No controlador do equipamento, \\
escolhe-se a aceleração de partida, \\
a velocidade e o tempo de rotação. \\
A solução é depositada sobre toda \\
a superfície do substrato.
\end{tabular}




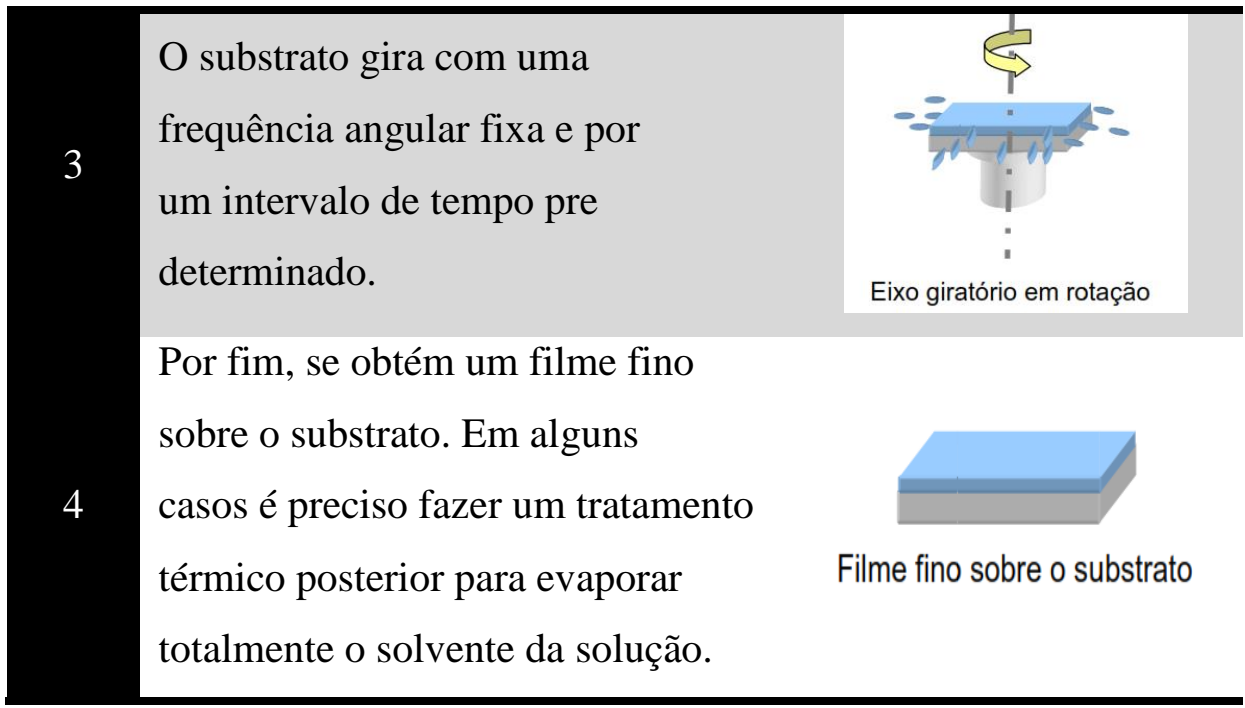

Tabela 3.1 Etapas para produção de filmes finos por spin coating. Tabela retirada da referência (Gianini, 2007).

\subsubsection{Evaporação Térmica Resistiva}

A evaporação térmica resistiva faz parte dos processos de deposição por fase vapor (PVD-Physical Vapor Deposition). Em geral um processo PVD consiste basicamente de quatro etapas (Legnani, 2006):

- Emissão de partículas de uma fonte, ou seja, aquecimento do material a ser depositado e consequente transformação do estado sólido para o estado gasoso.

- Transporte destas partículas até o substrato.

- Condensação no substrato.

- Processos de superfície ativados termicamente.

A técnica de evaporação começou a ser utilizada somente nos últimos 35 anos, depois que os equipamentos de vácuo progrediram tecnicamente. O processo é simples, consiste em aquecer o material a ser depositado a uma determinada temperatura, na qual a sua pressão de vapor seja suficientemente alta, de forma que suas partículas difundam da fonte para um substrato. Pelo fato do material estar confinado num ambiente de baixa pressão, a temperatura de evaporação será menor do que se estivesse à pressão atmosférica.

Para que uma molécula deixe a superfície do material, é necessário que a energia cinética correspondente á componente perpendicular à superfície seja maior que 
as forças intermoleculares. A energia cinética aumenta com a temperatura e, desta forma, a evaporação ocorre com perda de energia interna do material. Quando as moléculas encontram-se com a superfície do substrato, que permanece a temperatura ambiente, estas se condensarão formando um filme.

De fato, as moléculas que são desprendidas da superfície do material, viajam no espaço em uma linha reta até encontrar uma outra molécula ou a superfície do substrato. Para garantir que um número de colisões ocorra entre a fonte e o substrato, a concentração das moléculas que constituem a atmosfera residual deve ser baixa (alto vácuo) (Legnani, 2006).

\subsubsection{Descrição do sistema de deposição utilizado}

Para a deposição de um dos eletrodos de alumínio dos capacitores fabricados, ou seja, uma das placas planas dos condensadores; utilizou-se o sistema de deposição térmica do Laboratório de Espectroscopia Óptica e Optoeletrônica Molecular (LOEM) da PUC-Rio, apresentado na Figura 3.2. O sistema é composto de uma campânula, no interior da qual está colocado um suporte para substrato, um medidor de taxa de deposição (X-TAL), um obturador (shutter) e os eletrodos para a evaporação para até quatro materiais. No sistema existem dois medidores de pressão: um para alto vácuo (Penning) e um para baixo vácuo (Pirani). Para fornecer a corrente para os eletrodos existem duas fontes com as quais podemos ter um controle preciso da corrente utilizada para evaporar os materiais.

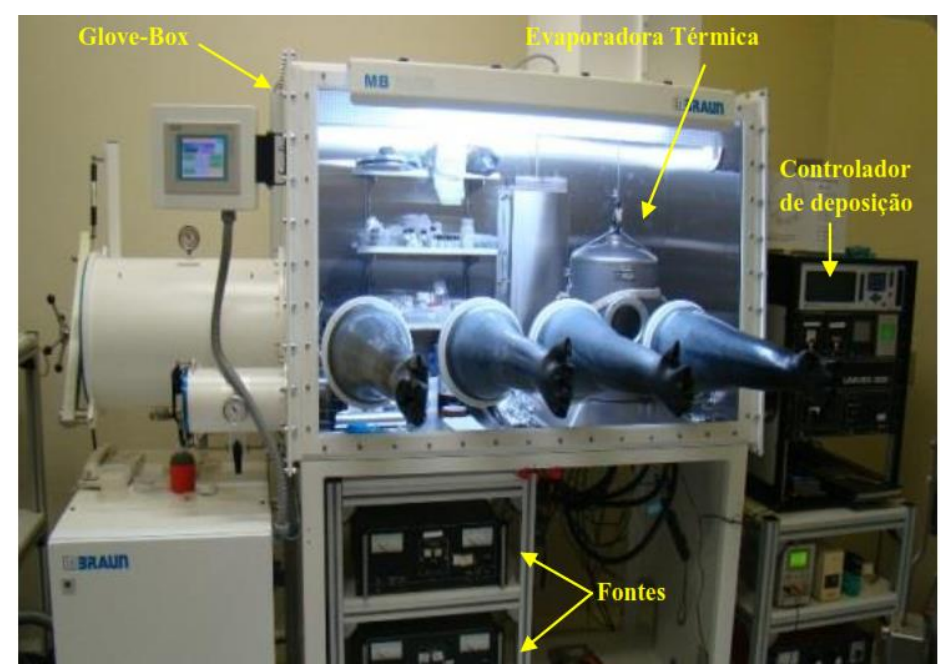

Figura 3.2 Sistema de deposição térmica do LOEM da Puc-Rio. 
O sistema descrito é um UNIVEX 300 fabricado pela Leybold, mostrado na Figura 3.2. Um sistema de bombas (bomba mecânica selada a óleo e bomba mecânica turbo-molecular) é utilizado para evacuação do sistema, chegando a fazer um vácuo de $10^{-6}$ Torr. A taxa de deposição é acompanhada através de um monitor modelo XTC-INFICON (Legnani, 2006).

A distância entre os cadinhos e os substratos, foi mantida fixa em $27 \mathrm{~cm}$. Todos os contatos de alumínio foram depositados com os substratos mantidos a temperatura ambiente. Como fonte de deposição para o alumínio, foram utilizados cadinhos tipo "basket" de tungstênio, como o apresentado na Figura 3.3. Este material foi o escolhido por apresentar baixa reatividade e alto ponto de fusão $\left(2240^{\circ} \mathrm{C}\right.$ a $10^{-6}$ Torr), que resultou em um controle mais preciso da corrente e da taxa de deposição (Aderne, 2013).

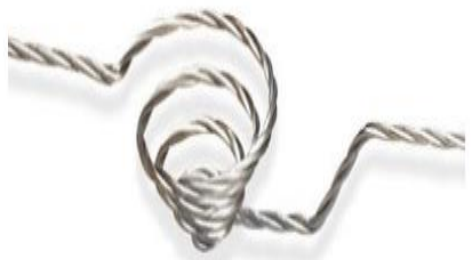

Figura 3.3 Cadinho de tungstênio utilizado para depositar alumínio.

\subsubsection{Técnica de Deposição por Feixe de Elétrons}

A técnica de deposição por feixe de elétrons ou eléctron-beam faz parte dos processos de deposição física por fase vapor (PVD) de filmes finos. Em geral, um processo PVD consiste substancialmente de quatro etapas, conforme foram já explicadas na evaporação térmica resistiva.

As deposições dos contatos de ouro e o gate para os OFETs foram realizadas em um sistema de alto vácuo da Leybold, modelo Univex 450, do Grupo LOEM da PUC-RIO, mostrado na Figura 3.4. Este equipamento utiliza-se da técnica de evaporação por feixe de elétrons (eléctron beam), que conta com uma câmara de alto vácuo, um sistema de bombeio, um sistema de produção e focalização de feixe de elétrons para o aquecimento do material e um medidor de espessura para o controle de diversos parâmetros, como a taxa de deposição, a potência do feixe de elétrons, etc. O sistema de vácuo é formado por dois tipos de bombas de vácuo: uma bomba mecânica, que permite chegar a um vácuo primário da ordem de 
$10^{-1}$ Torr na câmara de deposição, e uma bomba turbo molecular, ligada apenas quando já há vácuo primário na câmara, chega a uma pressão final de $10^{-6} \mathrm{Torr}$. Montados na câmara há ainda dois medidores de pressão, um do tipo Pirani (que mede a pressão até o limite mínimo de $10^{-1}$ Torr) e outro do tipo Penning, que permite o controle das condições de vácuo até a ordem de $10^{-6} \operatorname{Torr}$ (Sigaud, 2005).

A taxa de deposição dos filmes é monitorada através de um sensor de quartzo da Leybold, modelo XTC-Inficom, sendo totalmente automatizado. Uma vez inseridos os parâmetros físicos relativos ao material que se deseja depositar e escolhida a taxa de deposição, a potência do feixe de elétrons que incide sobre o material a ser evaporado é controlada diretamente por este dispositivo.

Para atingir o material a ser evaporado, o feixe de elétrons é defletido e focalizado por meio de um campo magnético. Se o feixe de elétrons é acelerado com uma voltagem apropriada, em geral entre $4 \mathrm{kV}$ e $150 \mathrm{kV}$, ele é capaz de provocar o aquecimento de muitos materiais, chegando ao seu ponto de fusão ou provocando a sublimação deles e, com isso, a vaporização. Para que um feixe de elétrons possa existir e ser controlado é necessário que a pressão seja igual ou inferior a $10^{-6}$ Torr, acima deste limite, vários efeitos indesejáveis, como descargas e capturas eletrônicas, podem provocar uma forte instabilidade do feixe e assim impossibilitar a sua utilização.

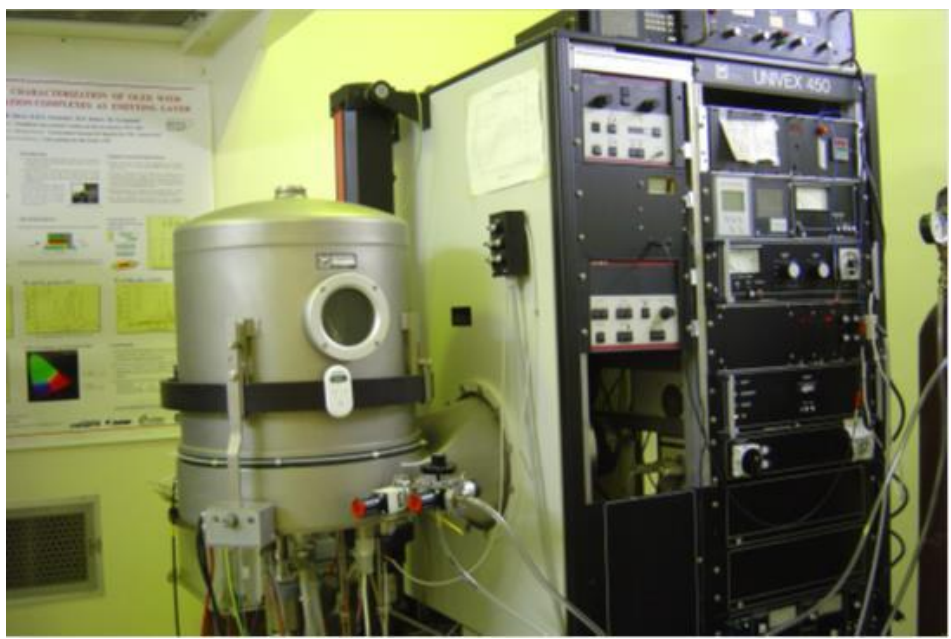

Figura 3.4 Equipamento utilizado no LOEM para a deposição por Electron beam. 
O material a ser evaporado é colocado num cadinho de cobre, refrigerado com água. Este esquema é ilustrado na Figura 3.5. O ponto principal desta técnica é que somente uma pequena parte do material evaporante chega à fusão ou sublima, e em virtude disso não existe contaminação do cadinho no filme. Isto não ocorre com outras técnicas de deposição por evaporação (e.g. a evaporação térmica resistiva), onde as principais desvantagens são: a possível contaminação dos cadinhos, aquecedores e materiais de suporte, além da limitação de trabalhar com temperaturas de evaporação relativamente baixas (Sigaud, 2005).

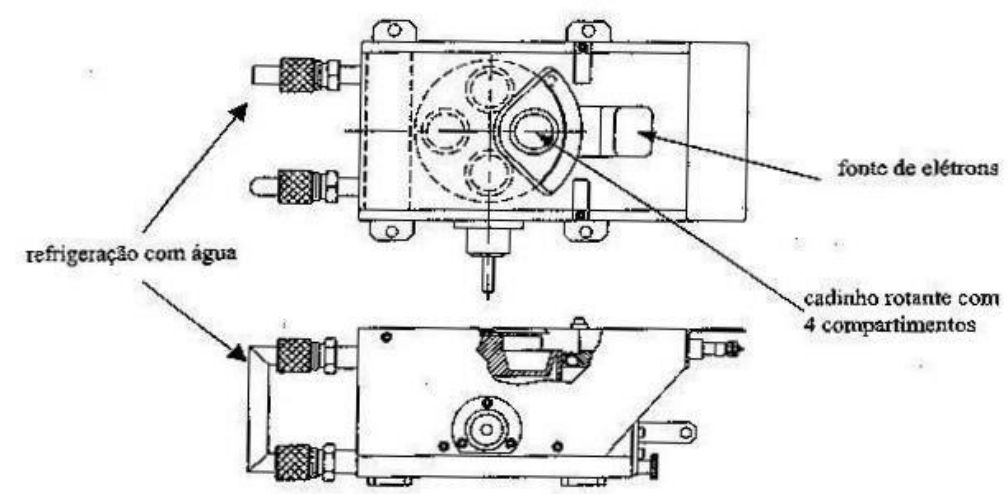

Figura 3.5 Unidade de evaporação por feixe de elétrons com cadinho rotante com quatro compartimentos. Figura retirada da referência (Sigaud, 2005).

Os substratos foram montados num porta-substratos, localizado na parte superior da câmara, a qual foi levada pelas bombas de vácuo a uma pressão base de $6 \times 10^{-6}$ Torr. O feixe de elétrons, por sua vez, incidiu com energia entre 6 e 12 $\mathrm{keV}$ (energia duas ordens de grandeza maior que o canhão de elétrons montado) sobre os pedaços de cristal, posicionados no cadinho na parte inferior da câmara, logo abaixo do porta substratos. Desta forma, a temperatura do material aumentou, obtendo-se a sua evaporação e sucessiva deposição em forma de filme fino com uma taxa de deposição de $0,5 \AA$ A $/$ s. A taxa de deposição foi mantida baixa propositalmente, para evitar um superaquecimento do material no cadinho, o que levaria a problemas de ejeção de fragmentos do mesmo cristal, danificando o crescimento do filme (Sigaud, 2005). 


\subsection{Técnicas de Caracterização}

\subsubsection{Perfilômetria}

No desenvolvimento de OFETs, o conhecimento do valor real da espessura das diferentes camadas envolvidas torna-se fundamental, para garantir o melhor desempenho no funcionamento do dispositivo.

As medidas da espessura e rugosidade foram feitas com um perfilômetro Veeco Dektak 150, mostrado na Figura 3.6. Este equipamento possui uma ponta da agulha de diamante com o diâmetro da ordem de $10 \mu \mathrm{m}$ e uma força aplicada que varia de 0.15 a 3mg. Cabe frisar que o perfilômetro disponível no LOEM da PUCRio, foi adquirido com um sistema especial "low force option" que permitiu a aplicação de forças extremamente pequenas para evitar que a ponta danificasse o composto orgânico, tipicamente muito macio (Aderne, 2013).

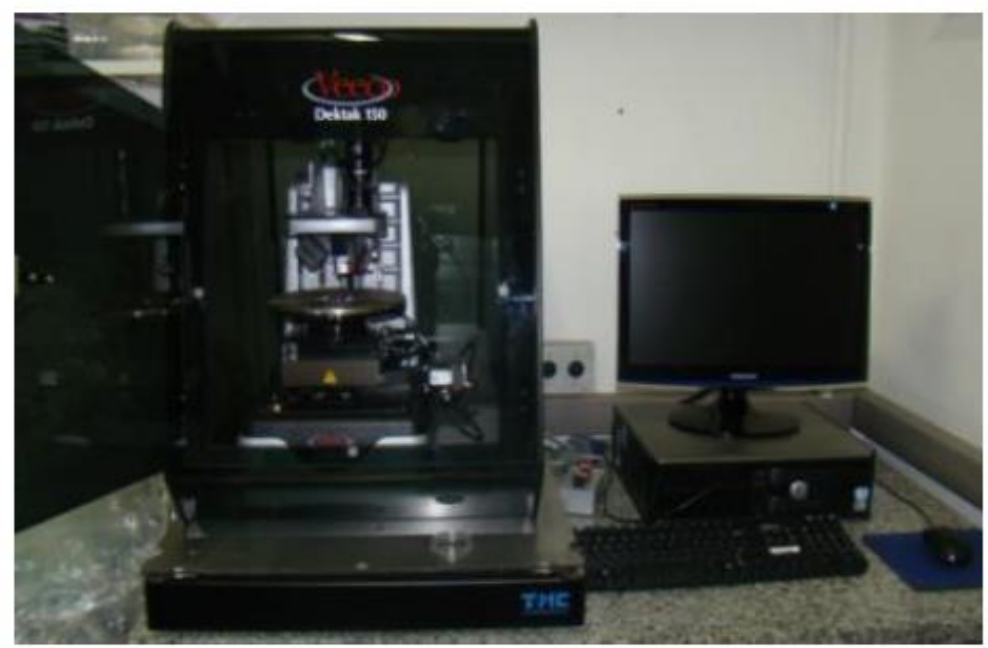

Figura 3.6 Perfilômetro Veeco Dektak 150, utilizado no LOEM da PUC-Rio para as medidas da espessura e rugosidade.

O perfilômetro do LOEM da Puc-Rio fez as medidas baseado no movimento mecânico de uma agulha de diamante que segue a topografia da amostra até se apresentar um desnível entre o filme e o substrato, medindo a diferença de níveis, conforme ilustrado na Figura 3.7, e assim pôde-se determinar a espessura do filme. Além disso, informações sobre a rugosidade também são obtidas, as quais acusam o grau de uniformidade do composto (Avila, 2012). 


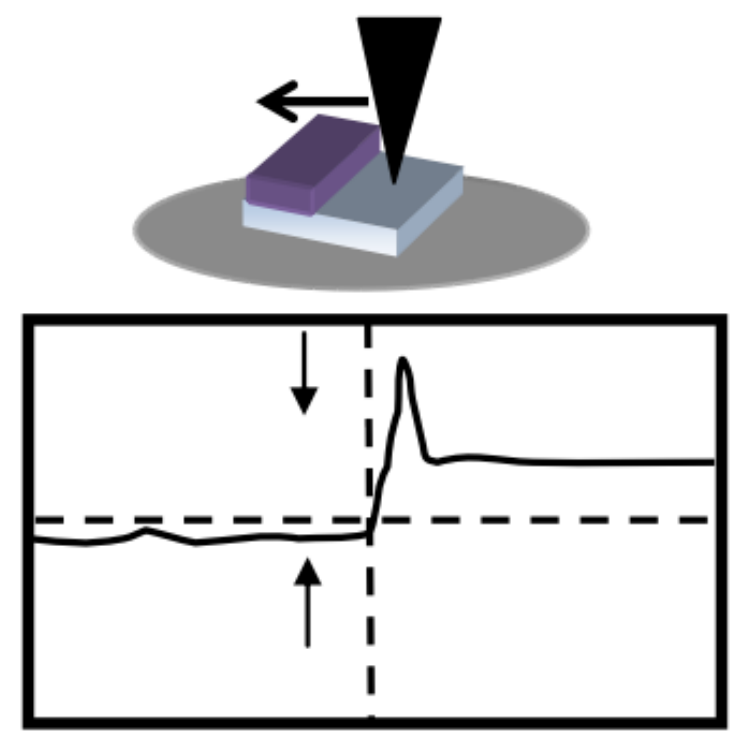

Figura 3.7 Medida do desnível efetuada pelo perfilômetro para medir a espessura e rugosidade. Figura retirada da referência (Avila, 2012).

\subsubsection{Caracterização Elétrica dos Dispositivos}

Neste trabalho foram desenvolvidos dois tipos de dispositivos:

- Capacitores orgânicos.

- OFETs.

A construção e caracterização elétrica dos dispositivos serão detalhadas a seguir.

\subsubsection{Capacitores Orgânicos}

Os capacitores orgânicos fabricados são condensadores de placas paralelas, ou seja, tem dois contatos de área igual e entre eles um dielétrico orgânico. Especificamente a arquitetura foi: ITO/Isolante/Al, esquematizado nas Figuras 3.7 e 3.9, para todos os materiais dielétricos estudados.

Os isolantes foram depositados por spin coating sobre o ITO, depois se depositou acima do dielétrico, por evaporação térmica resistiva, o contato de alumínio. Para cada isolante, optou-se por quatro espessuras depositadas por spin-coating; para que se pudesse fazer uma melhor análise do polímero dielétrico.

Destes capacitores orgânicos, foram obtidas para todos os dielétricos, as curvas da densidade de corrente $(J)$ versus tensão $(V)$, melhor conhecidas como curvas $J x V$; 
assim como, a capacitância por unidade de área $\left(C_{i}\right)$ e a constante dielétrica $\left(\varepsilon_{i}\right)$ de cada isolante.

\subsubsection{1.a. Obtenção das curvas densidade de corrente $(J)$ versus tensão $(V)$}

O circuito utilizado para a obtenção das curvas $J x V$ de cada dielétrico está esquematicamente mostrado na Figura 3.8, onde se tem um capacitor formado por ITO/Isolante/Alumínio. Para tomar as medidas utilizou-se uma fonte Keithley 2400, dual programável e para o controle desta fonte, um programa em linguagem LabVIEW foi utilizado, visualizado na Figura 3.9. As curvas $J x V$ foram obtidas para cada espessura de cada dielétrico utilizado nesse trabalho.

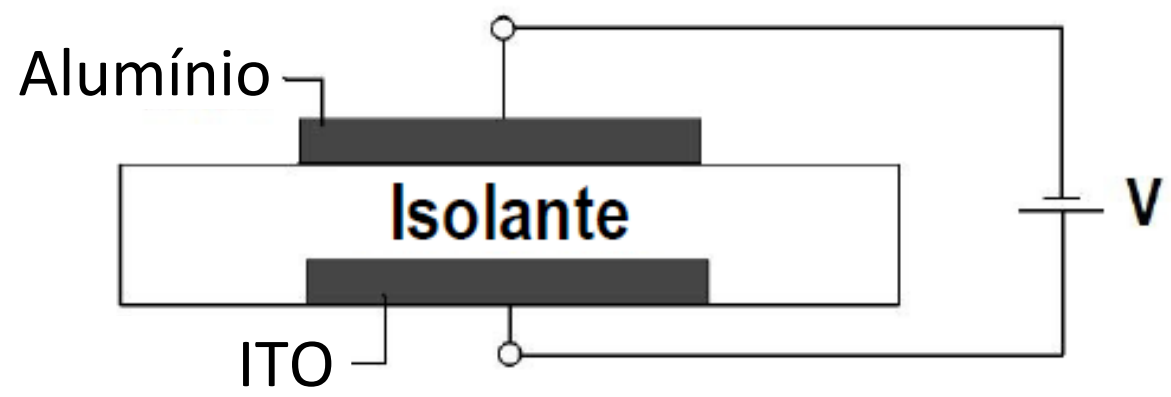

Figura 3.8 Esquema do circuito utilizado para a obtenção das curvas $J x V$. Figura modificada da referência (Machado, 2011).

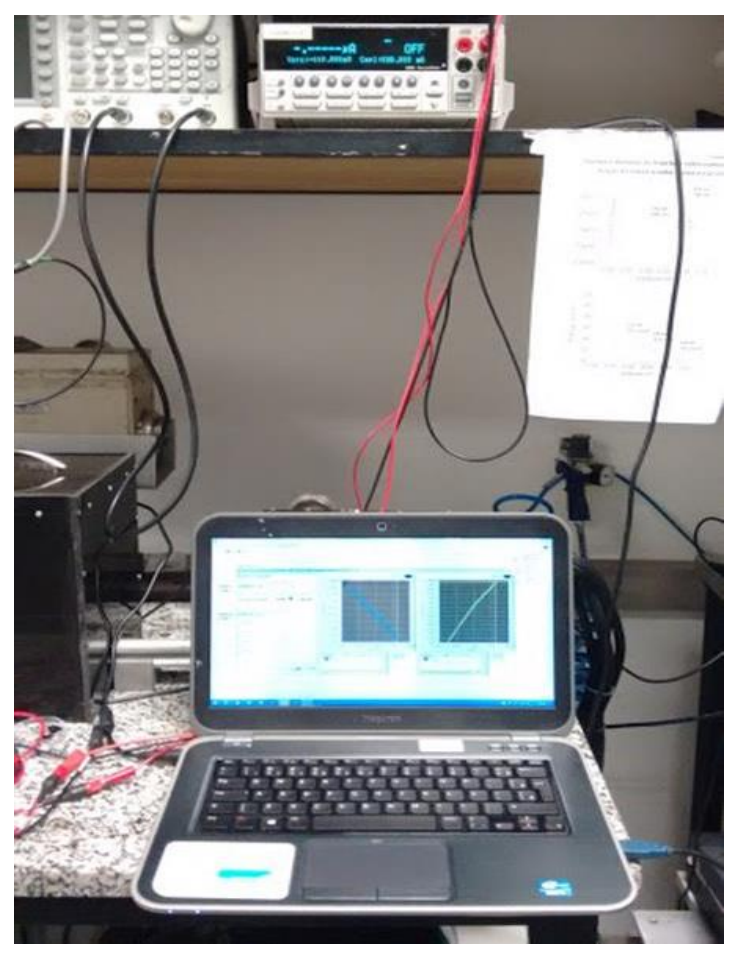

Figura 3.9 Fonte Keithley 2400 dual programável, destacando o programa em linguagem LabVIEW utilizado para medir as curvas $J x V$. 


\subsubsection{1.b. Medida da Capacitância}

Para a medida da capacitância em cada material isolante, utilizou-se os mesmos capacitores orgânicos que para as curvas $J x V$. A diferença nesta circunstância foi o circuito, que é ilustrado no esquema da figura 3.10, o qual consta de um condensador formado por ITO/Isolante/Alumínio; onde se utilizou para obter a capacitância um multímetro digital 21105 1/2 marca Keithley, mostrado na Figura 3.11. Como consequência da medida da capacitância para cada espessura dos isolantes utilizados; obteve-se também sua respectiva capacitância por unidade de área $\left(C_{i}\right)$ que é uma grandeza fundamental para caracterizar um OFET, de acordo com a equação (2.17). Além disso, calculou-se a constante dielétrica do isolante $\left(\varepsilon_{i}\right)$ para cada polímero com a equação (2.8).

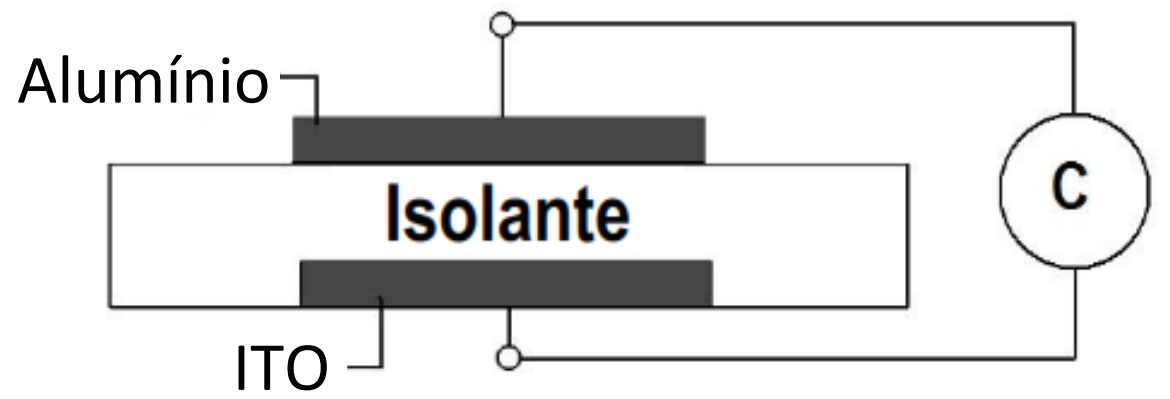

Figura 3.10 Esquema do circuito utilizado para a obtenção da capacitância, onde C foi um capacímetro. Figura modificada da referência (Machado, 2011).

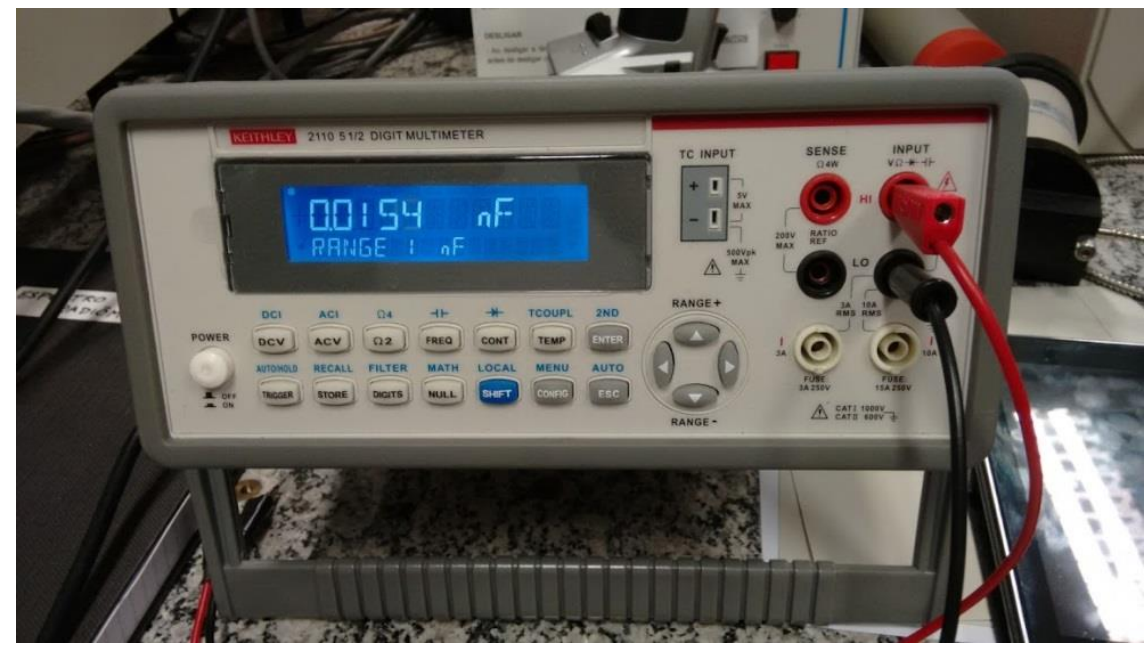

Figura 3.11 Multímetro digital 21105 1/2 marca Keithley, utilizado para medir a capacitância. 


\subsubsection{OFETs}

Os OFETs fabricados no laboratório do LOEM para este trabalho apresentaram uma característica comum, a camada semicondutora foi sempre do P3HT. E a diferença esteve na camada isolante e sua espessura; pois para cada tipo de OFET utilizou-se um polímero orgânico dielétrico, com até quatro espessuras.

\subsubsection{2.a. OFETs utilizando PMMA e PU como isolantes}

Os OFETs fabricados apresentaram uma arquitetura do tipo Top-Gate/BottomContacts (TGBC), com os materiais Au/P3HT/PMMA/Ag e Au/P3HT/PU/Ag. A única diferença entre eles foi a camada isolante, o primeiro tem como dielétrico PMMA e o segundo PU, ambos dissolvidos em MEK.

Em ambos os casos, os contatos de ouro, de $400 \AA$ de espessura, foram depositados por elétron beam sobre $30 \AA ̊$ de Cromo depositado por evaporação de feixe de elétrons, isto foi feito para fixar o Cromo/Ouro sobre os substratos de vidro. Posteriormente fez-se sobre o ouro a deposição por spin coating do P3HT, girando a 7000rpm durante 60s, para logo aquecer os substratos a $60^{\circ} \mathrm{C}$ durante 5minutos para terminar de evaporar o solvente. Como resultado, obteve-se uma camada única de $35 \mathrm{~nm}$ de P3HT para este tipo de dispositivos. Depois se depositou a camada isolante também por spin coating, porém a diferença é que foi para quatro diferentes espessuras, ou seja, que agora temos os substratos 1,2,3 e 4 (serão assim chamados daqui para frente) de diferentes espessuras, para um mesmo isolante. Este processo foi feito para o PMMA e o PU por separado. Logo estes substratos foram também aquecidas a $60^{\circ} \mathrm{C}$ durante 5 minutos para terminar de evaporar o solvente. Por último, depositou-se o gate (ou porta) de prata por elétron beam, com uma espessura de 100nm.

Para a deposição da bicamada Cromo/Ouro, o LOEM adquiriu uma mascara da Ossila, com cinco diferentes dispositivos num mesmo substrato, com canais de $L=30 \mu m, 40 \mu m, 50 \mu m, 60 \mu m$ e $80 \mu m$ de comprimento, conforme mostrado na Figura 3.12; e largura $W=1 \mathrm{~mm}$ em todos os casos. 


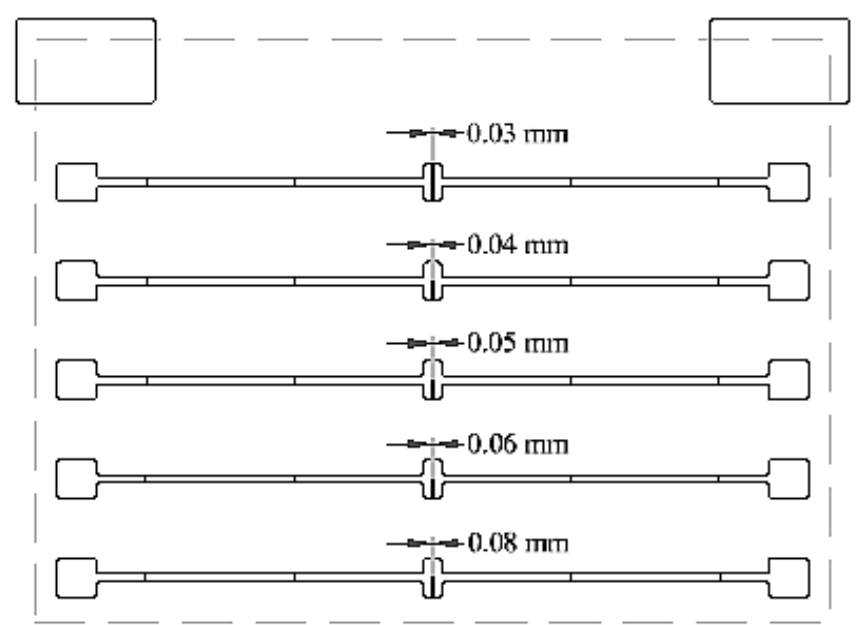

Figura 3.12 Mascara do LOEM utilizada para depositar os contatos de $\mathrm{Cr} / \mathrm{Au}$, ela tem diferentes canais que servem para fazer cinco dispositivos num mesmo substrato. Figura retirada da referência (Ossila, 2016).

Com respeito à deposição do "gate", o grupo do LOEM da Puc-Rio adquiriu uma máscara da Ossila, apresentando uma forma de "T", ideal para fazer contato de porta nos OFETs, a qual é mostrada na Figura 3.13.



Figura 3.13 Mascara do LOEM da PUC-Rio utilizada para depositar a porta dos OFETs. Figura retirada da referência (Ossila, 2016).

Na Figura 3.14 são mostradas as etapas da deposição de cada uma das camadas dos OFETs fabricados para este trabalho, assim como sua arquitetura TopGate/Bottom-Contacts (TGBC) já pronta.

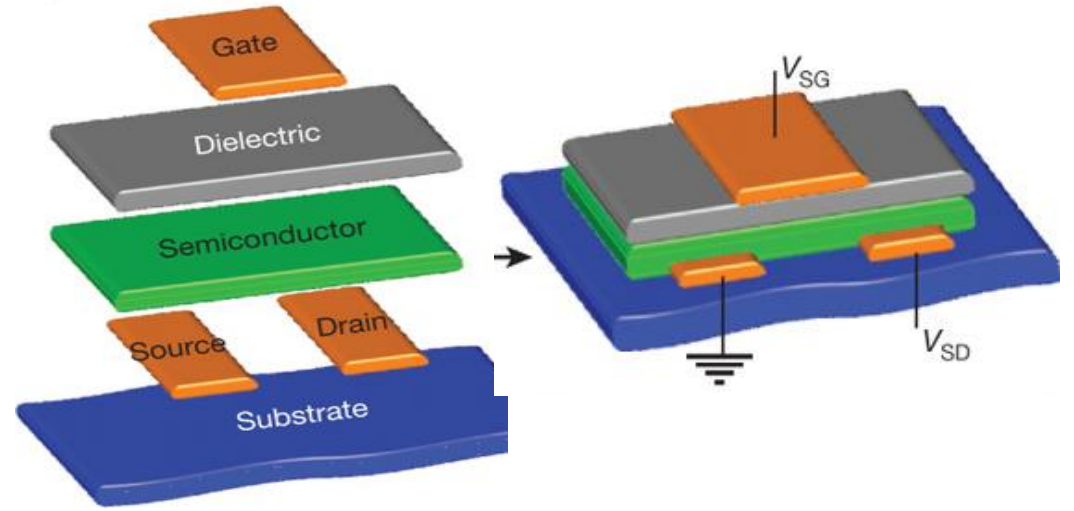

Figura 3.14 Etapas da deposição das camadas dos OFETs e sua arquitetura Top-Gate/Bottom-Contacts (TGBC) já pronta. Figura modificada da referência (Yan et al., 2009) 


\subsubsection{2.b. Caracterização elétrica dos OFETs}

Para obter os dados que se precisam para fazer as curvas de transferência e de saída nos OFETs, montou-se um circuito como se ilustra esquematicamente na Figura 3.15. As curvas de transferência extraíram-se aplicando uma tensão variável na porta $\left(V_{g}\right)$ para diferentes valores constantes de tensão no dreno $\left(V_{D S}\right)$, então se geraram um conjunto de curvas de transferência. Posteriormente, aplicouse uma tensão variável no dreno $\left(V_{D S}\right)$, para diferentes valores constantes de tensão no gate $\left(V_{g}\right)$, sendo gerado um conjunto de curvas de saída.

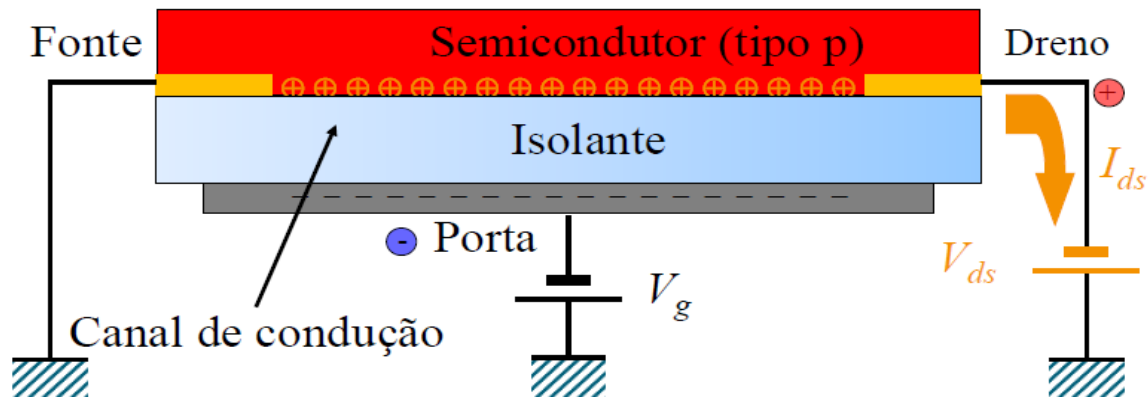

Figura 3.15 Esquema de um circuito montado para extrair as curvas de transferência e de saída num OFET.

A montagem do circuito no LOEM foi composto de duas Keithley 2400, estas são duais programáveis e para o controle destas fontes, um programa em linguagem LabVIEW foi utilizado, conforme mostrado na Figura 3.16.

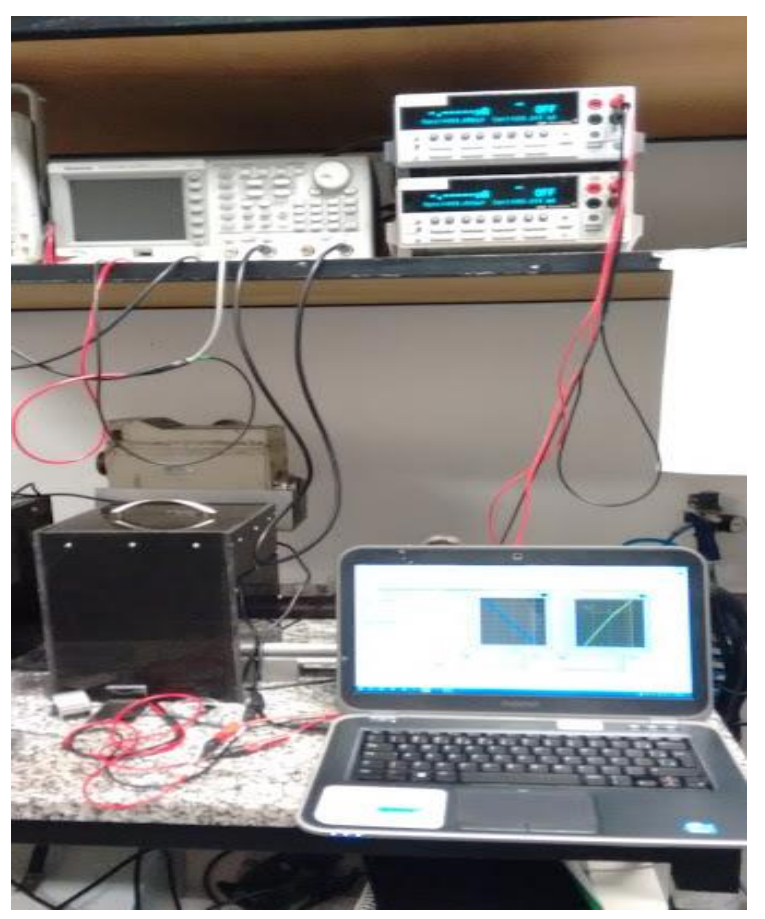

Figura 3.16 Montagem do circuito no LOEM para obter as curvas de transferência e saída nos OFETs. 


\section{4}

\section{Resultados e Discussão}

Para o funcionamento e bom desempenho de um OFET, precisa-se de muitos fatores, tais como baixa rugosidade dos filmes, um bom $\mathrm{SO}$, um isolante com boas propriedades dielétricas, etc. Por questões de ordem, os resultados apresentados serão divididos por dispositivos:

- Capacitores orgânicos.

- OFETs.

\subsection{Capacitores Orgânicos}

Como foi analisado, para caracterizar um OFET precisa-se conhecer a capacitância por unidade de área $\left(C_{i}\right)$, a qual foi obtida destes capacitores orgânicos. Sabe-se também que interessa as capacidades dielétricas da camada isolante dos OFETs, dentre delas é importante conhecer a constante dielétrica do isolante $\left(\varepsilon_{i}\right)$ e quanta corrente pode atravessar pelo dielétrico.

\subsubsection{Curvas $J x V$}

Uma das formas de saber quanta corrente atravessou por um dielétrico, foi medir num capacitor plano, as curvas $J x V$. Outro dado obtido das curvas $J x V$ foi a corrente de fuga através do dielétrico, que pode impedir o bom funcionamento de um OFET (Schroeder, et al., 2005). Pôde-se saber também a partir de que tensão pode funcionar um OFET, observando no gráfico o deslocamento da curva $J x V$ do zero, no eixo da tensão. Este deslocamento da curva $J x V$ pode-se dever a efeitos de carga, produto de elétrons livres do solvente ou das moléculas do polímero (Schroeder, et al., 2005; Schmidt, 1979). É conveniente fazer os gráficos $J x V$ semi-logarítmicas, colocando a densidade de corrente $(J)$ na escala logarítmica, pois não se consegue observá-las numa escala linear.

\subsubsection{PMMA}

Para obter as curvas $J x V$ do PMMA, foram feitos capacitores planos do tipo ITO/PMMA/Al, para diferentes espessuras do PMMA, depositado por spin coating, os valores das espessuras são mostradas na Figura 4.1. 
Nas curvas $J x V$ do PMMA para os quatro substratos, observa-se na Figura 4.1, que as densidades de corrente $(J)$ para $0 \mathrm{~V}$ estão entre $10^{-9}$ e $10^{-8}\left(A / \mathrm{cm}^{2}\right)$, que indica uma corrente de fuga em todas as espessuras. Esta corrente de fuga calculou-se com a área do capacitor, que foi aproximadamente de $3 \times 10^{-2} \mathrm{~cm}^{2}$ em todos os casos, então significa que as correntes estiveram entre $10^{-11}$ e $10^{-10} A$.

Observa-se nas curvas $J x V$ da Figura 4.1, um deslocamento da curva $J x V$ do zero, no eixo da tensão. Este fato deve-se em geral a efeitos de carga por causa de elétrons livres, por exemplo, no polímero (Schroeder, et al., 2005; Schmidt, 1979). Este deslocamento da curva $J x V$ do zero e as respectivas correntes de fuga podem explicar porque os OFETs de PMMA funcionam só a tensões maiores que 5V, pois antes dessa voltagem tem efeitos de carga que geraram correntes de fuga, as quais não permitem um isolamento correto. Contudo, após $5 \mathrm{~V}$ os filmes de PMMA cumprem sua função de isolantes, pois nas curvas $J x V$, conforme a tensão aumentou no capacitor, as densidades de corrente continuaram sendo baixas, da ordem de $10^{-8}$ e $10^{-7}\left(A / \mathrm{cm}^{2}\right)$, o que significa que as correntes foram em torno de $10^{-10}$ e $10^{-9} A$.

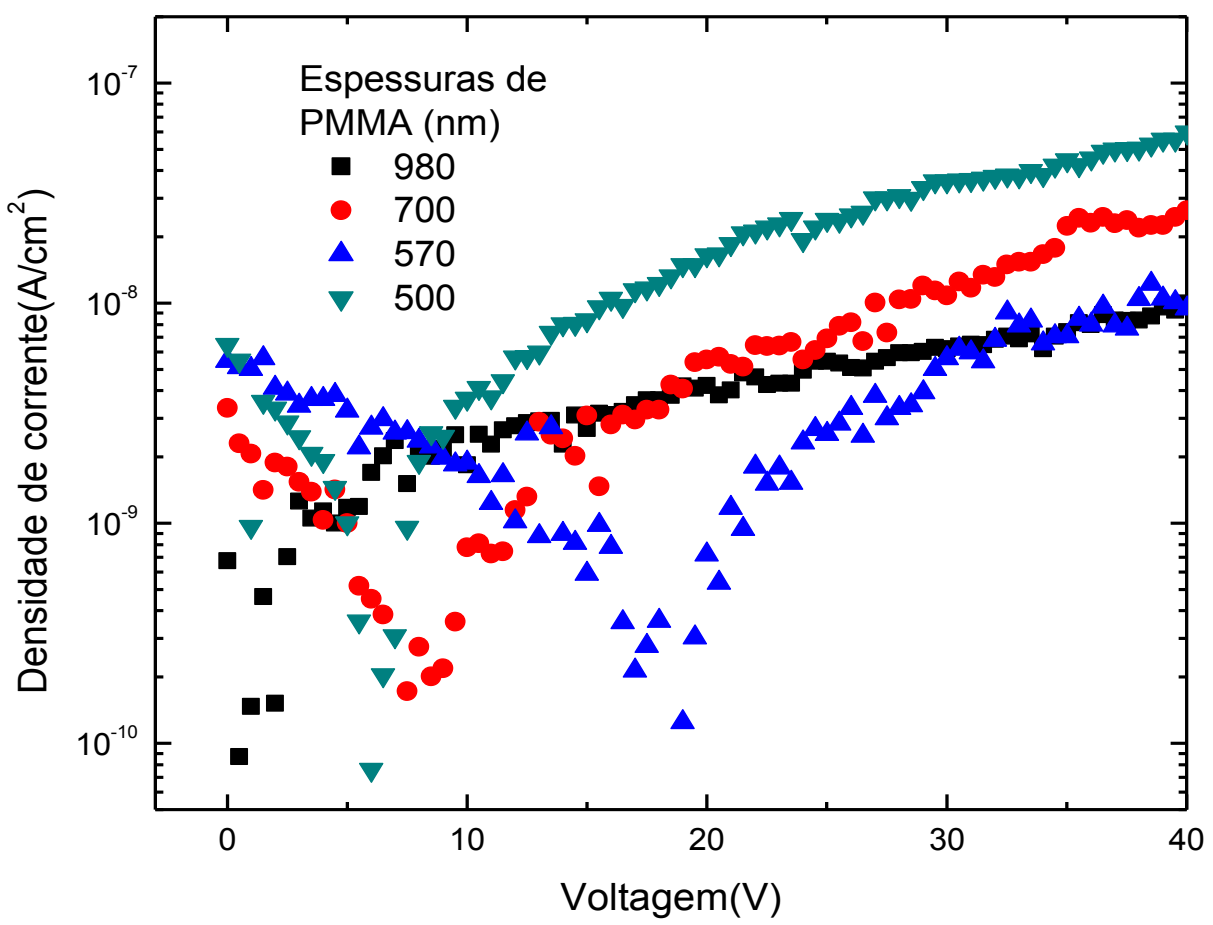

Figura 4.1 Curvas semi-logarítmicas $\boldsymbol{J} \boldsymbol{x V}$ dos dispositivos ITO/PMMA/Al para diferentes espessuras de PMMA. 


\subsubsection{PVA com diferentes tratamentos térmicos}

Lembrando que o solvente do PVA foi a água, e que quando se depositou um filme de PVA por spin coating, esta foi evaporada mediante algum tratamento térmico para que o PVA cumpra sua função isolante. Para obter as curvas $J x V$ dos filmes do PVA, de uma mesma espessura (1000nm), depositados por spin-coating e tratados termicamente de forma diferente; foram feitos capacitores de placas paralelas do tipo ITO/PVA/Al.

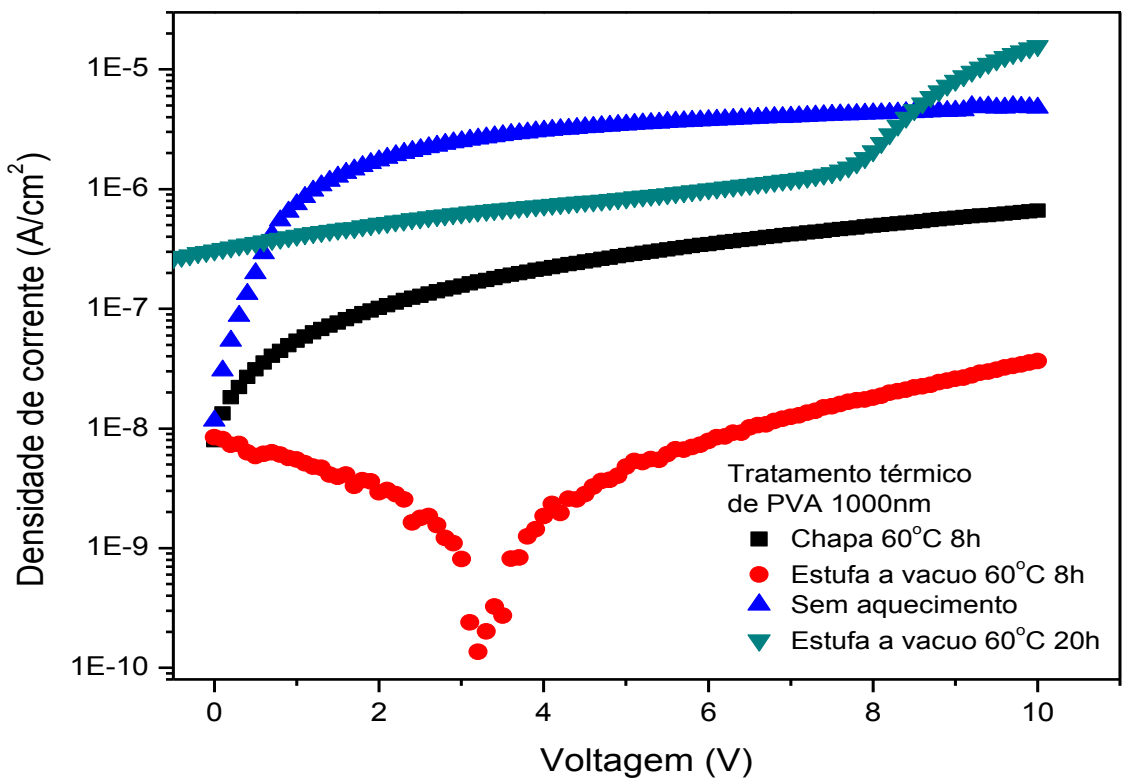

Figura 4.2 Curvas semi-logarítmicas $J x V$ dos dispositivos ITO/PVA/Al para diferentes tratamentos térmicos.

Na Figura 4.2, observa-se que as curvas $J x V$ de todos os filmes tiveram corrente de fuga, pois suas densidades de corrente foram da ordem de $10^{-8}$ e $10^{-7}\left(A / \mathrm{cm}^{2}\right)$ em $0 \mathrm{~V}$. Sabendo que as áreas foram em torno de $3 \times$ $10^{-2} \mathrm{~cm}^{2}$, significa que as correntes estiveram entre $10^{-10}$ e $10^{-9} \mathrm{~A}$.

Dentre as quatro curvas $J x V$ dos filmes do PVA tratados termicamente, observa-se na Figura 4.2, que o melhor candidato como isolante é o filme que foi secado na estufa a vácuo a $60^{\circ} \mathrm{C}$ por $8 \mathrm{~h}$. A corrente elétrica neste filme foi da ordem de apenas $10^{-10} A$. No entanto, tem um deslocamento da curva $J x V$ do zero, no eixo da tensão, de até $3 \mathrm{~V}$ devido a efeitos de carga, neste caso por causa dos elétrons livres das moléculas de água (Schroeder, et al., 2005). Infelizmente este processo de secagem para os substratos de PVA foi aplicado só no final da pesquisa, não dando oportunidade de fabricar OFETs com estes filmes. Considerava-se no inicio 
da pesquisa que quanto maior o tempo de secado, melhor seria o isolamento do PVA. Porém, se comparadas as curvas $J x V$ dos processos de secagem na estufa a vácuo a $60^{\circ} \mathrm{C}$ por $8 \mathrm{~h}$ com aquela de $20 \mathrm{~h}$, é obvio que esse raciocínio estava errado.

\subsubsection{PVA para diferentes espessuras}

Para obter as curvas $J x V$ do PVA, fez-se capacitores planos do tipo ITO/PVA/Al, depositando por spin coating diferentes espessuras do PVA, os valores das espessuras são mostradas na Figura 4.3. O tratamento térmico para evaporar a água foi o mesmo para todas as espessuras, secando na estufa a vácuo a $60^{\circ} \mathrm{C}$ por $20 \mathrm{~h}$.

As curvas $J x V$ dos quatro substratos do PVA mostram que as correntes de fuga ficaram entre $10^{-9}$ e $10^{-8} A$; sabendo que a área de cada capacitor foi da ordem $10^{-2} \mathrm{~cm}^{2}$ em todos os casos. Estas altas correntes de fuga observadas, não permitiram um bom funcionamento de OFETs feitos com PVA, pois se sabe que as correntes geradas num OFET com PVA são da ordem de nano-Ampere (Machado, 2011). Como consequência uma corrente de fuga não pode ser da mesma ordem que uma corrente gerada num OFET.

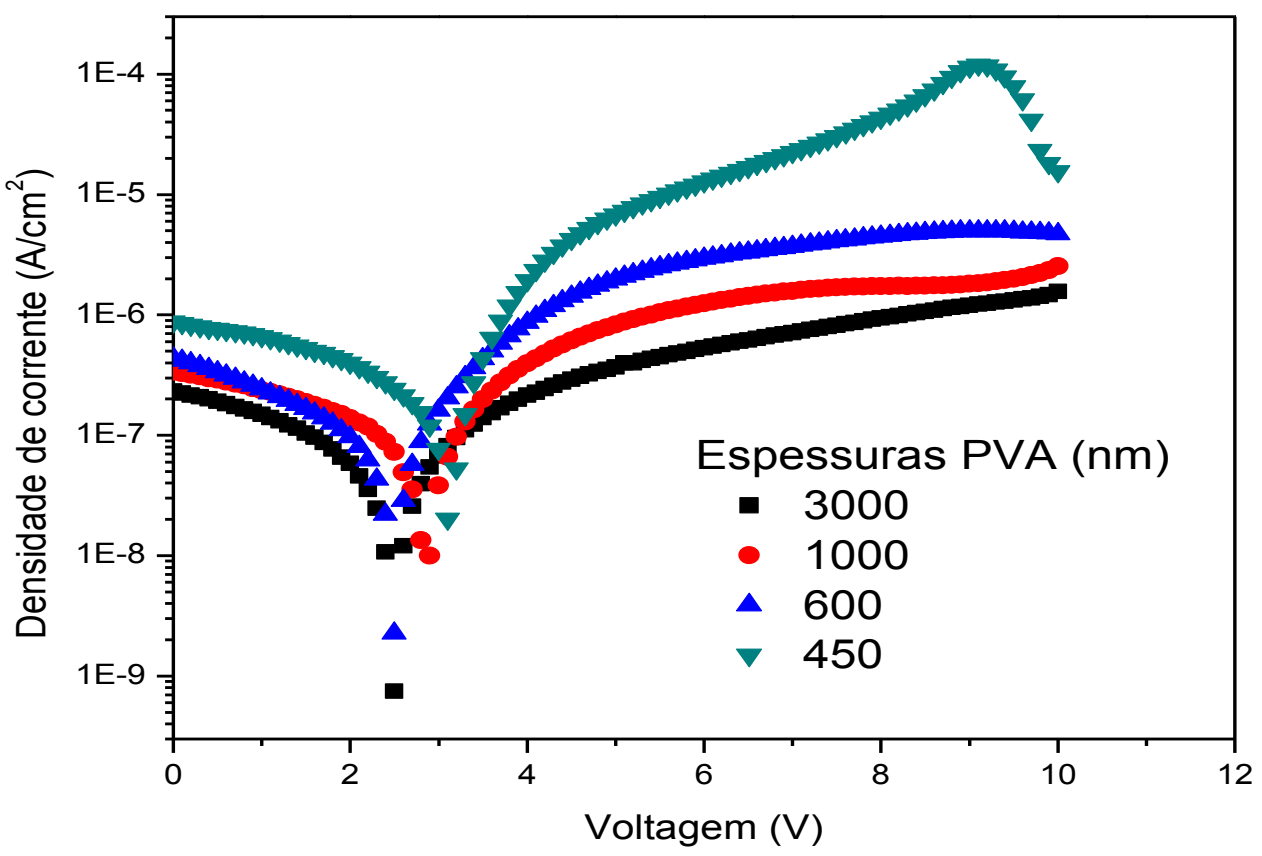

Figura 4.3 Curvas semi-logarítmicas $J x V$ dos dispositivos ITO/PVA/Al para diferentes espessuras e com o mesmo tratamento térmico, secando na estufa a vácuo a $60^{\circ} \mathrm{C}$ por $20 \mathrm{~h}$. 
Na Figura 4.3, observa-se também deslocamentos das curvas $J x V$ do zero, no eixo da tensão, de até $3 \mathrm{~V}$. Este fenômeno aconteceu provavelmente, devido a efeitos de carga gerados pelos elétrons livres das moléculas de água (Schroeder, et al., 2005).

\subsubsection{FORMVAR dissolvido em clorofórmio}

Após utilizar polímeros dielétricos conhecidos como PMMA e PVA buscavam-se isolantes novos para sua utilização em OFETs. Uma proposta foi o FORMVAR, neste caso optou-se como solvente o clorofórmio.

Para obter as curvas $J x V$ do FORMVAR, fez-se capacitores de placas paralelas do tipo ITO/FORMVAR(cloroformio)/Al, para diferentes espessuras do FORMVAR, depositado por spin coating, os valores das espessuras foram de: 620nm, 750nm, $900 \mathrm{~nm}$ e $1100 \mathrm{~nm}$.

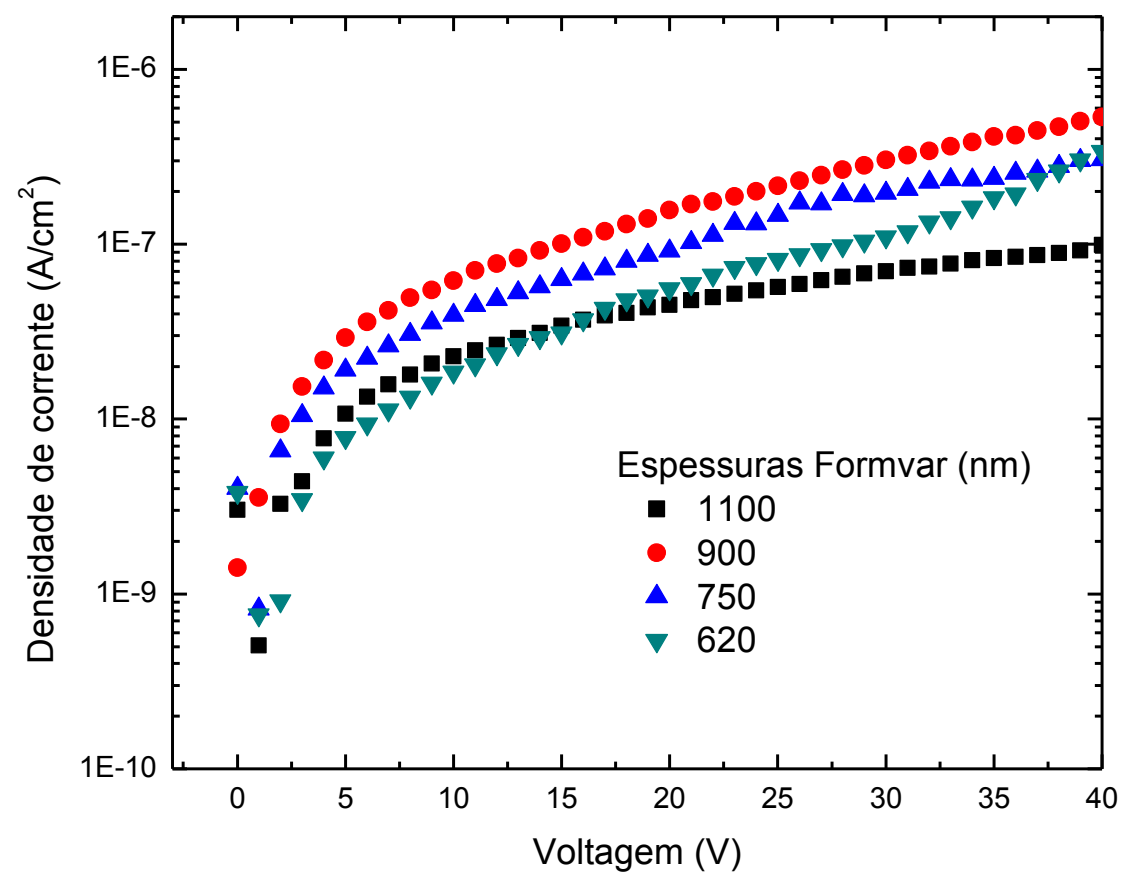

Figura 4.4 Curvas semi-logarítmicas $J x V$ dos dispositivos ITO/Formvar/Al para diferentes espessuras, com o FORMVAR dissolvido com Clorofórmio.

Na Figura 4.4, observa-se as curvas $J x V$ dos quatro substratos do FORMVAR. Nestas as correntes de fuga foram da ordem de $10^{-11}-10^{-10} A$ e o deslocamento das curvas $J x V$ do zero, no eixo da voltagem foi aproximadamente de $1 \mathrm{~V}$. Estas correntes de fuga indicam que o FORMVAR é um bom isolante desde um inicio, pois elas não excedem a ordem de $10^{-9} A$. O deslocamento das 
curvas $J x V$ do zero, em $1 \mathrm{~V}$, no eixo da tensão, indicam que um OFET feito com FORMVAR poderia funcionar a tensões baixas, ou seja, com tensões maiores que 1V. Pode-se ver também que os filmes do FORMVAR cumprem sua função de isolantes, pois nas curvas $J x V$, conforme a tensão aumentou no capacitor, as correntes que atravessaram o FORMVAR ficaram no intervalo de $10^{-10}$ $10^{-9} \mathrm{~A}$. Todas estas características fazem do FORMVAR um bom isolante e, portanto, um bom candidato para a camada dielétrica na construção de um OFET.

O problema de dissolver o FORMVAR em clorofórmio foi que este solvente é volátil (ponto de ebulição $61^{\circ} \mathrm{C}$ ), gerando filmes rugosos, já que o FORMVAR não terminou de se espalhar uniformemente sobre o vidro pela rápida evaporação do solvente. Estes filmes foram impróprios para a construção de OFETs. Por este motivo, decidiu-se utilizar outro solvente para o FORMVAR, como se descreve a seguir.

\subsubsection{FORMVAR dissolvido em dimetilformamida (DMF)}

Desta vez o FORMVAR foi dissolvido em DMF, um solvente menos volátil que o clorofórmio, cujo ponto de ebulição é de $153^{\circ} \mathrm{C}$. Então foram feitos três capacitores de placas paralelas do tipo ITO/FORMVAR(DMF)/Al, com filmes de $300 \mathrm{~nm}$ de espessura, depositados por spin coating, com tratamentos térmicos diferentes.



Figura 4.5 Curvas semi-logarítmicas $J x V$ dos dispositivos ITO/Formvar/Al, com o Formvar dissolvido com DMF, para uma única espessura e com diferentes tratamentos térmicos. 
Na Figura 4.5, observa-se que nas curvas $J x V$ as correntes que atravessam os filmes de FORMVAR conforme a tensão aumenta nos capacitores, foram da ordem de $10^{-6}-10^{-3} A$, consideradas altas para um isolante, as quais podem ser explicadas porque o DMF ainda não evaporou do filme. Estas correntes são também consideradas altas para a construção de OFETs, dado que um OFET trabalha em geral com correntes da ordem de micro ampere ou menores.

\subsubsection{PU dissolvido em tetraidrofurano(THF)}

Outro dos materiais isolantes que foi testado para sua utilização em OFETs como camada dielétrica foi o Poliuretano (PU), que foi dissolvido em THF. Para obter as curvas $J x V$ do PU, fizeram-se capacitores planos do tipo ITO/PU(THF)/Al, para diferentes espessuras do PU, depositados por spin coating.

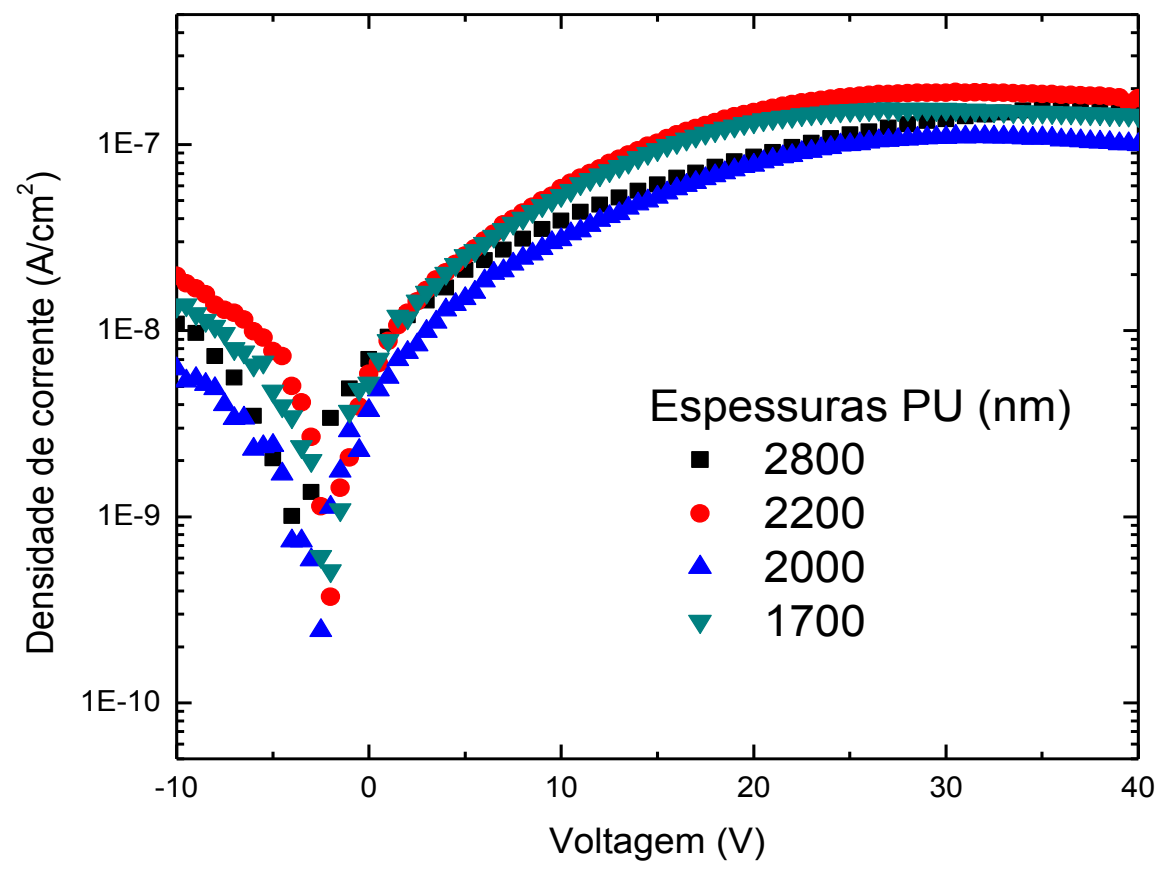

Figura 4.6 Curvas semi-logarítmicas $J x V$ dos dispositivos ITO/PU(THF)/Al para diferentes espessuras, utilizando como solvente o THF.

Na Figura 4.6, observa-se nas curvas $J x V$ dos quatro substratos do PU, que estes apresentaram correntes de fuga da ordem de aproximadamente $10^{-10} \mathrm{~A}$. Observou-se também o deslocamento das curvas $J x V$ do zero, no eixo da tensão, de $-3 \mathrm{~V}$ aproximadamente. Este deslocamento negativo pôde ter acontecido por que a varredura da tensão foi feita de voltagens negativos a positivos no capacitor. Pode-se ver também que os filmes do PU cumpriram sua função de isolantes, pois 
nas curvas $J x V$, conforme a tensão aumentou no capacitor, as correntes que atravessaram o PU estiveram no intervalo de $10^{-10}-10^{-9} A$, isto é, tem correntes baixas, típicas de um isolante. Todas estas características fazem do PU um excelente isolante e, portanto, parecia um bom candidato para a camada dielétrica na construção de um OFET. No entanto, não se fez os testes com espessuras menores, devido aos seguintes inconvenientes:

Um dos problemas com o THF utilizado como solvente para o PU, foi que o THF também é um solvente para o P3HT, que é o único SO utilizado nesse trabalho. Este fato impediria uma deposição consecutiva por Spin Coating de uma camada sobre a outra, quer dizer, que os solventes destes materiais não são ortogonais. Outro inconveniente foi dissolver o PU num solvente volátil como o THF (ponto de ebulição $66^{\circ} \mathrm{C}$ ), pois resultaram filmes rugosos, dado que o PU não termina de se espalhar uniformemente sobre o vidro pela rápida evaporação do solvente. Estes filmes foram impróprios para a construção de OFETs; por este motivo, decidiu-se utilizar outro solvente para o PU, como se descreve no seguinte item.

\subsubsection{PU dissolvido em MEK}

Neste caso o PU foi dissolvido em MEK, um solvente menos volátil que o THF, já que seu ponto de ebulição é de $80^{\circ} \mathrm{C}$. Para obter as curvas $J x V$ do PU(MEK) foram feitos capacitores de placas paralelas do tipo ITO/PU(MEK)/Al, para diferentes espessuras do PU, depositados por spin coating.

Na Figura 4.7, observa-se nas curvas $J x V$ dos quatro substratos do PU que as correntes de fuga ficaram no intervalo de $10^{-11}-10^{-10} A$ e que o deslocamento das curvas $J x V$ do zero, no eixo da voltagem foi quase inexistente. Estes fatos indicam que um OFET fabricado com PU(MEK) pode funcionar com tensões baixas, ou seja, menores que $1 \mathrm{~V}$ inclusive. Pode-se ver também que os filmes do PU cumpriram sua função de isolantes, pois nas curvas $J x V$, conforme a tensão aumentou nos capacitores, as correntes que atravessam o PU são da ordem de $10^{-9} A$; exceto para a curva do filme de $380 \mathrm{~nm}$ que deixa passar uma corrente de $10^{-8} A$. Todas estas características fazem do PU um bom isolante e, portanto, um bom candidato para a camada dielétrica na construção de um OFET. Desta vez, os 
solventes do PU (MEK) e do P3HT (Tolueno) são ortogonais, o que possibilitou a fabricação de OFETs.



Figura 4.7 Curvas semi-logarítmicas $\boldsymbol{J} \boldsymbol{x} \boldsymbol{V}$ dos dispositivos ITO/PU(MEK)/Al para diferentes espessuras, utilizando como solvente o MEK.

A continuação apresenta-se um resumo das grandezas obtidas das curvas $J x V$ de todos os materiais dielétricos envolvidos:

\begin{tabular}{|l|c|c|}
\hline Dielétrico & $\begin{array}{c}\text { Corrente de } \\
\text { fuga* }(\mathbf{A})\end{array}$ & $\begin{array}{c}\text { Deslocamento do zero } \\
(\mathbf{V})\end{array}$ \\
\hline PMMA & $10^{-11}-10^{-10}$ & $5-20$ \\
\hline PVA & $10^{-11}-10^{-10}$ & $2-3$ \\
\hline $\begin{array}{l}\text { FORMVAR } \\
\text { (Clorofórmio) }\end{array}$ & $10^{-11}-10^{-10}$ & $0-1$ \\
\hline $\begin{array}{l}\text { FORMVAR } \\
\text { (DMF) }\end{array}$ & $10^{-10}-10^{-7}$ & - \\
\hline PU (THF) & $10^{-10}$ & -3 \\
\hline PU (MEK) & $10^{-11}-10^{-10}$ & 0 \\
\hline
\end{tabular}

Tabela 4.1 Resumo das grandezas obtidas das curvas $J \boldsymbol{x V}$ para cada material dielétrico. 
*Temos que ressaltar que na Tabela 4.1, as correntes de fuga representam um intervalo dos dados extraídos das curvas $J x V$ e que foram calculadas baseadas no fato de que as áreas são sempre da ordem de $10^{-2} \mathrm{~cm}^{2}$.

\subsubsection{Capacitância por unidade de área $\left(C_{i}\right)$ e constante dielétrica $\left(\varepsilon_{i}\right)$}

Num capacitor plano, foi possível obter entre outros resultados, a capacitância $C$ por medição direita nas placas, um processo bem simples, que foi feito com um multímetro. Sabe-se também a área das placas, que em media foi de $3 \times$ $10^{-2} \mathrm{~cm}^{2}$. Então se calculou a capacitância por unidade de área $\left(C_{i}\right)$ dos dielétricos, que foi uma grandeza fundamental para conhecer a mobilidade de um SO num OFET, conforme a equação 2.17 ou 4.4.

Para calcular a constante dielétrica $\left(\varepsilon_{i}\right)$ dos polímeros isolantes, fez-se gráficos da capacitância por unidade de área $\left(C_{i}\right)$ dos dielétricos versus o inverso das espessuras dos filmes $(1 / d)$, depois se fez uma regressão linear com os pontos, e baseados na equação 2.8 tem-se:

$$
C_{i}=\frac{C}{A}=\varepsilon_{i} \varepsilon_{0} \frac{1}{d}
$$

Resultando que a inclinação $(b)$ das curvas $C_{i} \times 1 / d$ para cada isolante foi $b=\varepsilon_{i} \varepsilon_{0}$ e utilizando para a permissividade elétrica do vácuo $\varepsilon_{0}=8,85 \mathrm{pF} / \mathrm{m}$, tem-se que a constante dielétrica de cada polímero isolante foi:

$$
\varepsilon_{i}=\frac{b}{\varepsilon_{0}}
$$

A seguir são mostrados os cálculos feitos por esta análise para todos os polímeros isolantes:

\subsubsection{PMMA}

Na Tabela 4.2, são mostradas as capacitâncias por unidades de área $C_{i}$ para cada capacitor orgânico plano, do tipo ITO/PMMA/Al, para diferentes espessuras de PMMA. 


\begin{tabular}{|c|c|c|}
\hline Substrato & Espessura d $(\mathrm{nm})$ & $\boldsymbol{C}_{\boldsymbol{i}}\left(\boldsymbol{\mu} \boldsymbol{F} / \boldsymbol{m}^{\mathbf{2}}\right)$ \\
\hline 1 & 980 & 24.68 \\
\hline 2 & 700 & 41.13 \\
\hline 3 & 570 & 49.83 \\
\hline 4 & 500 & 65.75 \\
\hline
\end{tabular}

Tabela 4.2 Valores das capacitâncias por unidades de área para cada dispositivo ITO/PMMA/Al para diferentes espessuras.

Com os dados da Tabela 4.2, fez-se um gráfico $C_{i}$ versus $1 / d$, mostrado na Figura 4.8, para obter a constante dielétrica do PMMA com a equação 4.1.

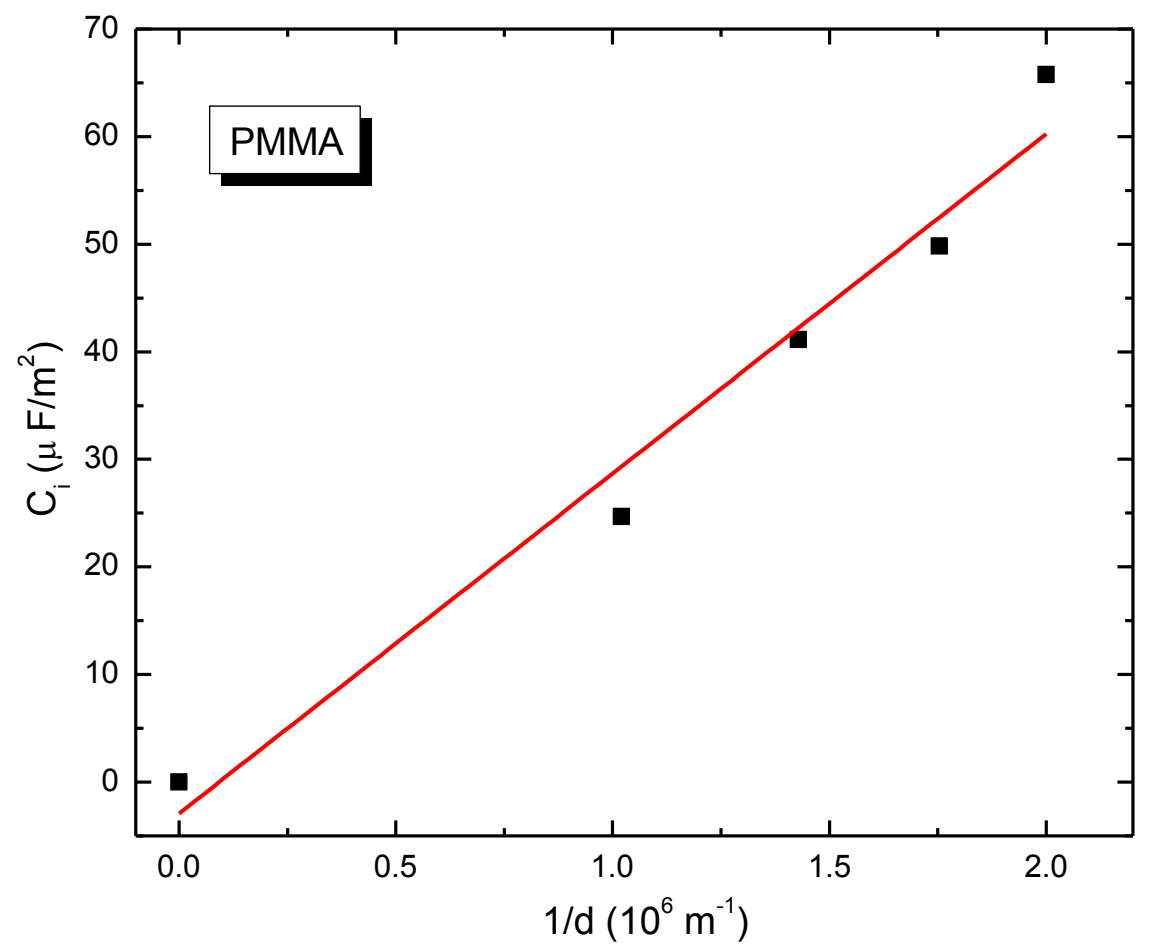

Figura 4.8 Gráfico das capacitâncias por unidades de área $\boldsymbol{C}_{\boldsymbol{i}}$ versus as inversas das espessuras $\mathbf{1} / \boldsymbol{d}$ para o PMMA. A constante dielétrica para o PMMA foi de 3,57.

Observa-se na Figura 4.8, que os pontos têm uma relação lineal, sendo válido então aplicar o "fit linear". Neste caso a constante dielétrica para o PMMA foi de 3,57 . 


\subsubsection{PVA}

Na Tabela 4.3, são exibidas as capacitâncias por unidades de área $C_{i}$ para cada capacitor orgânico de placas paralelas, do tipo ITO/PVA/Al, para diferentes espessuras de PVA.

\begin{tabular}{|c|c|c|}
\hline Substrato & Espessura d $(\mathrm{nm})$ & $\boldsymbol{C}_{\boldsymbol{i}}\left(\boldsymbol{\mu} \boldsymbol{F} / \boldsymbol{m}^{\mathbf{2}}\right)$ \\
\hline 1 & 2900 & 38.19 \\
\hline 2 & 950 & 97.59 \\
\hline 3 & 580 & 154.72 \\
\hline 4 & 460 & 213.36 \\
\hline
\end{tabular}

Tabela 4.3 Valores das capacitâncias por unidades de área para todos os dispositivos ITO/PVA/Al de diferentes espessuras.

Com os dados da Tabela 4.3, realizou-se um gráfico $C_{i}$ versus $1 / d$, mostrado na

Figura 4.9, para calcular a constante dielétrica do PVA com a equação 4.1.

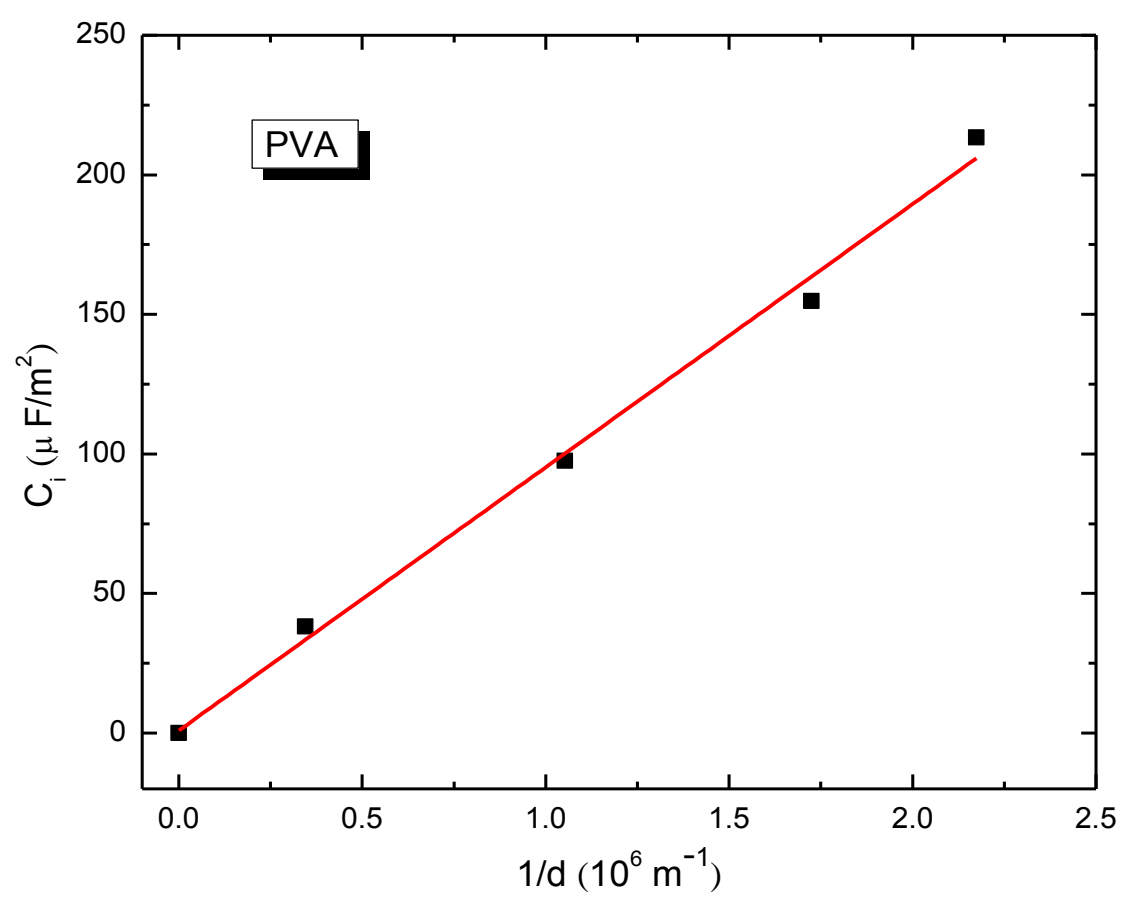

Figura 4.9 Gráfico das capacitâncias por unidade de área $\boldsymbol{C}_{\boldsymbol{i}}$ versus as inversas das espessuras $\mathbf{1} / \boldsymbol{d}$ para o PVA. A constante dielétrica para o PVA foi de 10,65

Observa-se na Figura 4.9, que os pontos têm uma relação lineal, sendo válido então aplicar a regressão linear. Neste caso a constante dielétrica para o PVA foi de 10,65 . 


\subsubsection{FORMVAR}

Na Tabela 4.4, são expostas as capacitâncias por unidades de área $C_{i}$ para cada capacitor orgânico plano, do tipo ITO/FORMVAR/Al, para diferentes espessuras de FORMVAR.

\begin{tabular}{|c|c|c|}
\hline Substrato & Espessura d $(\mathrm{nm})$ & $\boldsymbol{C}_{\boldsymbol{i}}\left(\boldsymbol{\mu} \boldsymbol{F} / \boldsymbol{m}^{\mathbf{2}}\right)$ \\
\hline 1 & 1100 & 27.49 \\
\hline 2 & 875 & 37.42 \\
\hline 3 & 750 & 45.55 \\
\hline 4 & 620 & 46.55 \\
\hline
\end{tabular}

Tabela 4.4 Valores das capacitâncias por unidades de área para todos os dispositivos ITO/Formvar/Al de diferentes espessuras.

Utilizando os dados da Tabela 4.4 , fez-se um gráfico $C_{i}$ versus $1 / d$ como se exibe na Figura 4.10, para obter a constante dielétrica do FORMVAR com a equação 4.1 .

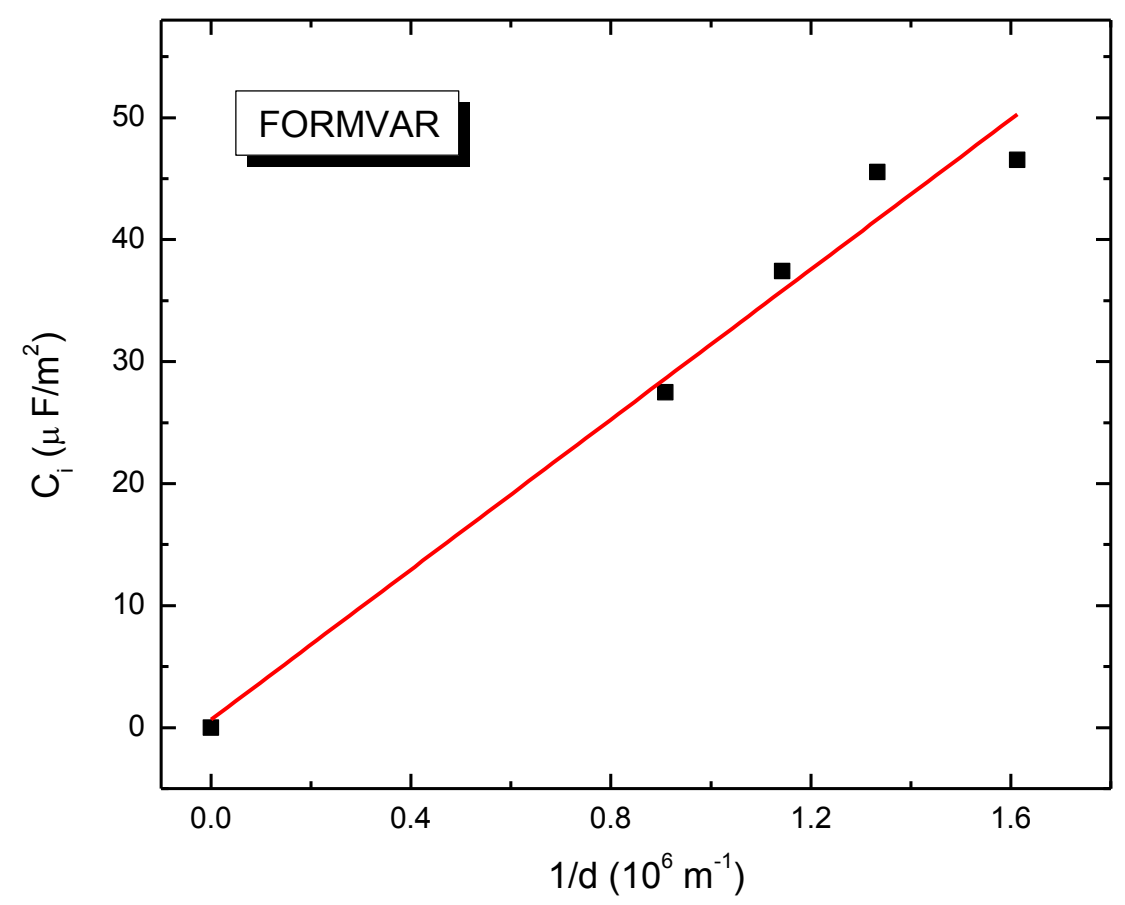

Figura 4.10 Gráfico das capacitâncias por unidade de área $\boldsymbol{C}_{\boldsymbol{i}}$ versus as inversas das espessuras $\mathbf{1} / \boldsymbol{d}$ para o FORMVAR. A constante dielétrica para o FORMVAR foi de 3,48.

Observa-se na Figura 4.10, que os pontos têm uma relação lineal, sendo válido então aplicar o "fit linear". Neste caso a constante dielétrica para o FORMVAR foi de 3,48 . 


\subsubsection{PU dissolvido em THF: PU(THF)}

Na Tabela 4.5, são exibidas as capacitâncias por unidades de área $C_{i}$ para cada capacitor orgânico de placas paralelas, do tipo ITO/PU(THF)/Al, para diferentes espessuras de PU(THF).

\begin{tabular}{|c|c|c|}
\hline Substrato & Espessura d $(\mathrm{nm})$ & $\boldsymbol{C}_{\boldsymbol{i}}\left(\boldsymbol{\mu} \boldsymbol{F} / \boldsymbol{m}^{\mathbf{2}}\right)$ \\
\hline 1 & 2800 & 18.40 \\
\hline 2 & 2200 & 22.01 \\
\hline 3 & 2000 & 26.10 \\
\hline 4 & 1700 & 32.30 \\
\hline
\end{tabular}

Tabela 4.5 Valores das capacitâncias por unidades de área para todos os dispositivos ITO/PU(THF)/Al de diferentes espessuras, nesse caso o PU foi dissolvido em THF.

Em base aos dados da Tabela 4.5 , realizou-se um gráfico $C_{i}$ versus $1 / d$, como se mostra na Figura 4.1, para calcular a constante dielétrica do PU com a equação 4.1 .

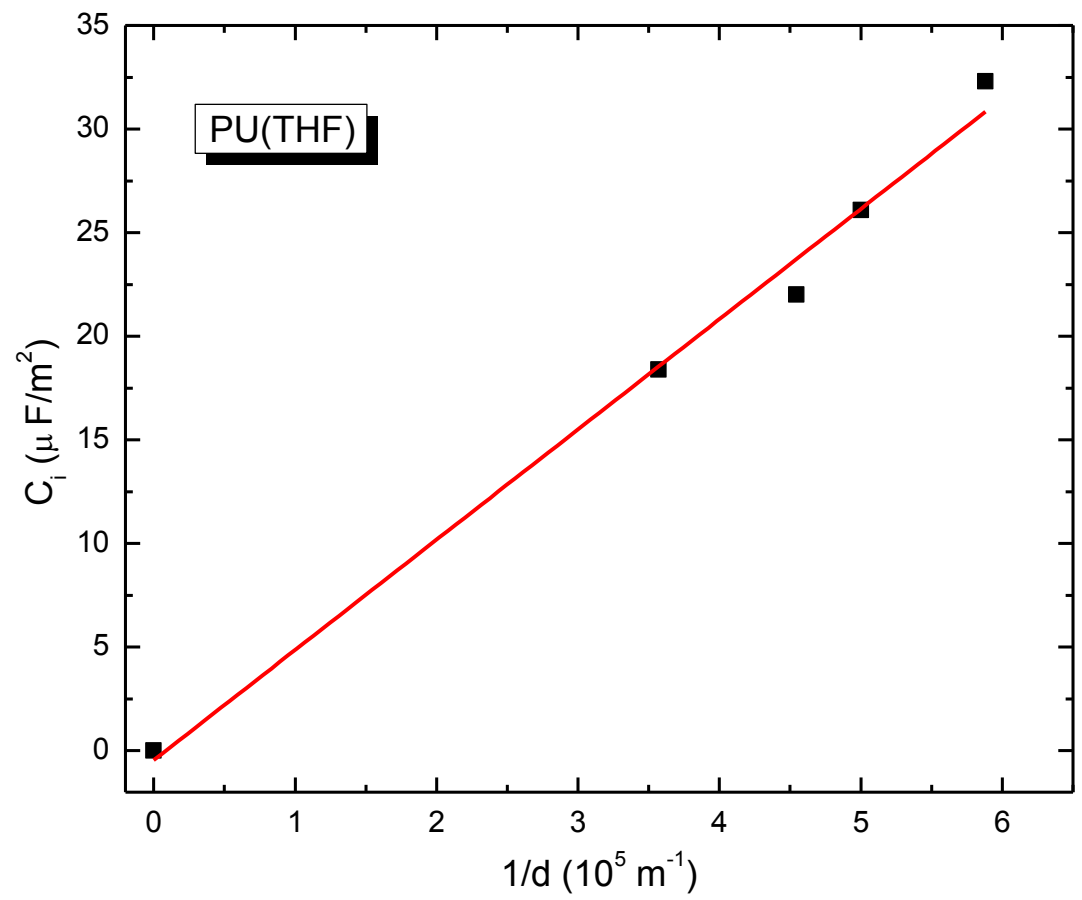

Figura 4.11 Gráfico das capacitâncias por unidade de área $\boldsymbol{C}_{\boldsymbol{i}}$ versus as inversas das espessuras $\mathbf{1} / \boldsymbol{d}$ para o PU dissolvido em THF. A constante dielétrica para o PU(THF) foi de 6,01.

Observa-se na Figura 4.11, que os pontos têm uma relação lineal, sendo válido então aplicar a regressão linear. Neste caso a constante dielétrica para o PU(THF) foi de 6,01 . 


\subsubsection{PU dissolvido em MEK: PU(MEK)}

Na Tabela 4.6, são expostas as capacitâncias por unidades de área $C_{i}$ para cada capacitor orgânico plano, do tipo ITO/PU(MEK)/Al para diferentes espessuras de PU(MEK).

\begin{tabular}{|c|c|c|}
\hline Substrato & Espessura d $(\mathrm{nm})$ & $\boldsymbol{C}_{\boldsymbol{i}}\left(\boldsymbol{\mu} \boldsymbol{F} / \boldsymbol{m}^{\mathbf{2}}\right)$ \\
\hline 1 & 380 & 84.60 \\
\hline 2 & 600 & 68.21 \\
\hline 3 & 700 & 50.50 \\
\hline 4 & 750 & 48.80 \\
\hline
\end{tabular}

Tabela 4.6 Valores das capacitâncias por unidades de área para todos os dispositivos ITO/PU(MEK)/Al de diferentes espessuras, nesse caso o PU foi dissolvido parcialmente em MEK.

Utilizando os dados da Tabela 4.6, fez-se um gráfico $C_{i}$ versus $1 / d$, como se observa na Figura 4.12, para obter a constante dielétrica do PU com a equação 4.1 .

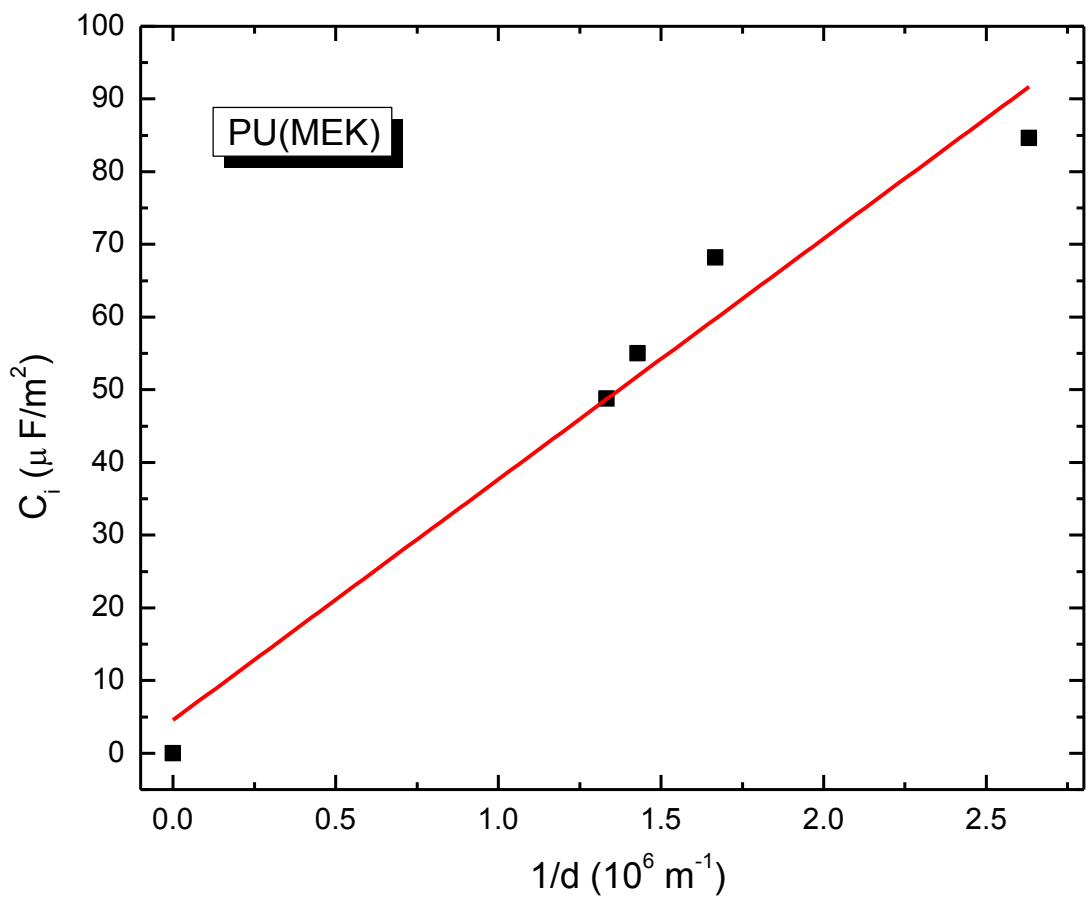

Figura 4.12 Gráfico das capacitâncias por unidade de área $\boldsymbol{C}_{\boldsymbol{i}}$ versus as inversas das espessuras $\mathbf{1} / \boldsymbol{d}$ para o PU dissolvido em MEK. A constante dielétrica para o PU(MEK) foi de 3,74.

Observa-se na Figura 4.12, que os pontos têm uma relação lineal, com exceção do ponto gerado pelo substrato 1 , mesmo assim, fez-se a regressão linear. Neste caso a constante dielétrica para o PU(MEK) foi de 3,74. 
A seguir, registra-se na Tabela 4.7, os valores das constantes dielétricas obtidos para os materiais isolantes utilizados nessa dissertação:

\begin{tabular}{l|c|} 
Polímero Isolante & constante dielétrica $\left(\boldsymbol{\varepsilon}_{\boldsymbol{i}}\right)$ \\
\hline PMMA & $3,57 \pm 0,20$ \\
PVA & $10,65 \pm 0,73$ \\
FORMVAR & $3,48 \pm 0,18$ \\
PU(THF) & $6,01 \pm 0,44$ \\
PU(MEK) & $3.74 \pm 0,10$ \\
\hline
\end{tabular}

Tabela 4.7 Resumo do calculo das constantes dielétricas dos materiais isolantes utilizados neste trabalho.

Da Tabela 4.7, tem-se que ressaltar que os valores das constantes dielétricas, calculados experimentalmente dos capacitores orgânicos fabricados, são concordantes com os teóricos da Tabela 2.1.

É necessário reparar nos valores das constantes dielétricas do PU(THF) e PU(MEK) que em teoria deveriam ser os mesmos. A diferença entre eles pôde-se dever a que o PU para dissolver no MEK foi aquecido a $100^{\circ} \mathrm{C}$ por $48 \mathrm{~h}$; tal como foi descrito na parte dos materiais utilizados; este fato pode ter variado algumas propriedades dielétricas do polímero.

Outro aspecto a frisar, é a razão de por que na construção dos OFETs, decidiu-se utilizar o PU(MEK) e não o PU(THF); mesmo sabendo que o PU(THF) tem maior constante dielétrica que o PU(MEK). A resposta é que o PU(THF) gerou filmes rugosos, devido à volatilidade do THF (ponto de ebulição $66^{\circ} \mathrm{C}$ ); dado que o PU não terminou de se espalhar uniformemente sobre o vidro pela rápida evaporação do solvente. Estes filmes foram impróprios para a construção de OFETs;

\subsection{OFETs}

Todos os dispositivos e cálculos, feitos até agora, chame-se: capacitores orgânicos para cada material dielétrico, curvas $J x V$, capacitância por unidade de área $\left(C_{i}\right) \mathrm{e}$ a constante dielétrica $\left(\varepsilon_{i}\right)$ para cada polímero isolante; serviram para caracterizar, calcular e apresentar as grandezas típicas dos OFET. Esta caracterização como foi explicado na teoria, constou em fazer dois tipos de curvas: as de transferência e as de saída. Em base a estas curvas, procedeu-se a calcular as grandezas 
características dos OFETs, tais como a mobilidade $(\mu)$, razão On/Off da corrente de dreno e a tensão limiar $\left(V_{T}\right)$.

Devemos lembrar para esta dissertação que o SO P3HT foi uma característica comum nos dos tipos de OFETs desenvolvidos, não havendo sido utilizado nenhum outro SO. A diferença nos OFETs fabricados esteve na camada isolante, pois para cada tipo de OFET, utilizou-se um polímero orgânico isolante diferente. Portanto, os resultados dividiram-se por tipos de OFETs segundo o dielétrico:

- OFETs com PMMA.

- OFETs com PU(MEK).

Antes de apresentar os resultados para cada tipo de OFETs, será explicada a forma de calculo das grandezas características dos OFETs, tais como a mobilidade $\left(\mu_{s}\right)$ no regime de saturação, razão On/Off e a voltagem limiar $\left(V_{T}\right)$. Foi utilizado o método "Y-function" descrito em (Yong et al., 2015; Smith et al. 2010; Rossi, 2013; Machado, 2011) que consiste em linearizar a equação 2.17, ficando assim:

$$
I_{d s}^{1 / 2}=\left(\mu_{s} C_{i} \frac{W}{2 L}\right)^{1 / 2}\left(V_{g}-V_{T}\right)
$$

Por tanto, a equação 4.2 pode ser expressada da forma:

$$
I_{d s}^{1 / 2}=a+b V_{g}
$$

Então, da equação 4.3, pode-se mostrar que:

$$
\mu_{s}=\frac{2 L}{W C_{i}} b^{2}
$$

$\mathrm{E}$

$$
V_{T}=-\frac{a}{b}
$$

Onde $b$ é a inclinação da reta e $a$ o intercepto na equação 4.3.

A razão On/Off é o cociente entre o sinal do dispositivo no estado ligado e o sinal do mesmo dispositivo no estado desligado. Este parâmetro foi obtido da curva de transferência a partir da razão entre a corrente de saturação do estado ligado $I_{d s}$ 
para $\left|V_{g}\right|>\left|V_{d s}\right|$ e a corrente de saturação do estado desligado, quer dizer, menor valor de $I_{d s}$ obtido da curva de transferência.

O método "Y-function" para a extração dos parâmetros necessários para o cálculo da mobilidade $\left(\mu_{s}\right)$ no regime de saturação, razão On/Off e a voltagem limiar $\left(V_{T}\right)$ se ilustra na Figura 4.13 (Yong et al., 2015) .

As curvas de transferência foram extraidas aplicando uma tensão variável na porta $\left(V_{g}\right)$ para diferentes valores constantes de tensão no dreno $\left(V_{D S}\right)$, então se geraram um conjunto de curvas de transferência. Depois, aplicou-se uma tensão variável no dreno $\left(V_{D S}\right)$, para diferentes valores constantes de tensão no gate $\left(V_{g}\right)$, gerando um conjunto de curvas de saída. A informação em extenso sobre as curvas dos OFETs foi já explicada na fundamentação teórica.

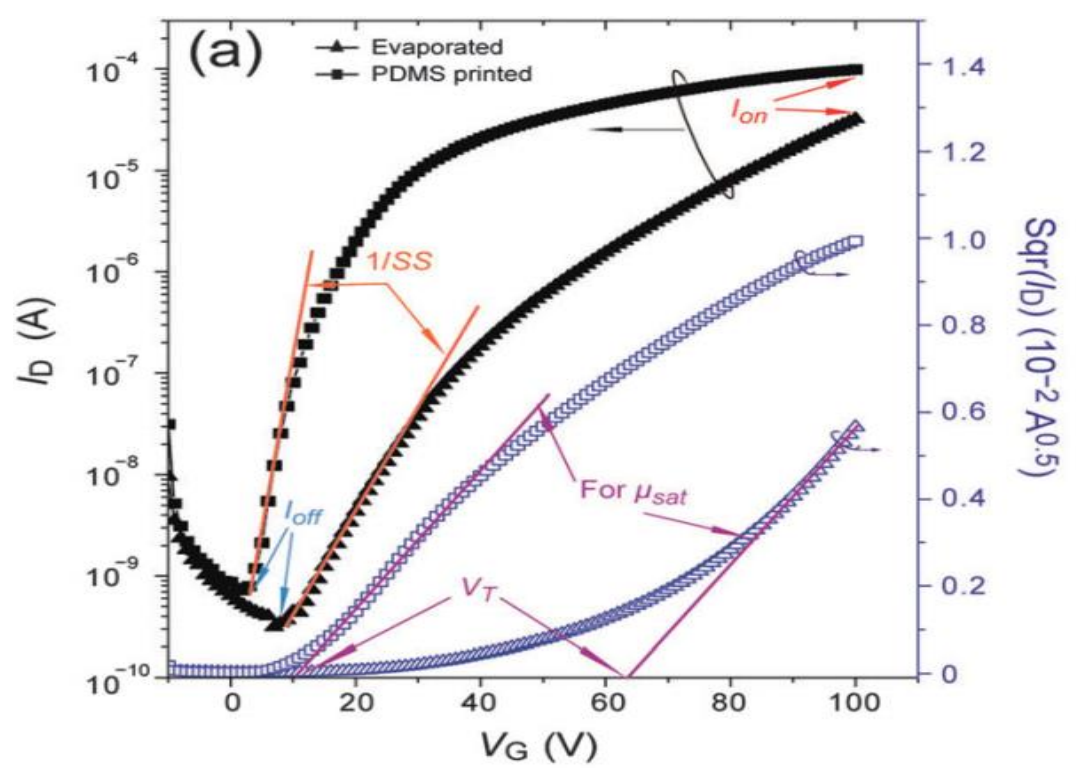

Figura 4.13 Gráfico que ilustra a extração de parâmetros para o calculo da mobilidade $\left(\boldsymbol{\mu}_{\boldsymbol{s}}\right)$ no regime de saturação, razão On/Off e a voltagem limiar $\left(\boldsymbol{V}_{\boldsymbol{T}}\right)$. Figura retirada da referência (Yong et al., 2015)

\subsubsection{OFETs com PMMA}

Os OFETs construídos com PMMA tiveram a arquitetura Top-Gate/BottomContacts $(T G B C)$ e foram feitos com os seguintes materiais Au/P3HT/PMMA/Ag. Os resultados aqui apresentados foram para o canal de $L=40 \mu \mathrm{m}$. E para efeitos de compreensão e comparação, foram divididos nas quatro espessuras de PMMA utilizadas, que foram chamadas de substratos. Como já se disse antes, a camada de P3HT não muda em cada tipo de OFET, ela tem 35nm de espessura nesse caso. 


\section{Substrato 1: 980nm}

A seguir, são mostradas as curvas de transferência e as curvas de saída para o OFET feito com PMMA como camada isolante, com uma espessura de 980nm.

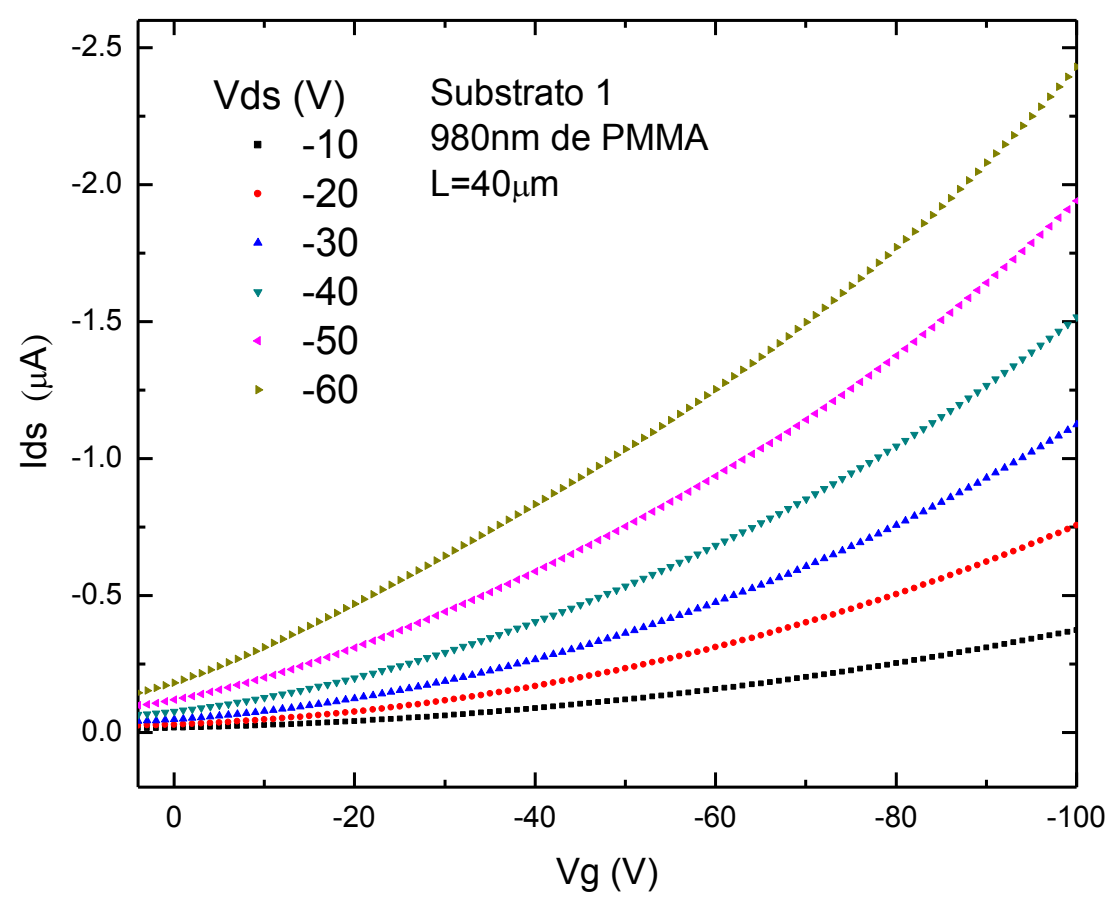

Figura 4.14 Curvas de transferência do OFET com PMMA para o substrato 1.



Figura 4.15 Curvas de saída do OFET com PMMA para o substrato 1. 
Na Figura 4.14, observa-se que as curvas de transferência para o substrato 1 (980nm) tiveram um comportamento característico de transistor, ou seja, conforme a tensão $V_{g}$ aumenta, a corrente $I_{d s}$ também. A curva de transferência $V_{d s}=-60 \mathrm{~V}$ atingiu uma corrente $\left|I_{d s}\right|$ de $2.5 \mu \mathrm{A}$ para uma tensão no gate $V_{G}$ de 100V. No entanto, as curvas de saída do substrato 1, conforme mostra a Figura 4.15, não apresentaram um comportamento típico de transistor, pois o regime de saturação não é bem comportado, já que a corrente continua aumentando, isto é, que a saturação no dispositivo foi deficiente. Este fato pode-se dever à grande espessura do substrato (980nm), quanto maior espessura menor capacitância por unidade de área (equação 2.8 e Tabela 4.2), e segundo a equação 2.8.a, precisaria de maior voltagem também. Tal vez se aumentasse a tensão $V_{G}$, o regime de saturação melhoraria.

Com o objetivo de comparar resultados, extraiu-se das Figuras 4.16 e 4.17, os parâmetros para calcular a mobilidade $\left(\mu_{s}\right)$ no regime de saturação, razão On/Off e a voltagem limiar $\left(V_{T}\right)$ para o OFET feito com PMMA como camada isolante, com uma espessura de 980nm. Primeiro a partir da curva de transferência $V_{d s}=-50 \mathrm{~V}$ na Figura 4.16, e depois para $V_{d s}=-40 \mathrm{~V}$ da Figura 4.17.

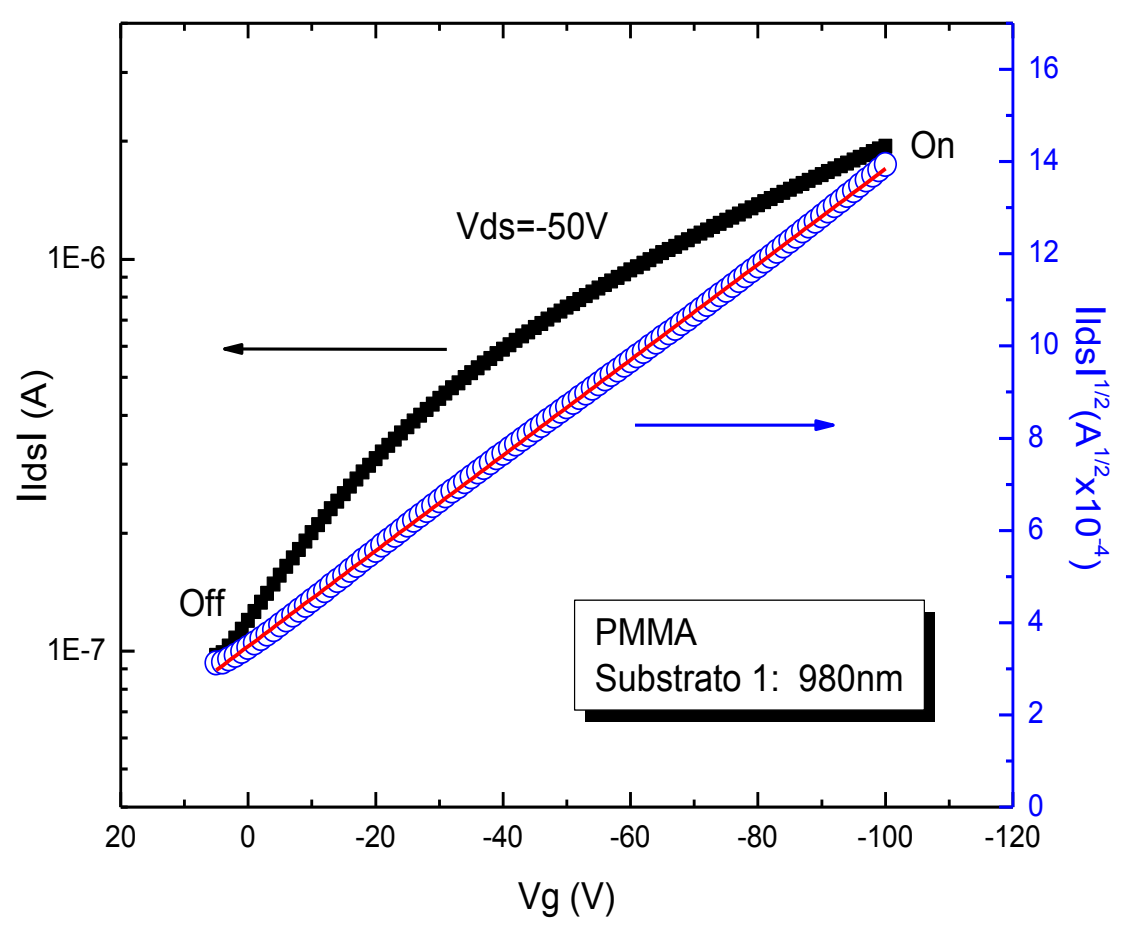

Figura 4.16 Curvas utilizadas para calcular as grandezas características do OFET de PMMA com 980nm de espessura para $\boldsymbol{V}_{\boldsymbol{d} \boldsymbol{s}}=\mathbf{- 5 0}$. 


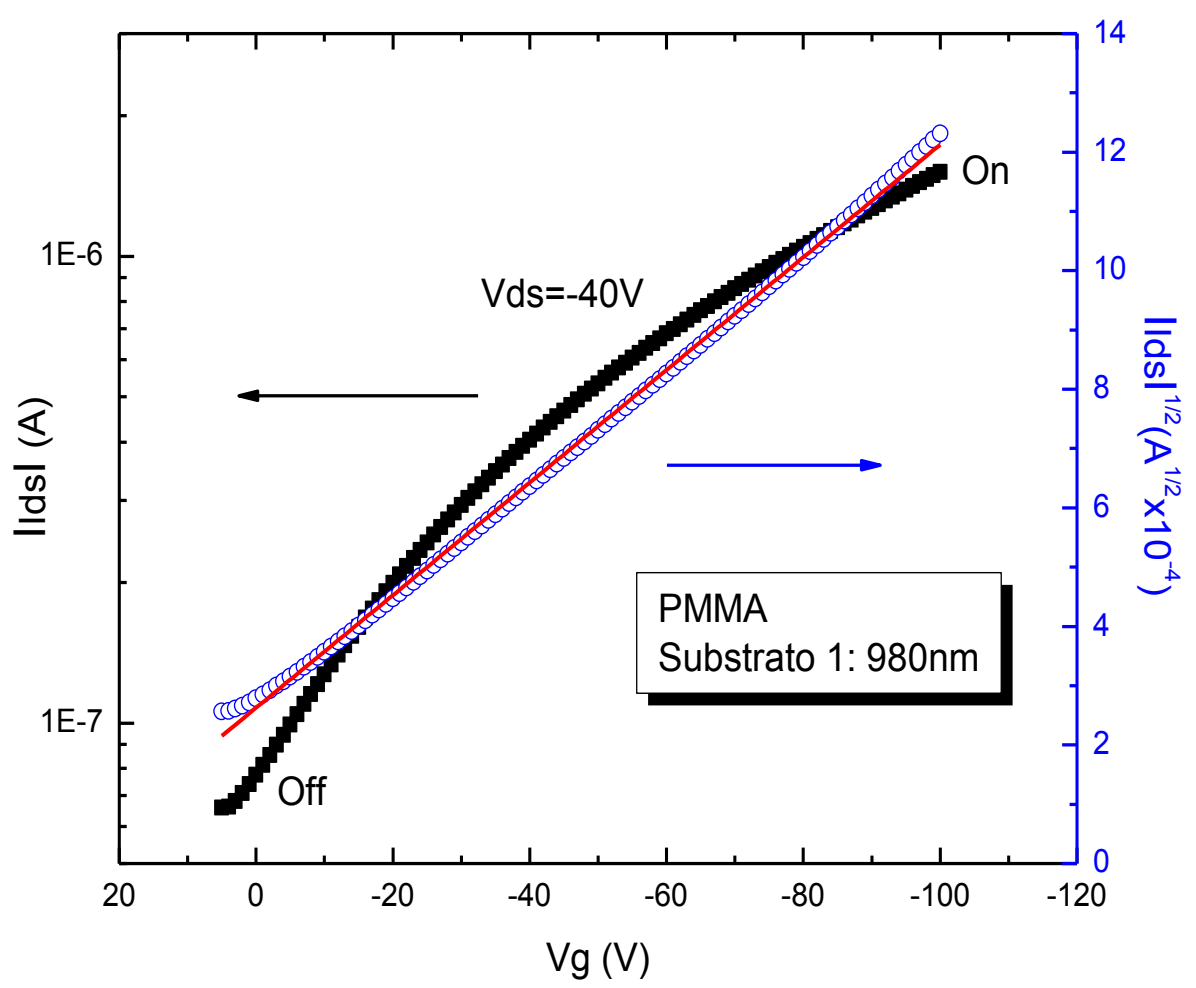

Figura 4.17 Curvas utilizadas para calcular as grandezas características do OFET de PMMA com 980nm de espessura para $\boldsymbol{V}_{\boldsymbol{d s}}=\mathbf{- 4 0 V}$.

Para conhecer a diferença entre as grandezas características deste OFET, porém com $V_{d s}$ diferentes, fez-se a seguinte Tabela 4.8:

\begin{tabular}{|c|c|c|c|}
\hline $\boldsymbol{V}_{\boldsymbol{d} \boldsymbol{s}}(\boldsymbol{V})$ & $\boldsymbol{\mu}\left(\boldsymbol{c m}^{\mathbf{2}} \boldsymbol{V}^{-\mathbf{1}} \boldsymbol{s}^{\mathbf{- 1}} \boldsymbol{x} \mathbf{1 0}^{-\mathbf{3}}\right)$ & $\boldsymbol{V}_{\boldsymbol{T}}(\boldsymbol{V})$ & On/Off \\
\hline-40 & $2.93 \pm 0.45$ & 27.68 & 20 \\
\hline-50 & $3.48 \pm 0.27$ & 33.60 & 16 \\
\hline
\end{tabular}

Tabela 4.8 Diferença entre as grandezas características do OFET de PMMA com $980 \mathrm{~nm}$ de espessura mas com $\boldsymbol{V}_{\boldsymbol{d} \boldsymbol{s}}$ diferentes.

Conclui-se que quanto maior o $\left|V_{d s}\right|$, maior mobilidade e voltagem limiar, porém, menor razão On/Off.

\section{Substrato 2: 700nm}

Desta vez, são exibidas as curvas de transferência e as curvas de saída para um OFET fabricado com uma camada isolante de PMMA, de 700nm de espessura. 


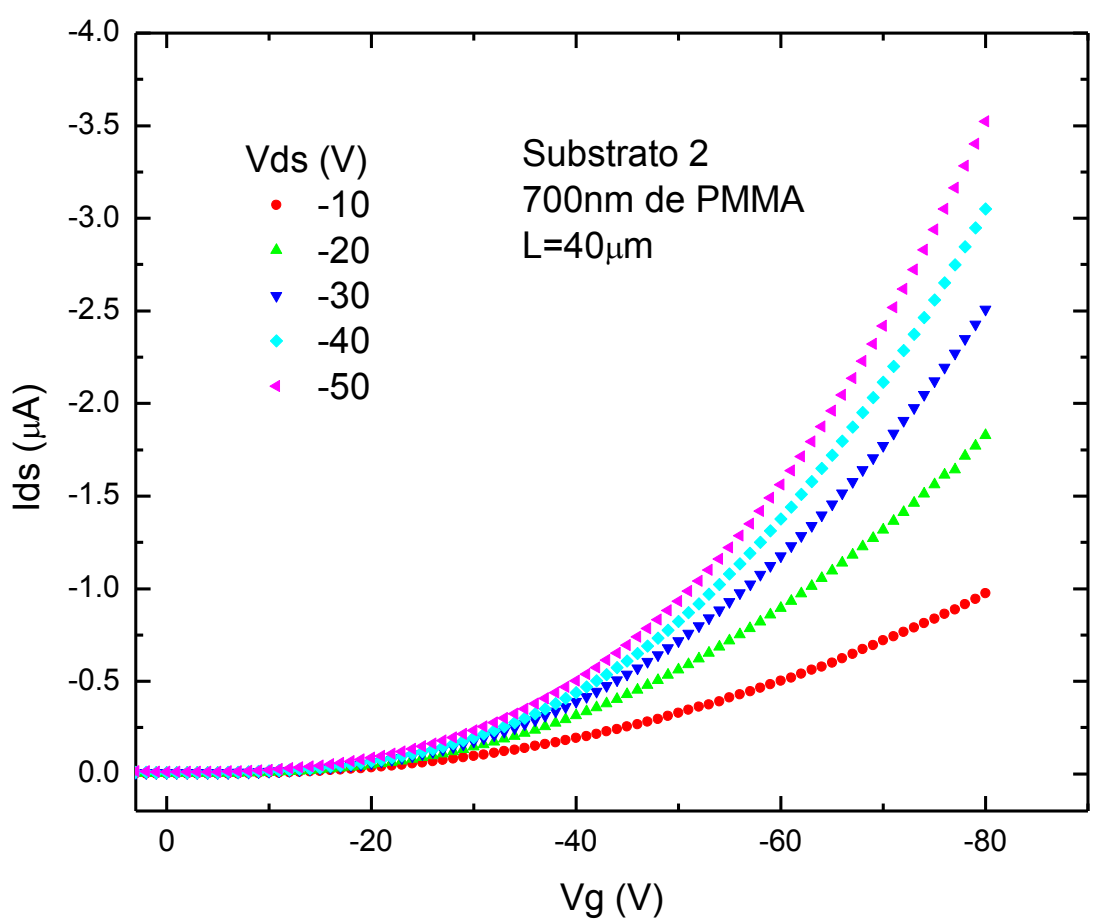

Figura 4.18 Curvas de transferência de um OFET com PMMA para o substrato 2.



Figura 4.19 Curvas de saída do OFET com PMMA para o substrato 2 . 
Observa-se que as curvas de transferência mostradas na Figura 4.18, para o substrato $2(700 \mathrm{~nm})$ tiveram um comportamento característico de transistor, ou seja, conforme a tensão $V_{g}$ aumentou, a corrente $I_{d s}$ também. A curva de transferência $V_{d s}=-50 \mathrm{~V}$ atingiu uma corrente $\left|I_{d s}\right|$ de $3.5 \mu \mathrm{A}$ para uma tensão no gate $V_{G}$ de $-80 \mathrm{~V}$. Pode ser observado na Figura 4.19, as curvas de saída, elas mostraram uma boa modulação e saturação para os diferentes valores de tensão na porta $V_{G}$, indicando o funcionamento do transistor.

A seguir, do gráfico da Figura 4.20, extraiu-se os parâmetros para calcular a mobilidade $\left(\mu_{s}\right)$ no regime de saturação, razão On/Off e a voltagem limiar $\left(V_{T}\right)$. A partir da curva de transferência de $V_{d s}=-50 \mathrm{~V}$, para um OFET fabricado com uma camada isolante de PMMA de 700nm de espessura.

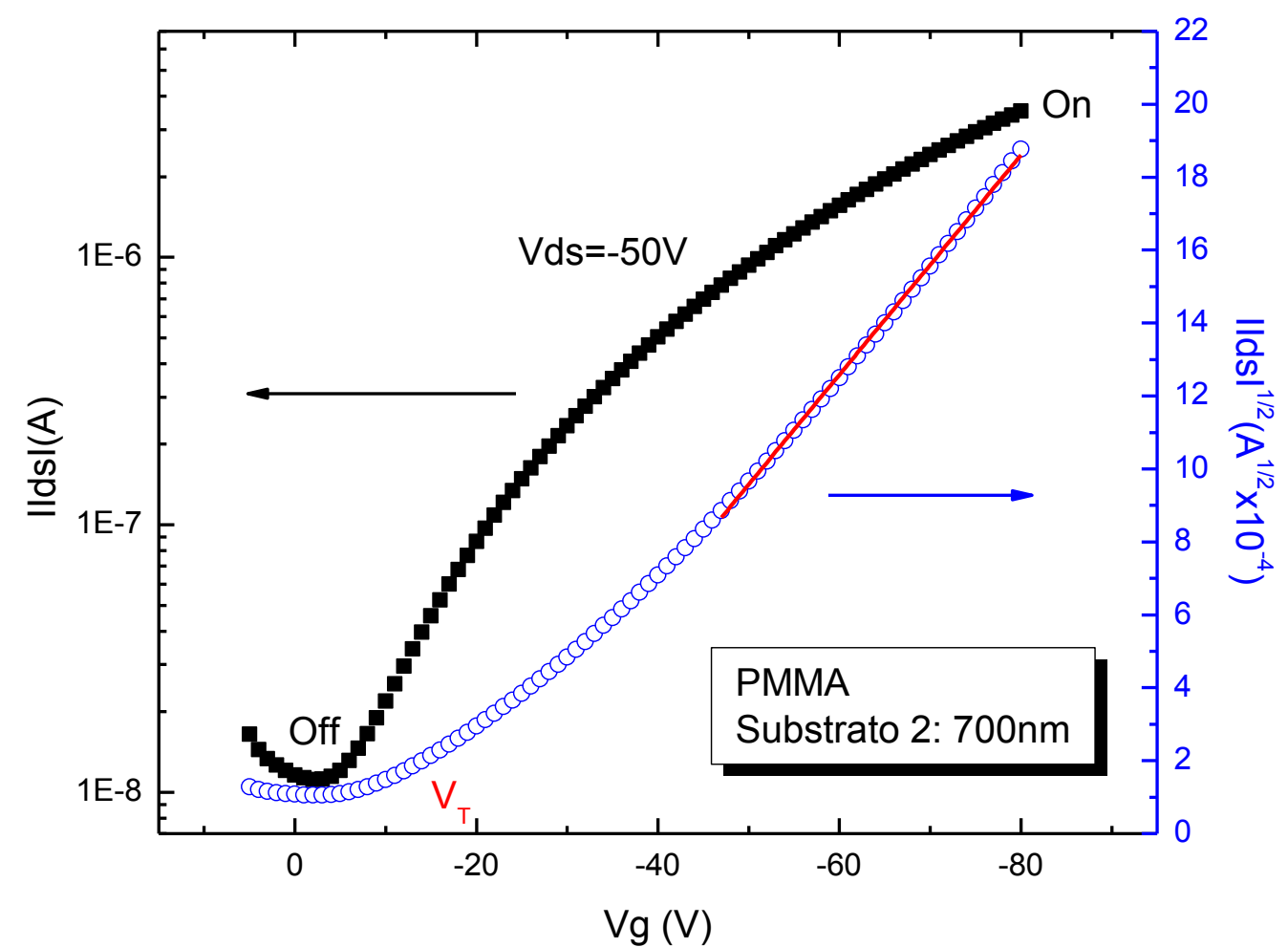

Figura 4.20 Curvas utilizadas para calcular as grandezas características do OFET de PMMA com 700nm de espessura para $\boldsymbol{V}_{\boldsymbol{d} \boldsymbol{s}}=\mathbf{- 5 0} \boldsymbol{V}$.

\section{Substrato 3: 570nm}

Agora mostra-se as curvas de transferência e as curvas de saída para um OFET desenvolvido com PMMA como camada isolante, de uma espessura de 570nm. 


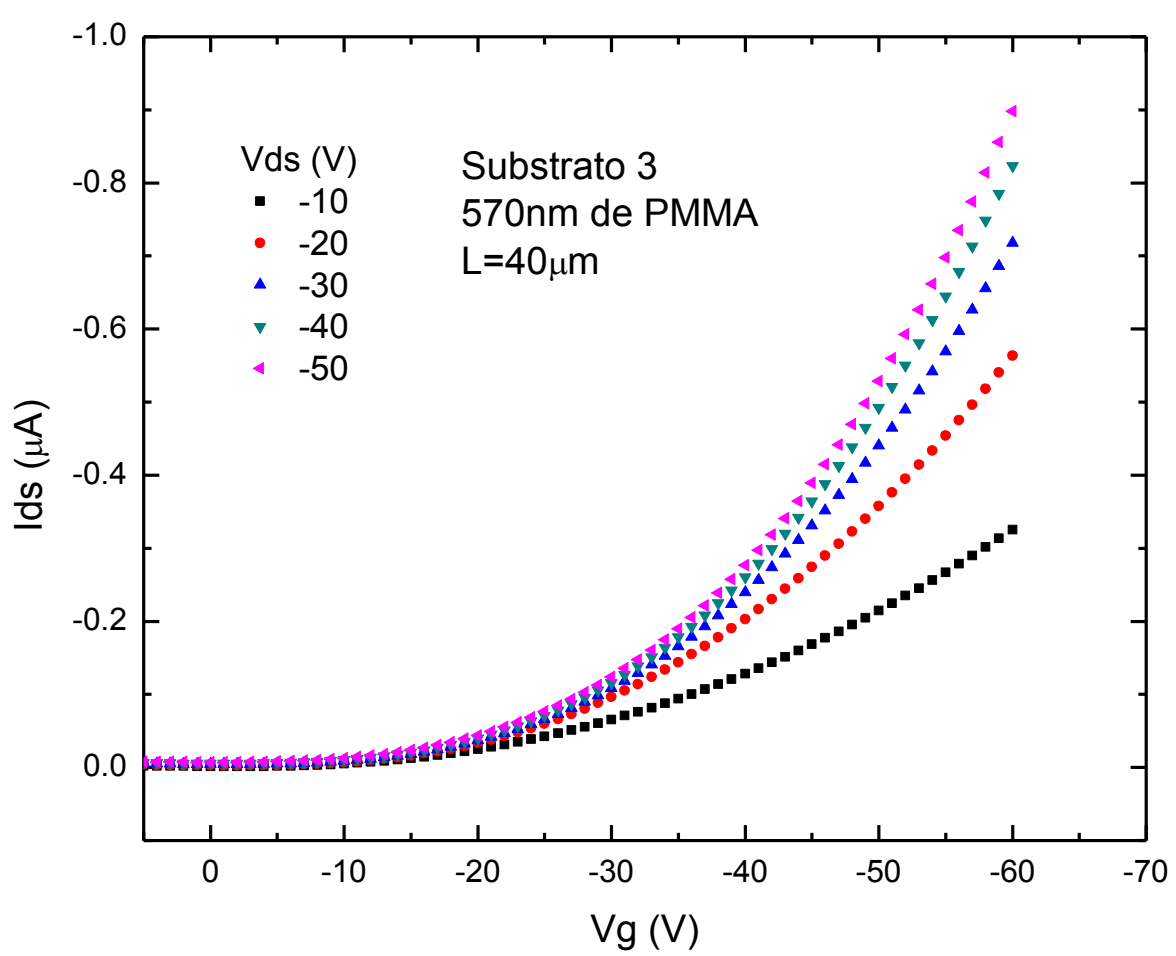

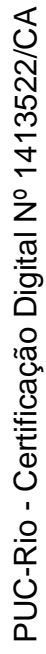

Figura 4.21 Curvas de transferência de um OFET com PMMA para o substrato 3 .



Figura 4.22 Curvas de saída do OFET com PMMA para o substrato 3 . 
Note-se que as curvas de transferência mostradas na Figura 4.21, para o OFET com o substrato 3 (570nm), apresentaram um comportamento característico de transistor, quer dizer, conforme a tensão $V_{g}$ aumentou, a corrente $I_{d s}$ também. A curva de transferência $V_{d s}=-50 \mathrm{~V}$ alcançou uma corrente $\left|I_{d s}\right|$ de $0.9 \mu \mathrm{A}$ para uma tensão no gate $V_{G}$ de $-60 \mathrm{~V}$. É possível distinguir claramente nas curvas de saída da Figura 4.22, o regime linear do regime de saturação, este fato pôde-se dever à alta capacidade por unidade de área do substrato 3 (Tabela 4.2) indicando assim, um comportamento típico de transistor.

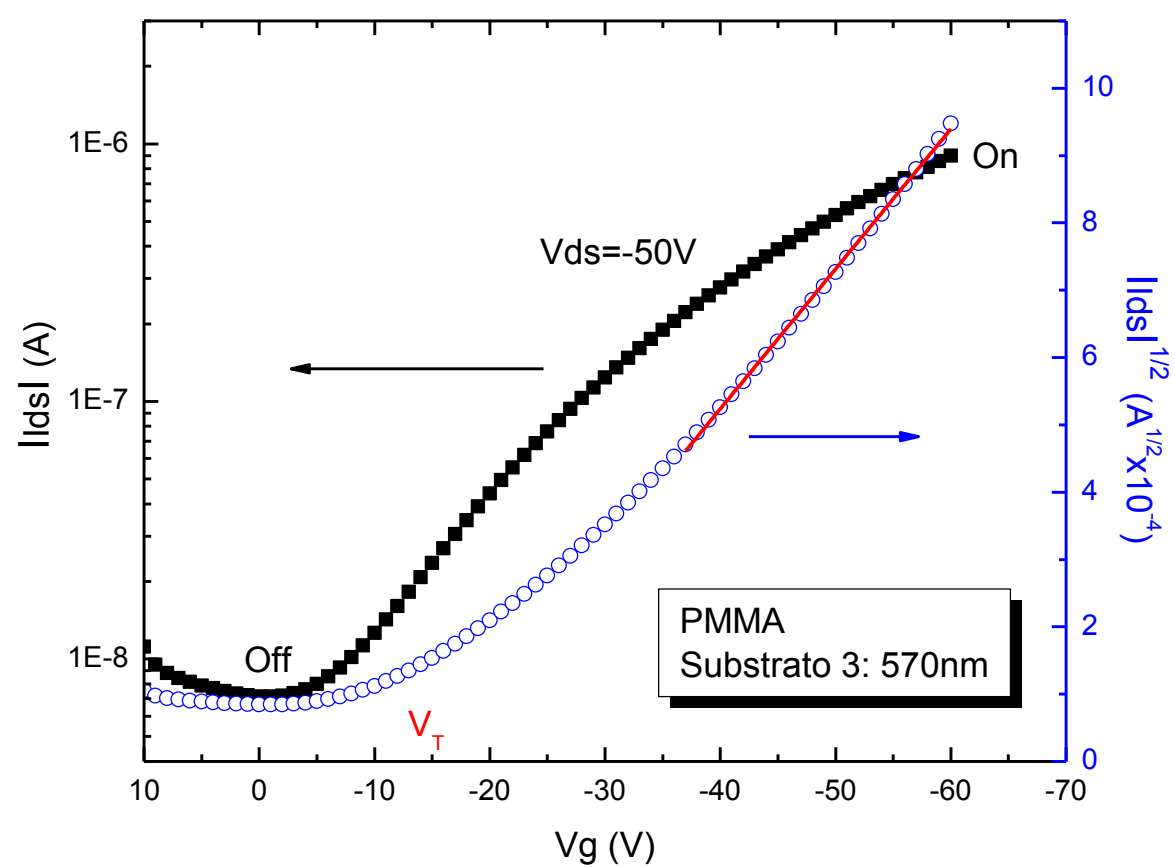

Figura 4.23 Curvas utilizadas para calcular as grandezas características do OFET de PMMA com 570nm de espessura para $\boldsymbol{V}_{\boldsymbol{d s}}=\mathbf{- 5 0}$.

Seguidamente, da Figura 4.23, obteve-se os parâmetros para calcular a mobilidade $\left(\mu_{s}\right)$ no regime de saturação, razão On/Off e a voltagem limiar $\left(V_{T}\right)$. A partir da curva de transferência de $V_{d s}=-50 \mathrm{~V}$, para um OFET fabricado com uma camada isolante de PMMA de 570nm de espessura.

\section{Substrato 4: 500nm}

Desta vez, são exibidas as curvas de transferência e as curvas de saída para um OFET fabricado com uma camada isolante de PMMA, de 500nm de espessura.

Pode-se observar, nas Figuras 4.24 e 4.25, que este OFET feito com o substrato 4 (500nm) tem um comportamento similar ao OFET com o substrato 3 (570nm), 
devido à proximidade nas espessuras, porém, atinge correntes menores. As curvas de transferência (Figura 4.24) e as curvas de saída (Figura 4.25) descrevem um comportamento esperado de transistor.

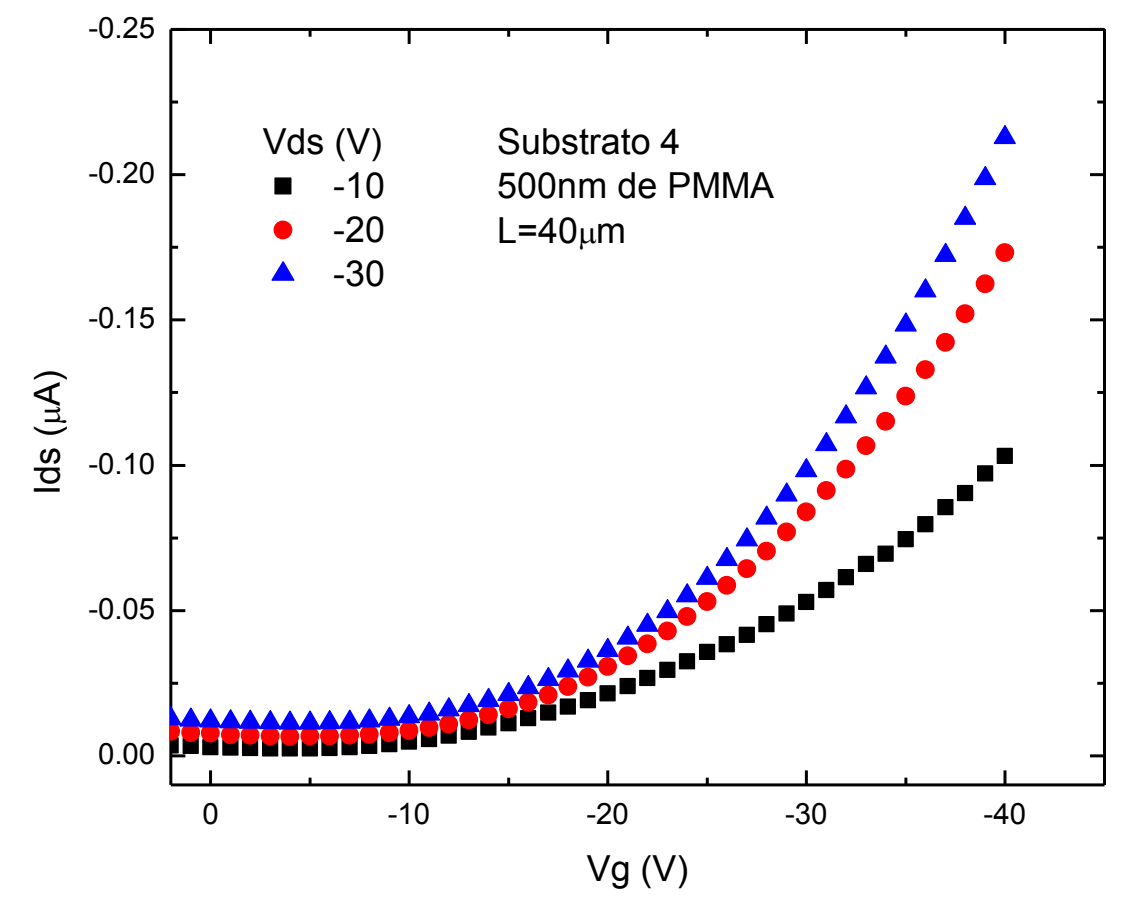

Figura 4.24 Curvas de transferência de um OFET com PMMA para o substrato

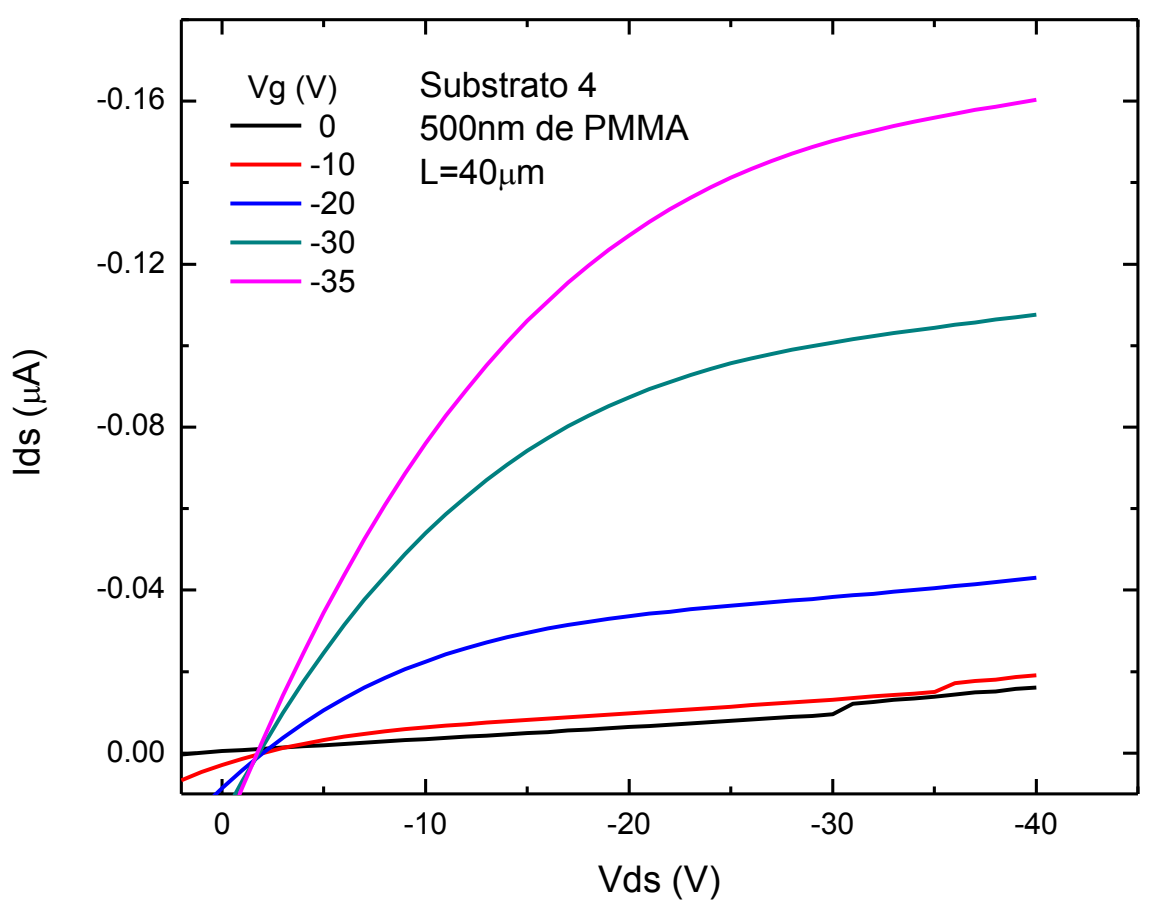

Figura 4.25 Curvas de saída do OFET com PMMA para o substrato 4.

Da Figura 4.26, extraiu-se os parâmetros para calcular a mobilidade $\left(\mu_{s}\right)$ no regime de saturação, razão On/Off e a voltagem limiar $\left(V_{T}\right)$. A partir da curva de 
transferência de $V_{d s}=-30 \mathrm{~V}$, para um OFET fabricado com uma camada isolante de PMMA de 500nm de espessura.



Figura 4.26 Curvas utilizadas para calcular as grandezas características do OFET de PMMA com 500nm de espessura para $\boldsymbol{V}_{\boldsymbol{d} \boldsymbol{s}}=\mathbf{- 3 0 V}$.

\begin{tabular}{|c|c|c|c|c|c|}
\hline Substrato & $\boldsymbol{V}_{\boldsymbol{d} \boldsymbol{s}}(\boldsymbol{V})$ & Espessura $(\mathrm{nm})$ & $\boldsymbol{\mu}\left(\boldsymbol{c m}^{\mathbf{2}} \boldsymbol{V}^{-\mathbf{1}} \boldsymbol{s}^{\mathbf{- 1}} \boldsymbol{x} \mathbf{1 0}^{-\mathbf{3}}\right)$ & $\boldsymbol{V}_{\boldsymbol{T}}(\boldsymbol{V})$ & On/Off \\
\hline 1 & -50 & 980 & $3.48 \pm 0.17$ & 33.60 & 16 \\
\hline 2 & -50 & 700 & $17.62 \pm 0.88$ & -18.21 & 305 \\
\hline 3 & -50 & 570 & $6.95 \pm 0.29$ & -14.76 & 126 \\
\hline 4 & -30 & 500 & $2.32 \pm 0.61$ & -7 & 18 \\
\hline
\end{tabular}

Tabela 4.8 Comparação entre as grandezas características dos OFETs de PMMA para as quatro espessuras.

Para efeitos de comparação, na Tabela 4.8, observa-se os resultados das mobilidades para os dispositivos com $L=40 \mu m$ de 4 substratos de PMMA.

Tem-se que frisar, que não pôde entrar na comparação o OFET de PMMA do substrato 4, pois ele mostrou-se instável para $V_{d s}$ maiores que $-40 \mathrm{~V}$. O OFET desenvolvido com PMMA de 700nm, foi quem se mostrou mais eficiente. No entanto, qualitativamente o OFET do substrato 3, teve um melhor desempenho, já que as curvas de transferência e as curvas de saída tiveram melhor modulação. 


\subsubsection{OFETs com PU(MEK)}

Os OFETs construídos com PU (dissolvido em MEK) tiveram a arquitetura TopGate/Bottom-Contacts (TGBC) e foram desenvolvidos com os seguintes materiais: Au/P3HT/PU/Ag. Os resultados aqui apresentados são para o canal de $L=60 \mu m$. E para efeitos de compreensão e comparação, serão divididos nas quatro espessuras de PU utilizadas, que foram denominadas de substratos. Como já se disse antes, a camada de P3HT não muda em cada tipo de OFET, ela tem $35 \mathrm{~nm}$ de espessura nesse caso. Uma das claras diferenças dos OFETs de PU com os de PMMA, foi que os OFETs de PU trabalharam com tensões $\left(V_{g}\right.$ e $\left.V_{d s}\right)$ baixas e os de PMMA com tensões $\left(V_{g}\right.$ e $\left.V_{d s}\right)$ altas. Este fato deveu-se a que os filmes do PU não mostraram um deslocamento das curvas $J x V$ do zero, no eixo da voltagem, quer dizer, que eles apresentaram características isolantes a partir de 0V. Em quanto que o deslocamento das curvas $J x V$ do zero, no eixo da tensão dos filmes de PMMA foi de mais de 5V, ou seja, que eles apresentaram um comportamento isolante a partir de $5 \mathrm{~V}$.

\section{Substrato 1: 380nm}

Para esta espessura não houve dispositivos OFETs que funcionassem. Talvez devido à menor espessura, as correntes de fuga não permitem um bom isolamento da camada.

\section{Substrato 2: 600nm}

A seguir, são mostradas as curvas de transferência e as curvas de saída para o OFET fabricado com PU como camada isolante, com uma espessura de 600nm.

Pode-se observar na Figura 4.27, que as curvas de transferência para o substrato 2 $(600 \mathrm{~nm})$ tiveram um comportamento característico de transistor, ou seja, conforme a tensão $V_{g}$ aumentou, a corrente $I_{d s}$ também. Mas se observou que as curvas de $V_{d s}=-0.4 \mathrm{~V} ;-0.6 \mathrm{~V}$ tenderam a deformar-se conforme aumentou a voltagem na porta $V_{G}$. Este comportamento pôde ter acontecido devido à pouca espessura do filme. 


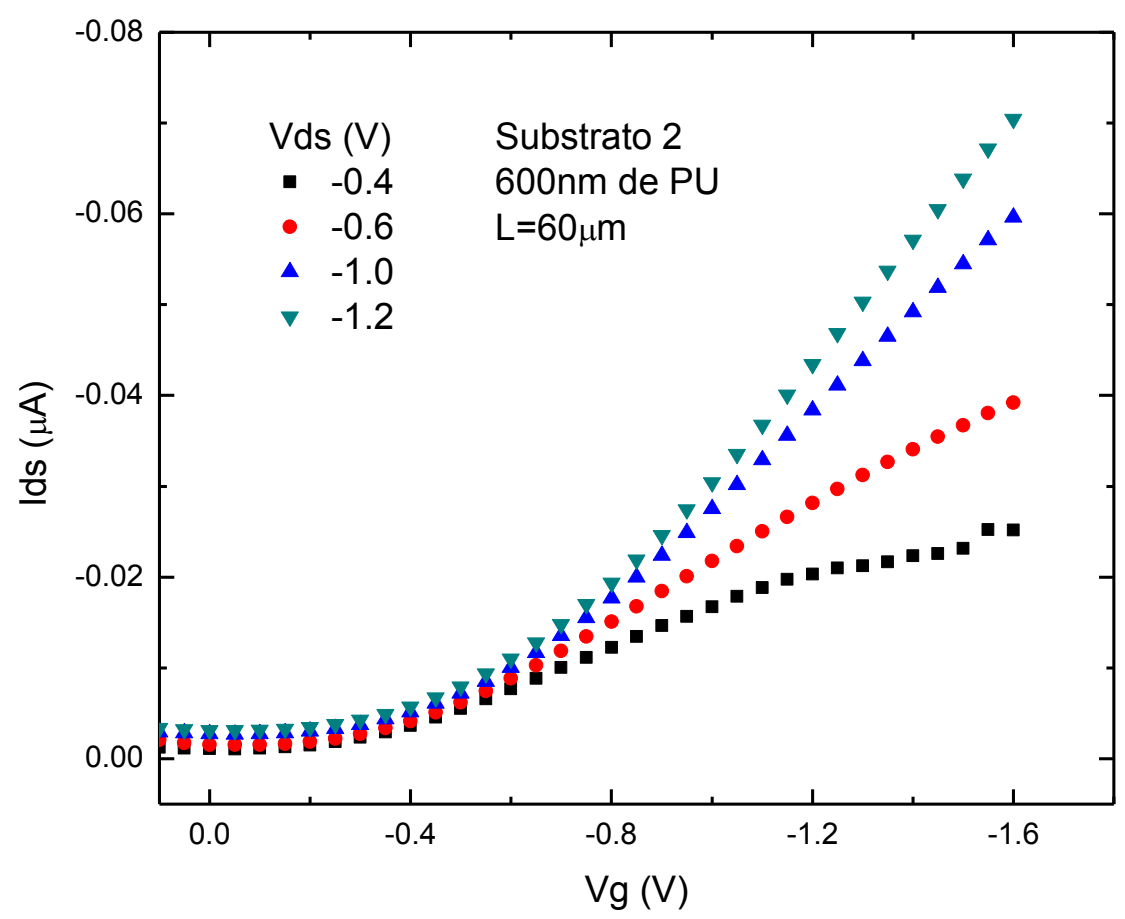

Figura 4.27 Curvas de transferência de um OFET com PU para o substrato 2.

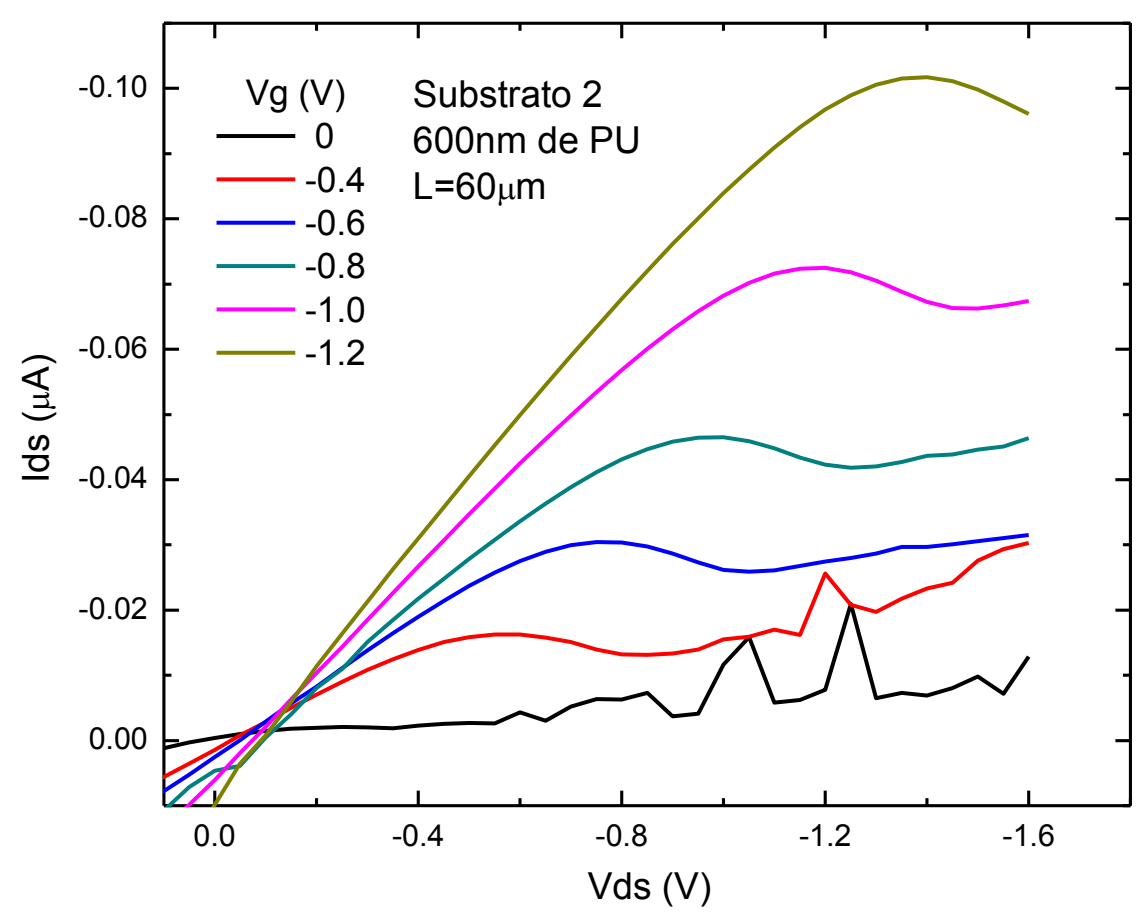

Figura 4.28 Curvas de saída do OFET com PU para o substrato 2 . 
Com respeito às curvas de saída, apresentadas na Figura 4.28, observa-se que geraram os típicos regimes linear e de saturação de um OFET. Exceto pelas curvas mal comportadas de $V_{G}=0 ;-0.4 V$, cujo comportamento pôde ter acontecido devido à espessura delgada do filme.

É necessário explicar a origem dos picos nas curvas de saída, segundo Lung et al., considera-se que é simplesmente pela absorção de agua e oxigênio por parte do isolante, já que as medidas são feitas no ar.

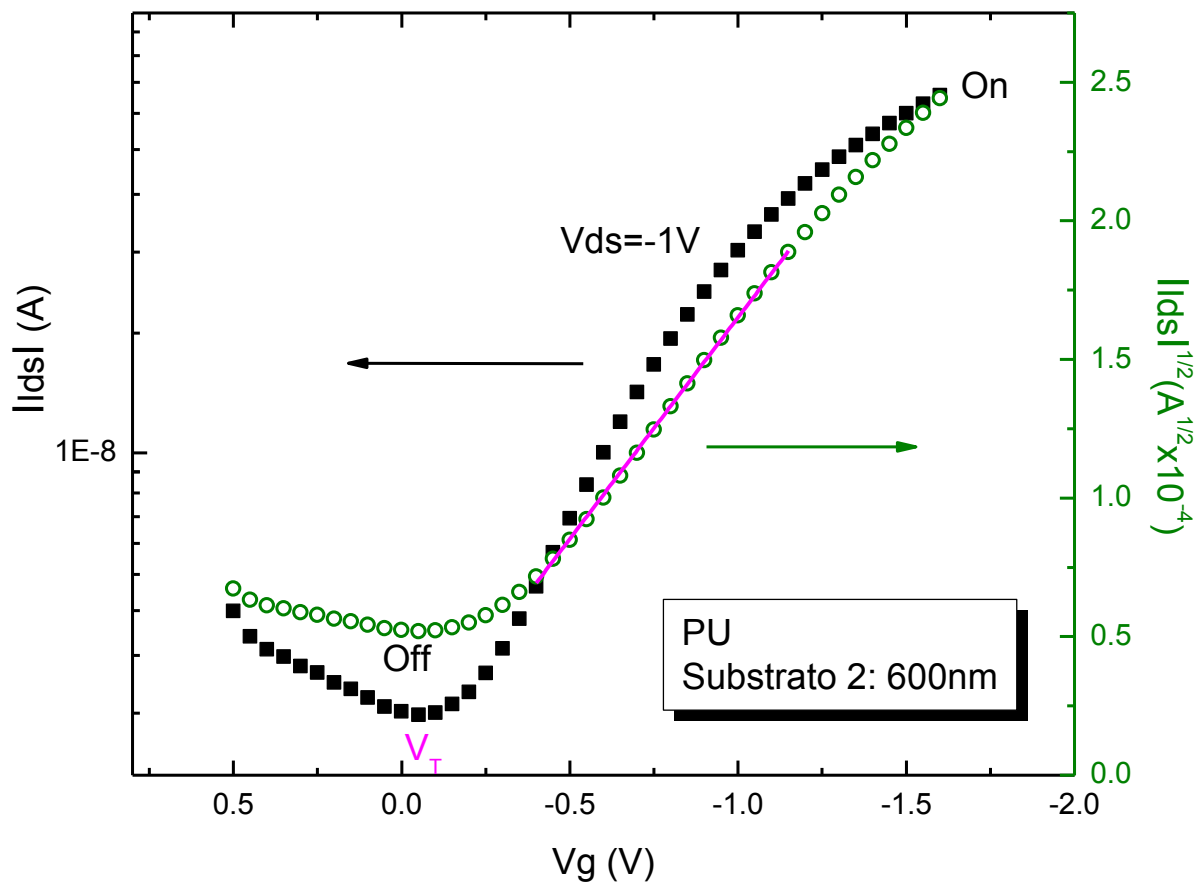

Figura 4.29 Curvas utilizadas para calcular as grandezas características do OFET de PU com 600nm de espessura para $V_{d s}=-1 V$.

Da Figura 4.29, extraiu-se os parâmetros para calcular a mobilidade $\left(\mu_{s}\right)$ no regime de saturação, razão On/Off e a voltagem limiar $\left(V_{T}\right)$ para o OFET feito com PU como camada isolante, tendo uma espessura de 600nm. Os cálculos foram feitos a partir da curva de transferência $V_{d s}=-1 \mathrm{~V}$.

\section{Substrato 3: 700nm}

Desta vez, são exibidas as curvas de transferência e as curvas de saída para um OFET fabricado com uma camada isolante de PU, com 700nm de espessura. 




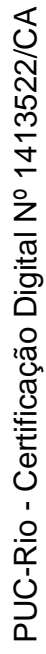

Figura 4.30 Curvas de transferência de um OFET com PU para o substrato 3 .

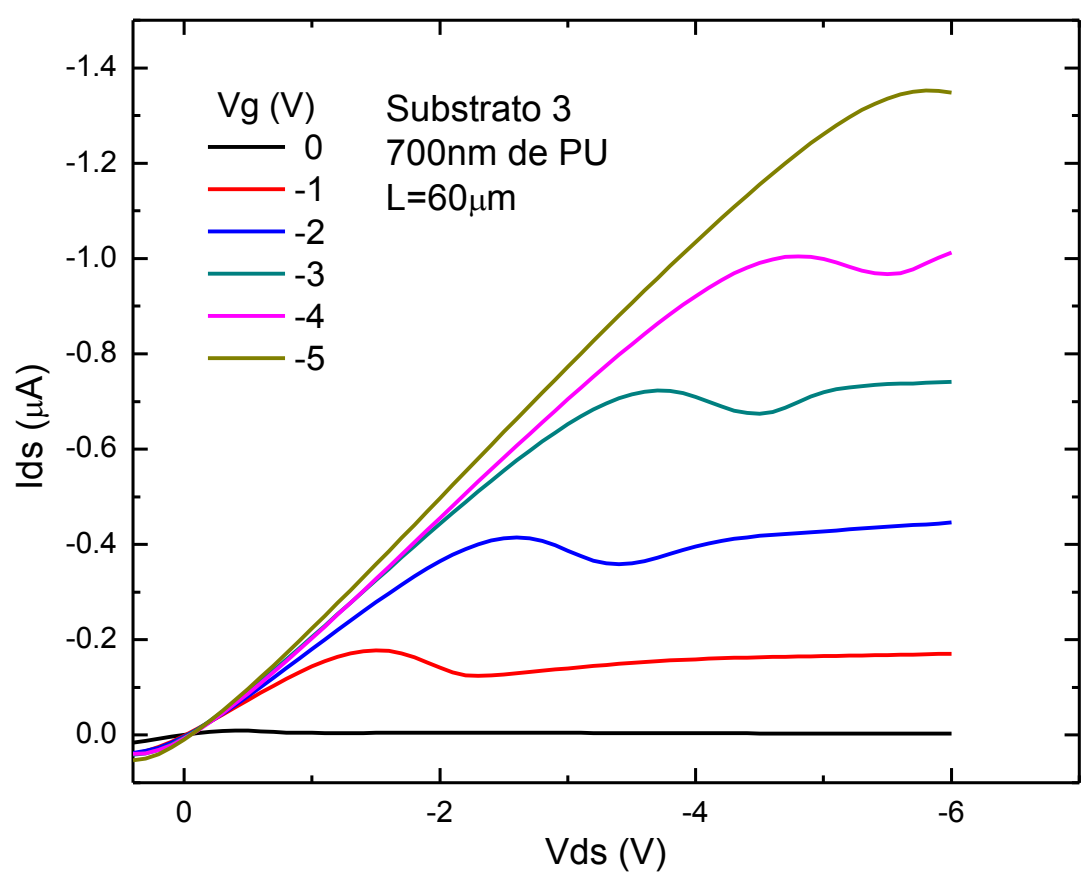

Figura 4.31 Curvas de saída do OFET com PU para o substrato 3 . 
Note-se que as curvas de transferência da Figura 4.30, para o OFET do substrato 3 (700nm) tiveram um comportamento característico de transistor, isto é, conforme a tensão $V_{g}$ aumentou, a corrente $I_{d s}$ também. Os OFETs com PU trabalharam com tensões baixas, um requisito para a maioria de aplicações orgânicas. A curva de transferência $V_{d s}=-5 \mathrm{~V}$ alcançou uma corrente $\left|I_{d s}\right|$ de $1.4 \mu \mathrm{A}$ para uma tensão no gate $V_{G}$ de $-6 \mathrm{~V}$, ou seja, com uma tensão baixa se atingiu uma corrente alta; para um dispositivo OFET, isso é ideal. Uma anomalia foi que a curva $V_{d s}=-5 V$ começou a abrir-se a partir de $V_{G}=-5 V$, fazendo com que a corrente $\left|I_{d s}\right|$, não aumente mais.

Com respeito às curvas de saída, mostradas na Figura 4.31, é possível distinguir claramente o regime linear do regime de saturação. Este fato pôde-se dever à alta capacidade por unidade de área do substrato 3 (Vide a Tabela 4.6), indicando assim, um comportamento típico de transistor. A origem dos picos pôde ter sido devido a um fato trivial já explicado no transistor do substrato 2 de PU.

Seguidamente, da Figura 4.32, obteve-se os parâmetros para calcular a mobilidade $\left(\mu_{s}\right)$ no regime de saturação, razão On/Off e a voltagem limiar $\left(V_{T}\right)$, a partir da curva de transferência de $V_{d s}=-1 V$, para um OFET fabricado com uma camada isolante de PU de 700nm de espessura.

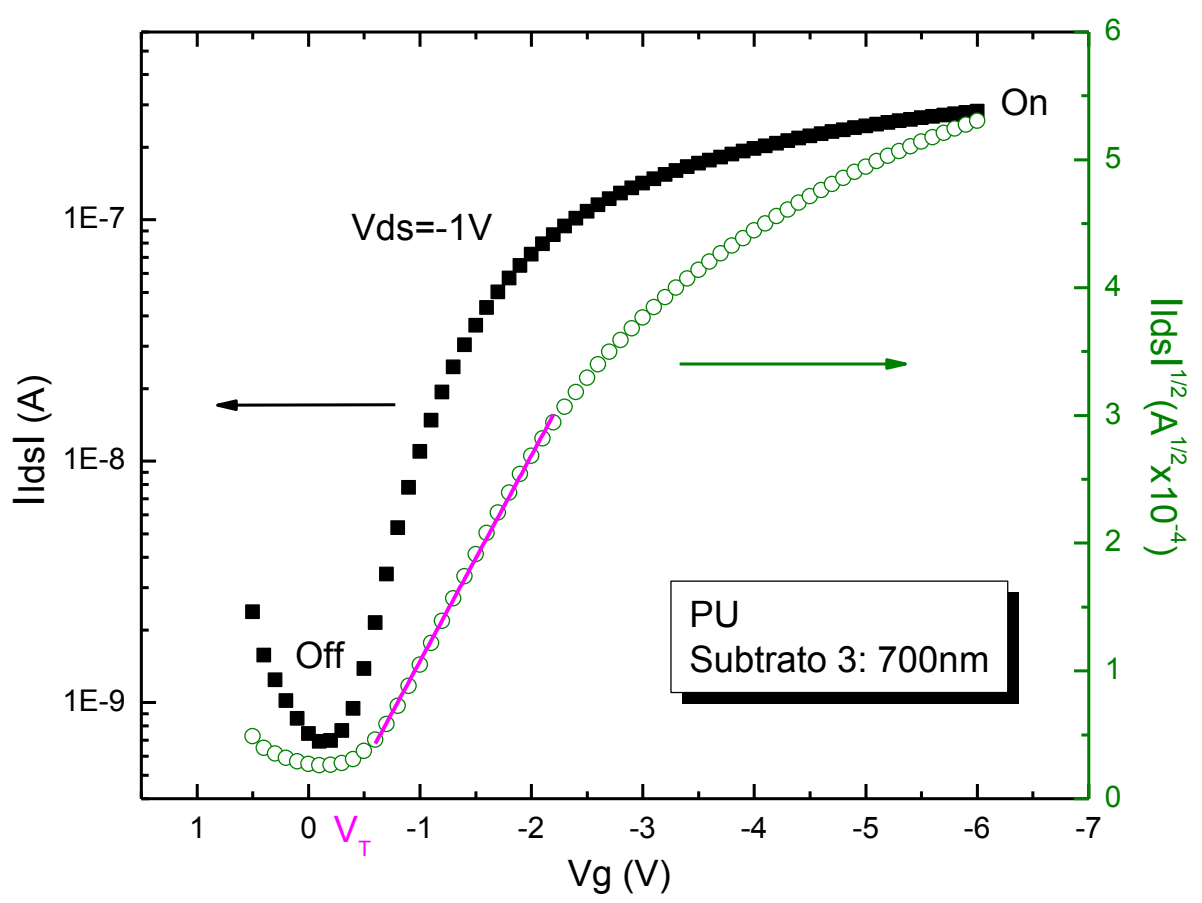

Figura 4.32 Curvas utilizadas para calcular as grandezas características do OFET de PU com 700nm de espessura para $\boldsymbol{V}_{\boldsymbol{d s}}=\mathbf{- 1} \boldsymbol{V}$. 
A partir da curva de transferência de $V_{d s}=-5 V$, do dispositivo OFET de PU, com o substrato 3 utilizado como dielétrico, extraiu-se da Figura 4.33, todos os parâmetros para calcular a mobilidade $\left(\mu_{s}\right)$ no regime de saturação, razão On/Off e a voltagem limiar $\left(V_{T}\right)$.

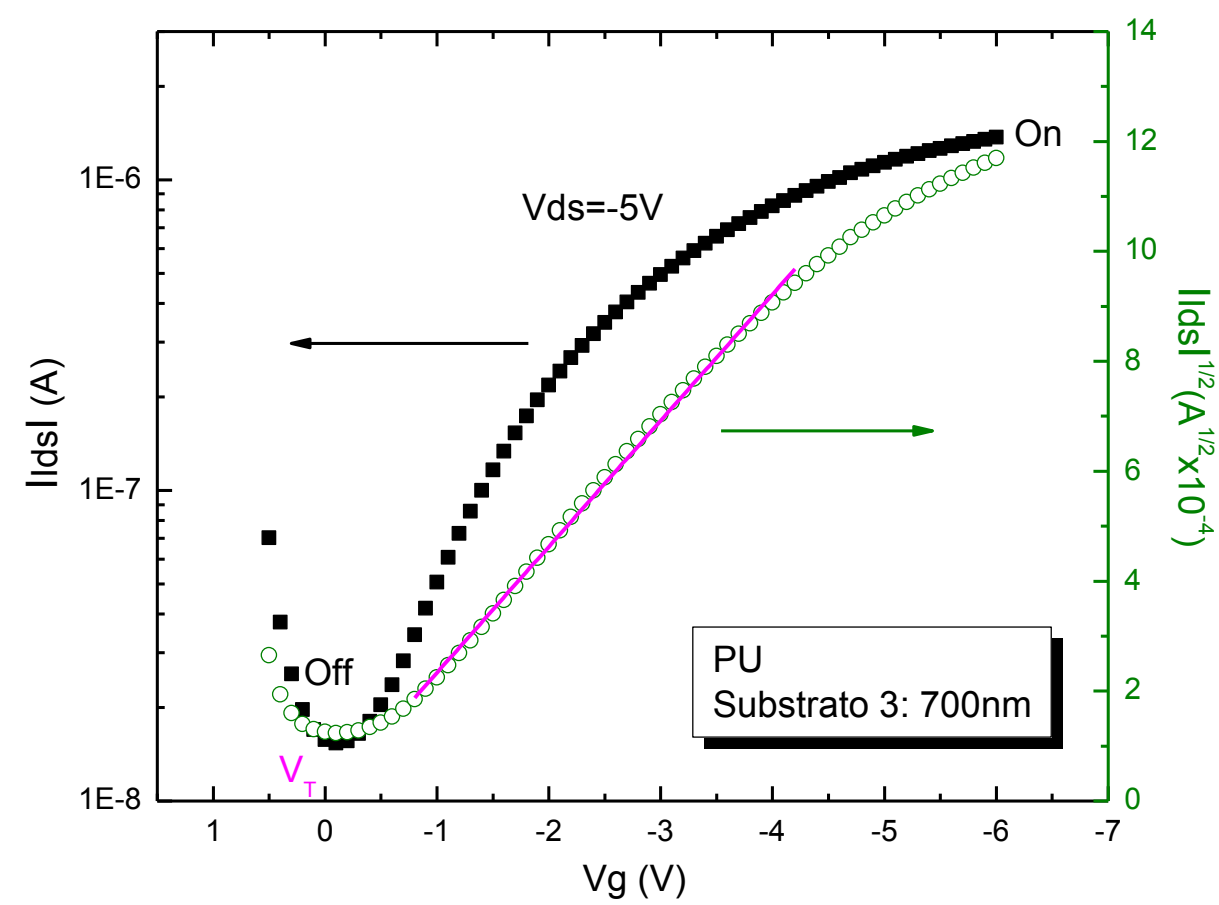

Figura 4.33 Curvas utilizadas para calcular as grandezas características do OFET de PU com 700nm de espessura para $\boldsymbol{V}_{\boldsymbol{d s}}=\mathbf{- 5} \boldsymbol{V}$.

Para conhecer a diferença entre as grandezas características deste OFET, porém com $V_{d s}$ diferentes, fez-se a seguinte Tabela 4.9:

\begin{tabular}{|c|c|c|c|}
\hline $\boldsymbol{V}_{\boldsymbol{d} \boldsymbol{s}}(\boldsymbol{V})$ & $\boldsymbol{\mu}\left(\boldsymbol{c m}^{\mathbf{2}} \boldsymbol{V}^{\mathbf{- 1}} \boldsymbol{s}^{\mathbf{1}}\right)$ & $\boldsymbol{V}_{\boldsymbol{T}}(\boldsymbol{V})$ & On/Off \\
\hline-1 & $0.62 \pm 0.04$ & -0.33 & 380 \\
\hline-5 & $1.25 \pm 0.09$ & 0.02 & 90 \\
\hline
\end{tabular}

Tabela 4.9 Diferença entre as grandezas características do OFET de PU com 700nm de espessura e com $\boldsymbol{V}_{\boldsymbol{d}}$ diferentes.

Conclui-se que quanto maior o $\left|V_{d s}\right|$, maior mobilidade e voltagem limiar, porém, menor razão On/Off. Com $V_{d s}=-5 V$ conseguiu-se o máximo desempenho do dispositivo, pois foi a maior mobilidade atingida. Este OFET de PU apresentou mobilidades altas, em seu melhor performance, a mobilidade para o P3HT num dispositivo de PU foi de $1.25 \mathrm{~cm}^{2} / \mathrm{V}$.s. Sendo a maior mobilidade registrada para o 
P3HT num dispositivo até esta data (Wang et al., 2003; Singh et al., 2008). Este resultado está sendo corroborado no laboratório do LOEM.

\section{Substrato 4: 750nm}

Neste caso, são mostradas as curvas de transferência e as curvas de saída para o OFET fabricado com PU como camada isolante, com uma espessura de 750nm.

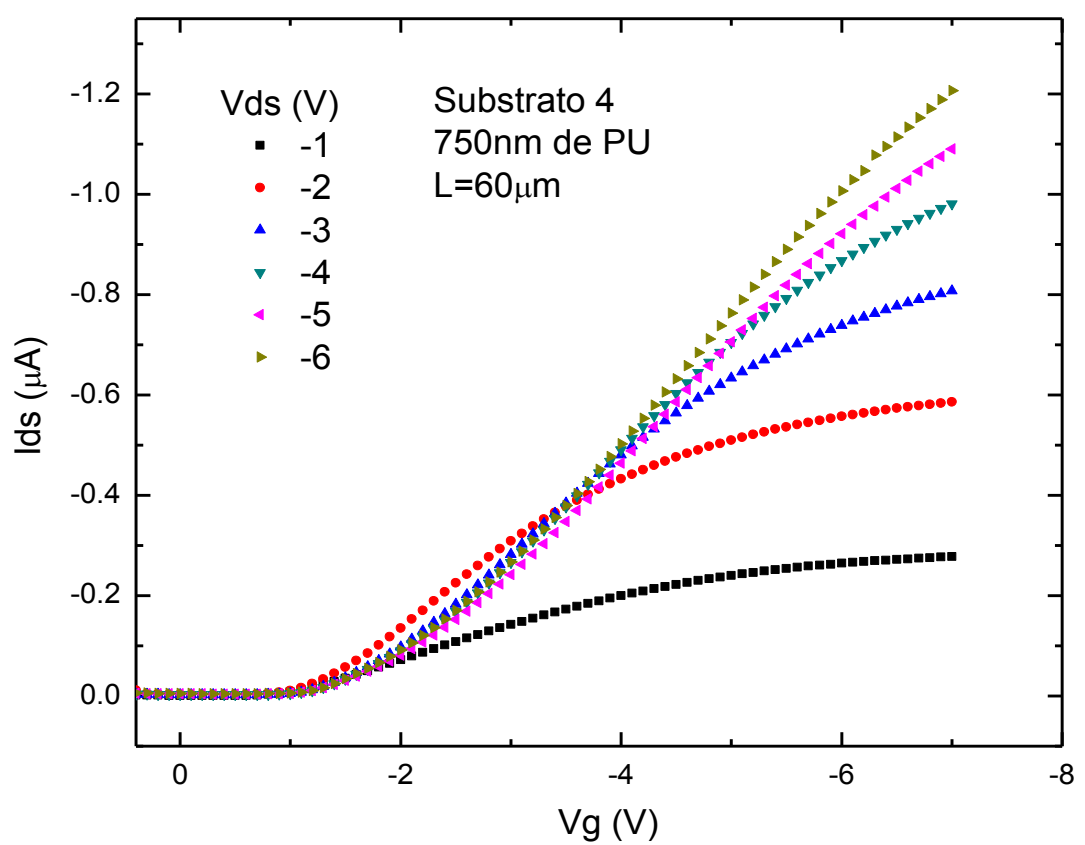

Figura 4.34 Curvas de transferência de um OFET com PU para o substrato 4.



Figura 4.35 Curvas de saída do OFET com PU para o substrato 4. 
Na Figura 4.34 e 4.35 , pôde-se observar que este OFET feito com o substrato 4 $(750 \mathrm{~nm})$ teve um comportamento bem parecido ao OFET com o substrato 3 $(700 \mathrm{~nm})$, devido à proximidade nas espessuras, porém, atingiu correntes menores. As curvas de transferência (Figura 4.34) e as curvas de saída (Figura 4.35) foram bem moduladas e descreveram um comportamento típico de um transistor. No entanto algumas curvas $V_{d s}$ cruzaram-se, e se continuou observando a anomalia das curvas $V_{d s}$, ou seja, que quando a tensão da porta $V_{G}$ aumentou, as curvas $V_{d s}$ começaram-se a abrir, fazendo com que a corrente $\left|I_{d s}\right|$ já não aumente como no inicio, e como consequência a mobilidade também não.

Seguidamente, da Figura 4.36, extraiu-se os parâmetros para calcular a mobilidade $\left(\mu_{s}\right)$ no regime de saturação, razão On/Off e a voltagem limiar $\left(V_{T}\right)$ para o OFET feito com PU como camada isolante, tendo uma espessura de $750 \mathrm{~nm}$. Os cálculos foram feitos a partir da curva de transferência $V_{d s}=-1 \mathrm{~V}$.



Figura 4.36 Curvas utilizadas para calcular as grandezas características do OFET de PU com $750 \mathrm{~nm}$ de espessura para $V_{d s}=-1 V$. 
Para efeitos de comparação, na Tabela 4.10, mostra-se os resultados das mobilidades para o dispositivos de $L=60 \mu m$ de 3 substratos de PU para uma tensão igual de $V_{d s}=-1 V$.

\begin{tabular}{|c|c|c|c|c|}
\hline Substrato & Espessura d $(\mathrm{nm})$ & $\mu\left(\mathrm{cm}^{2} V^{-1} \mathrm{~s}^{-1}\right)$ & $V_{T}(V)$ & On/Off \\
\hline 2 & 600 & $0.45 \pm 0.02$ & -0.03 & 22 \\
\hline 3 & 700 & $0.62 \pm 0.07$ & -0.33 & 380 \\
\hline 4 & 750 & $0.81 \pm 0.04$ & -0.48 & 260 \\
\hline
\end{tabular}

Tabela 4.10 Comparação entre as grandezas características dos OFETs de PU para três espessuras com $V_{d s}=-1 V$.

Neste caso dos OFETs com PU, observa-se uma relação entre espessura, mobilidade e tensão limiar. Em quanto aumentou a espessura, a mobilidade e $\left|V_{T}\right|$ também aumentaram. Porém, qualitativamente o OFET desenvolvido com o substrato $3(700 \mathrm{~nm})$ foi o melhor comportado. 


\section{Conclusões}

A interdisciplinaridade é fundamental para o desenvolvimento da ciencia, e sobremaneira na Eletrônica Orgânica, pois se está na busca de novos compostos e na fabricação de dispositivos cada vez mais eficientes. Nesta dissertação diversas áreas atuaram em conjunto: a Química, a Física e a Engenharia de materiais; com a utilização de polímeros já conhecidos, mas não utilizados na construção de dispositivos OFETs.

Inicialmente pesquisou-se sobre polímeros isolantes e semicondutores orgânicos (SOs) com seus respectivos solventes, que acostumam ser usados na construção de OFETs. Decidiu-se utilizar como único SO o P3HT e como polímeros dielétricos optou-se dois conhecidos: o PMMA e o PVA. E como possiveis polímeros isolantes não utilizados ainda na fabricação de OFETs: o FORMVAR e o PU.

Caracterizou-se filmes finos depositados por spin coating do P3HT, PMMA, PVA, FORMVAR e PU. Nessa caracterização, mediu-se quatro espessuras para cada isolante e suas respectivas rugossidades. Para o P3HT caracterizou-se só uma espessuras e sua rugossidade também. Após esta caracterização, soube-se que os filmes de PVA tem uma rugosidade mínima e o FORMVAR(cloroformio) e PU(THF) tem rugossidade altas, sendo inviaveis para sua utilização em OFETs. Esta rugosidade é uma consequencia dos solventes volateis do FORMVAR e PU.

Posteriormente foram construidos e caracterizados capacitores orgânicos com os quatro polímeros dielétricos: PMMA, PVA, FORMVAR e PU. Da caracterização elétrica destes capacitores de placas paralelas, obtiveram-se as curvas $J x V$, as capacidades por unidade de área e as constantes dielétricas de cada polímero isolante. A partir destas caracterizações, avaliou-se a potencialidade e a viabilidade destes polímeros dielétricos para a construção de OFETs.

Produto desta caracterização elétrica, confirmaram-se as propriedades dielétricas do PMMA. No final da pesquisa, conseguiu-se um tratamento para evaporar a água dos filmes de PVA e assim conferir suas propriedades diétricas. Nao houve 
tempo para tentar utilizar estes filmes na construção de OFEts. As tentativas de fabricar OFETs com outros tratamentos térmicos testados foi infrutuosa.

Também se soube mediante uma análise das curvas $J x V$ que o FORMVAR(cloroformio) e PU(MEK) tem correntes de fuga mínimas e que o deslocamento das curvas $J x V$ do zero, no eixo da tensão, foi de até $1 \mathrm{~V}$ e nulo, respectivamente. Este fato indicaria que podem trabalhar a baixas tensões. Além disso, calculou-se que a constante dielétrica do FORMVAR é 3,5 e do PU esta entre os valores de 3,7-6. Todas estas propriedades dielétricas, confirmaram suas propriedades isolantes, porém só o PU(MEK) resultou ser um bom candidato para a construção de OFETs. Pois o FORMVAR gerou filmes muito rugosos, devido ao solvente volátil.

Tem-se que salientar, que nas curvas $J x V$ do PMMA, observou-se um deslocamento de $5 \mathrm{~V}$ das curvas $J x V$ do zero, no eixo da tensão; que indicaria o porque os OFETs fabricados com este isolante funcionam só a partir de $5 \mathrm{~V}$. A diferença apresentada nas curvas $J x V$ do PU(MEK), foi que o deslocamento das curvas $J x V$ do zero, no eixo da voltagem foi nulo. Este fato indicaria porque os OFETs com PU(MEK) funcionan a partir de tensões baixas. Parece ser, que este deslocamento das curvas $J x V$ do zero, no eixo da tensão, impede a operação dos OFETs a voltagens menores que o deslocamento.

Primeiro fabricamos OFETs conhecidos, começamos com o PMMA, com a arquitetura Top-Gate/Bottom-Contacts (TGBC) e os seguintes materiais Au/P3HT/PMMA/Ag, para o PMMA utilizaram-se as quatro espessuras já caracterizadas e as informações dielétricas obtidas do capacitor orgânico de PMMA. Os OFETs foram caracterizados com sucesso, observando-se um bom desempenho deles, com valores de mobilidade, tensão limiar e razão On/Off concordantes com a literatura. Dos OFETs de PMMA, soube-se que operam a partir de tensões maiores que $5 \mathrm{~V}$, pelo qual são inviáveis para muitas das aplicações da eletrônica orgânica. O OFET de PMMA com melhor desempenho indicou para a mobilidade $17,62 \times 10^{-3} \mathrm{~cm}^{2} V^{-1} s^{-1}$ e para a razão On/Off 305 .

Outro problema resultou ser que os solventes do FORMVAR que é o clorofórmio e para o PU o tetraidrofurano; são também solventes do P3HT, quer dizer os 
solventes não são ortogonais. Então a chave foi encontrar outros solventes para estes isolantes. Após muitos testes, encontrou-se um solvente parcial para o PU, era o mesmo que para o PMMA, ou seja, o MEK.

Ao fim, desenvolveram-se OFETs com o PU dissolvido em MEK, com a mesma arquitetura utilizada para o PMMA, quer dizer, Top-Gate/Bottom-Contacts (TGBC) e com os materiais nesta ordem Au/P3HT/PU/Ag. Para o PU utilizaramse as quatro espessuras já caracterizadas e as informações dielétricas obtidas do capacitor orgânico de PU.

Os novos OFETs de PU apresentaram tensões de operação baixas, menores que $5 \mathrm{~V}$, que é um requisito para a integração destes OFETs em aplicações orgânicas atuais. Estes OFETs conseguiram atingir correntes da ordem de $\mu A$, ou seja, o dispositivo produziu corrente altas com tensões baixas aplicadas. Os OFETs de PU apresentaram mobilidades altas, em seu melhor performance a mobilidade registrada para o P3HT num dispositivo de PU foi de $1.25 \mathrm{~cm}^{2} / \mathrm{V}$.s, sendo a maior mobilidade registrada para o P3HT num dispositivo até esta data. Este resultado está sendo corroborado no laboratório do LOEM. Neste mesmo dispositivo a tensão limiar foi de 0.02 e a razão On/Off de 90. 


\section{Referências Bibliográficas}

ADERNE, E. Dissertação de Mestrado, Desenvolvimento e caracterização de OLEDs baseados em sondas fluorescentes. PUC-Rio, 2013.

ADVANCED INDUSTRIAL SCIENCE AND TECHNOLOGY-AIST. <http://www.aist.go.jp/aist_e/latest_research/2004/20041118/20041118.html>. Retirado em Abril, 2016.

AMERICAN CHEMISTRY COUNCIL (ACC).

<https://polyurethane.americanchemistry.com>. Retirado em Abril, 2016.

ASSADI, A. et al. Appl.Phys. Lett., 53, 195, 1988.

AVILA, H. Dissertação de Mestrado, Desenvolvimento e caracterização de dispositivos orgânicos eletroluminescentes (OLEDs) baseados em novos complexos tetrakis 8-hidroxiquinolina de terras raras. Puc-Rio, 2012.

BALDO, M. A.; FORREST, S. R. Physical Review B, 64 (2001) 085201.

BAO, Z.; DODABALAPUR, A.; LOVINGER, A.J. Soluble and processable regioregular poly(3-hexylthiophene) for thin film field-effect transistor applications with high mobility. Applied Physics Letters, v.69, n. 26, p. 4108, Oct. 1996.

BENVENHO, A. R. V. Tese de Doutorado, Caracterização elétrica e óptica de novos Poli(bifenilenovinileno)s e utilização do poli(9,9-dioctil-1,4-fluorenileno vinileno) na construção de dispositivos emissores de luz com novas combinações de materiais, UFPR, 2005.

BLOM, P. W. M.; DE JONG M. J.; BREEDIJK, S. Applied Physics Letters, 71 (1997) 930.

BOSEOK, K.; WI HYOUNG L.; KILWON CHO. Recent Advances in Organic Transistor Printing Processes, Applied Materials and Interfaces, 2013, 5, 2302 (Invited Review Article). 
BOTTEGER, H. E. V. and BRYKSIN, V. Hopping Conduction in Solids. (Akademie Verlag Berlin, 1985).

BRÜTTING, W. Physics of Organics Semiconductors. (WILEY-VCHVerlag, 2005).

BUNDGAARD, E.; KREBS, F.C; Low band gap polymers for organic photovoltaics; Solar energy Materials \& Solar Cells, v.91, p. 954-985, 2007.

CAMPBELl, A. J.; BRADLEY, D. D. C.; LIDZEY, D. G. Journal of Applied Physics 82 (1997) 6326.

CHANG, J. F. et al. Chem. Mater., 16, 4772 (2004).

CHEN, T. A.; WU, X.; RIEKE, R.D. Regiocontrolled synthesis of poly(3-alkyl thiophenes) mediated by rieke zinc: their characterization and solid-state properties. Journal of the American Chemical Society, v. 117, n.1, p. 233-244, Jan. 1995.

DIMITRAKOPOULOS, CD; MASCARO, DJ. Organic thin-film transistors: A review of recent advances, IBM Journal of Research and Development 45 (1), 11-27, 2001.

DOI, M. Introduction to polymer Physics, Oxford Science Publications, 1997.

GLOBAL POLYMER INDUSTRIES INC.

<http://www.globalpolymer.com/index.htm>. Retirado em Abril, 2016.

GUANGMING, W. et al. Increased mobility from regioregular poly(3hexylthiophene) field-effect transistors. J. Appl. Phys., Vol. 93, No. 10, 15 May 2003.

HE, YAN. et al. A high-mobility electron-transporting polymer for printed transistors, NATURE, Vol 457-5, February, 2009.

HOROWITZ, G. Organic Field-Effect Transistor, Advanced Materials 5, 10, 1998.

HOROWITZ, G. Organic thin film transistors: From theory to real devices. J. Mater. Res. V.19, n.7, p. 1946-1962, jul, 2004. 
HÜMMELGEN, I. A. et. al. Applied Physics Letters, 68 (1996) 3194.

HUNG, L.S.; CHEN, C.H. Recent progress of molecular organic electroluminescent materials and devices, Materials Science and Engineering, R:Reports, v.39, p.143-222, 2002.

KANO, M.; MINARI, T.; TSUKAGOSHI, K. Improvement of subthreshold current transport by contact interface modification in p-type organic fieldeffect transistor. Applied Physics Letters, v.94, n.14, p. 143304, Aug. 2009.

KAO, K. C.; HWANG, W. Electrical Transport in Solids (Pergamon Press, 1981).

KOEHLER, M. Dissertação de Mestrado, Universidade Federal de Santa Catarina, (2000)

LEGNANI, C. Dissertação de Mestrado, Produção e caracterização de dispositivos orgânicos eletroluminescentes (OLEDs) baseados em complexos supramoleculares. PUC-Rio, 2006.

LORENZINI, R.G. et. al. The rational design of polyurea \& polyurethane dielectric materials, Polymer (2013) 1-5.

LUNG-KAI, MAO. et. al. The role of water in the device performance of $\mathbf{n}$ type PTCDI-C8 organic field-effect transistors with solution-based gelatin dielectric. Organic Electronics 15 (2014) 920-925.

MACIEL ALEXANDRE, C. Tese de Doutorado, Fabricação e estudo das propriedades de transporte de transistores de filmes finos orgânicos, IFSC, USP, 2012.

MADELUNG, O., Introduction to Solid State Physics, Springer, 1996.

MALIK, S.; NANDI, A. K. Crystallization mechanism of regioregular poly(3alkyl thiophene)s. Journal of Polymer Science Part B: Polymer Physics, v.40, n.18, p. 2073-2085, Sept. 2002.

MEIER, H. Organic Semiconductors: Dark and photoconductivity of organic solids, Monographs in modern chemistry-vol.2, 1974. 
MUHARREM, G.; TUNCAY, T. Enhancement of Dielectric Characteristics of Polyvinyl Alcohol (PVA) Interfacial Layer in Au/PVA/n-Si Structures by Bi2O3 Disperse, Int. J. Appl. Ceram. Technol., 10 [S1] E64-E69 (2013).

NATORY, A.Y. Dissertação de Mestrado, Universidade Federal do Paraná, Curitiba, 2003.

O'NEILL, M.; KELLY, S. M. Ordered Materials for Organic Electronics and Photonics, Advanced Materials, v. 23, n. 5, p. 566-584. 2011.

ORGANIC ELECTRONICS ASSOCIATION (OEA), Brochure organic and printed electronics, 3. ed, 2009.

ORGANIC SEMICONDUCTORS WORLD. <http://www.orgworld.de/>. Retirado em Janeiro, 2016.

OSSILA. <http://www.ossila.com/> Retirado em Abril, 2016.

PARK, JI HOON. et al. Studies on poly(methyl methacrylate) dielectric layer for field effect transistor: Influence of polymer tacticity, Thin Solid Films 515 (2007) 4041-4044.

POPE, M. and SWENBERG, C.E. Electronic Processes in organic crystals and Polymers, Oxford University Press, 1999.

PUIGDOLLERS, J. et al. Journal of Non-Crystaline Solids, 338 (2004) 617.

QUIRINO, W. G. Dissertação de Mestrado, Produção e caracterização de dispositivos orgânicos eletroluminescentes (OLEDs) baseados em complexos $\boldsymbol{\beta}$-dicetonatos de Terras-Raras, PUC-Rio, 2007.

REZENDE, S. M. A Física de Materiais e Dispositivos Eletrônicos, Editora da Universidade Federal de Pernambuco, Recife, 1996.

RIORDAN, M. and HODDESON, L. Crystal Fire: The Invention, Development and Impact of the Transistor, IEEE SSCS NEWS, Spring 2007.

ROSSI, L. Tese de Doutorado, Transistores Orgânicos de Efeito de Campo em Arquitetura Vertical, UFPR, 2013. 
SCHMIDT, W. Materiais Elétricos, Isolantes e Magnéticos, Volume 2, 2.a edição revista, Editora Blucher, Brasil, 1979.

SCHROEDER, R.; MAJEWSKI, L. A. and GRELL, M. Adv. Mater., 17, 1535 (2005).

SEIDEL, K. Tese de Doutorado, Efeitos de preenchimento de armadilhas de portadores de cargas em transistores orgânicos de efeito de campo, UFPR, 2008 .

SERBENA, J. P. M. Dissertação de Mestrado, Propriedades Elétricas de Blendas Moleculares de 4,7-bis(piridina-2-iletinil)- 2,1,3-benzotiadiazol e tris(8-hidróxido quinolina) alumínio, UFPR (2005).

SHIMODA, T. et al. Inkjet Printing of light-emitting Polymer Displays, MRS Bulletin, p.821-827, nov, 2003.

SHIRAKAWA, H. et al. J. Chem. Soc., Chem. Commun., 1977, 578-580.

SIGAUD, L. M. Dissertação de Mestrado, Caracterização da emissão de radiação na faixa de $U V$ induzida por elétrons em materiais em forma de filmes finos, PUC-Rio, 2005.

SIGMA-ALDRICH.<http://www.sigmaaldrich.com/>. Retirado em Abril, 2016.

SINGH, TH. B. et al. Handbook of Organic Electronics and Photonics, Volume 3, American Scientific Publishers, 2008.

SIQUEIRA, R. C. Dissertação de Mestrado, Montagem e caracterização de um dispositivo eletrônico usando polímero condutor, UNICAMP, SP,2004.

SIRRINGHAUS, H. et al. Two-dimensional charge transport in self-organized, high-mobility conjugated polymers. Nature, v.401, n. 6754, p. 685-688, Oct. 1999.

SMITH, J. et al. Solution-processed organic transistors based on semiconducting blends; J. Mater. Chem., 2010,20, 2562-2574. 
SOUZA MACHADO, W. Tese de Doutorado, Memórias orgânicas baseadas em esferas de carbono e transistores de efeito de campo orgânicos de baixa tensão de operação, EFPR, 2011.

SPI SUPPLIES. <http://www.2spi.com/>. Retirado em Abril, 2016.

STALLINGA, P. Electrical Characterization of Organic Electronic Materials and Devices,Wiley (2009).

STEFAnElO, J. C. Tese de Doutorado, Fabricação e caracterização de transistores orgânicos por impressão de jato de tinta, USP, São Carlos, 2014.

TANG, C.W. Two layer organic photovoltaic cell, Appl. Phys. Lett., v.48, p.183-185, 1986.

TANG, C.W. and VAN SLYKE S.A. Organic electroluminescent diodes, Appl. Phys. Lett., v.51, p.913-915, 1987.

TONEZER, C. Dissertação de Mestrado, Universidade Federal do Paraná. Curitiba (2007).

TSUMURA, A.; KOEZUKA, K.; ANDO, T. Macromolecular electronic device: Field effect transistor with a polythiophene thin film, Appl. Phys. Lett., v.49, p.1210-1212, 1986.

UKAI, S. et al. Electrical conduction of regioregular and regiorandom poly(3hexylthiophene) doped with iodine, Journal of the Physics Society Japan, v. 74, n. 12, p. 3314-3319, Dec. 2005.

VALASKI, R. et al. Journal of Applied Physics, 92 (2002) 2035.

VAN ETTEN, E. A. et al. Insulating characteristics of polyvinyl alcohol for integrated electronics, Thin Solid Films 568 (2014) 111-116.

VERES, J. et al. Gate Insulators in Organic Field-Effect Transistors, Chem. Mater., Vol. 16, No. 23, 2004.

WANG, G. et al. Increased mobility from regioregular poly(3-hexylthiophene) field-effect transistors, Journal of Applied Physics, v. 93, n. 10, p. 6137, Feb. 2003. 
YONG, XU. et al. Development of high-performance printed organic fieldeffect transistors and integrated circuits, Phys. Chem. Chem. Phys., 2015,17, 26553-26574. 